\title{
Bidirectional, unlike unidirectional transport, allows transporting axonal cargos against their concentration gradient
}

\author{
Ivan A. Kuznetsov $^{(\mathrm{a}),(\mathrm{b})}$ and Andrey V. Kuznetsov ${ }^{(\mathrm{c})}$

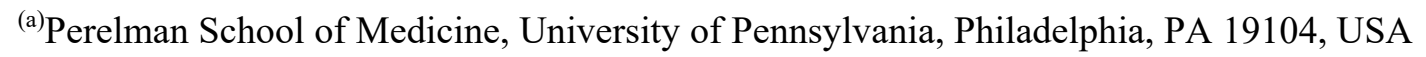 \\ ${ }^{(b)}$ Department of Bioengineering, University of Pennsylvania, Philadelphia, PA 19104, USA \\ ${ }^{(c)}$ Dept. of Mechanical and Aerospace Engineering, North Carolina State University, \\ Raleigh, NC 27695-7910, USA; e-mail: avkuznet@ncsu.edu
}

\begin{abstract}
Even though most axonal cargos are synthesized in the soma, the concentration of many of these cargos is larger at the presynaptic terminal than in the soma. This requires transport of these cargos from the soma to the presynaptic terminal or other active sites in the axon. Axons utilize both bidirectional (for example, slow axonal transport) and unidirectional (for example, fast anterograde axonal transport) modes of cargo transport. Bidirectional transport seems to be less efficient because it requires more time and takes more energy to deliver cargos. In this paper, we studied various models which differ by the modes of axonal cargo transport (such as anterograde and retrograde motor-driven transport and passive diffusion) as well as by the presence or absence of pausing states. The models are studied to investigate their ability to simulate axonal transport against the cargo concentration gradient. Due to the great lengths of the axons, anterograde transport mostly relies on molecular motors, such as kinesins, to deliver cargos synthesized in the soma to the terminal and other active sites in the axon. Retrograde transport can be also motor-driven, in which case cargos are transported by dynein motors. However, retrograde transport can also occur by cargo diffusion. If cargo concentration at the axon tip is higher than at axon hillock, diffusion will move cargo in the retrograde direction. However, for many cargos diffusion is very slow, often negligible, as for large cargos diffusivity is very small. We argue that because bidirectional axonal transport includes both the anterograde and retrograde cargo populations, information about cargo concentration at the axon entrance and at the presynaptic terminal can travel in both anterograde and retrograde directions. This allows bidirectional axonal transport to account for the concentration of cargos at the presynaptic terminal. On the contrary, in unidirectional axonal transport without diffusion cargo transport occurs only in one direction, and this disallows transport of information about the cargo concentration at the opposite boundary. For the case of unidirectional anterograde transport, this means that proximal regions of the axon do not receive information about cargo concentration in the distal regions. This does not allow for
\end{abstract}


bioRxiv preprint doi: https://doi.org/10.1101/2021.01.27.428531; this version posted December 7, 2021. The copyright holder for this preprint

(which was not certified by peer review) is the author/funder, who has granted bioRxiv a license to display the preprint in perpetuity. It is made available under aCC-BY-NC-ND 4.0 International license.

the imposition of a higher concentration at the presynaptic terminal in comparison to the cargo concentration at the axon hillock.

Keywords neuron; axon; mathematical modeling; slow and fast axonal transport; alpha-synuclein 


\section{Introduction}

To ensure reliable operation over decades, neurons need to constantly replace their functional components. In neurons, the delivery of new components to distal parts of an axon is accomplished by active transport that requires involvement of molecular motors. It is likely that most neuronal proteins are replaced once every several weeks by new proteins arriving from the soma [1,2].

Cytosolic proteins are transported from the soma, where they are synthesized, to active sites, e.g., the presynaptic terminal, by slow component-b (SCb). SCb is involved in the transport of $\sim 200$ proteins [3]. The average rate of SCb-transport is $\sim 2-8 \mathrm{~mm} /$ day $(0.023-0.093 \mu \mathrm{m} / \mathrm{s})$. One of the proteins transported in $\mathrm{SCb}$ is $\alpha$-synuclein ( $\alpha$-syn), which is mostly known for its involvement in Parkinson's disease (PD) [4,5]. In a healthy neuron $\alpha$-syn predominantly exists as a monomer [6], and hereafter when we write $\alpha$-syn we mean $\alpha$-syn monomer unless we specify otherwise. $\alpha$-syn is synthesized in the soma and is then transported to the synapse, mostly in SCb [7-9]. In healthy neurons $\alpha$-syn predominantly localizes in the presynaptic terminal [10-12]. As for any SCb protein, $\alpha$-syn motion is characterized by periods of fast transport, pauses, and changes in movement direction [13]. Fast anterograde and retrograde motions of $\alpha$ syn are propelled by kinesin and dynein motors, respectively [14].

An intriguing question is why cytosolic proteins, such as $\alpha$-syn [15], are moved in SCb. SCb includes both anterograde and retrograde components, although the net flux of these proteins is anterograde. Transporting cargos using molecular motors requires energy [16]. Bidirectional transport takes more energy to move a cargo by the same distance compared to unidirectional transport. For some unknown reason neurons use slow axonal transport, which is inherently bidirectional, to deliver three times more protein to the presynaptic terminal than by fast axonal transport [16]. This is especially surprising because protein delivery to the presynaptic terminal is essential and a lack of presynaptic proteins can lead to synaptic degeneration [17]. Why then do proteins transported via SCb to the presynaptic terminal rely on a mode of transit that includes a retrograde component?

Back-and-forth movements of cargos with overall net directionality toward a certain destination seemingly constitute an inefficient transport mechanism. Possible explanations for the utilization of bidirectional transport include facilitating maneuvering of molecular motors around obstacles on microtubules (MTs) and providing an error correction mechanism for the delivery of cargo to a proper location [18]. It was also suggested that the purpose of bidirectional transport (especially of slow axonal transport) is dynamic recruitment and redistribution of cargos in response to changing metabolic needs [19]. 
Bidirectional transport (especially slow axonal transport) is slower than unidirectional transport. Slow axonal transport along human motor neurons can take up to a year. This may predispose neurons to being unable to properly supply presynaptic terminal with key proteins, as slow transport acts as a bottleneck and may predispose them to proteolytic degradation in transport. Indeed, the cellular environment is quite hostile to most proteins, and most of them are short-lived, days or weeks at the most [2]. Why has evolution chosen to use something that seems to be less efficient?

Unlike previously suggested hypotheses, our hypothesis is that bidirectional transport in neurons allows for the movement of cargos from a location with a lower cargo concentration to a location with a higher cargo concentration. We refer to this situation as cargo transport against its concentration gradient; it requires cargo transport against its diffusion-driven flux. From a physics perspective, transport against a concentration gradient is not unusual; it requires energy to allow the corresponding decrease in entropy. Ion pumps, for example, transport ions through pores against a gradient using energy supplied by ATP hydrolysis. Similarly, ATP hydrolysis drives the stepping of the molecular motors and the generation of force allowing transport against cargo concentration. Situations where cargos must be transported against their concentration gradient are common in neurons. One example is the transport of tau protein, which is known for its involvement in Alzheimer's disease [20]. To be transported from the soma, where it is synthesized, to the axon, tau has to pass the tau diffusion barrier [21]. Tau concentration in the axon is larger than in the soma, and thus, tau entry into the axon requires transport against the concentration gradient. A model of this process has recently been developed in [22]. Additionally, tau concentration at the axon tip is larger than its concentration in the proximal axon [23]. Thus, in the axon, tau is also transported against its concentration gradient [24,25].

Additionally, tau concentration at the axon tip is larger than its concentration in the proximal axon [23]. Thus, in the axon, tau is also transported against its concentration gradient [24,25]. Other examples involving anterograde protein transport against the protein's concentration gradient include dynein, which cannot move in the anterograde direction on its own [26], and synapsin, which is also enriched at synapses [27].

\section{Methods and models}

\subsection{The model of slow (bidirectional) axonal transport of cytosolic proteins}

A continuum model of slow axonal transport of neurofilaments (which move in slow component-a (SCa), which is characterized by an average velocity of $0.2-1 \mathrm{~mm} /$ day [8]) was proposed in [28]. Refs. [29] and 
[30] extended this model to cytosolic proteins, which are transported in SCb and can diffuse in the cytoplasm. This model extension was done by the addition of diffusion and degradation terms in the free state.

Although our model of slow axonal transport is applicable to any of the proteins transported in $\mathrm{SCb}$, all of which move bidirectionally, here we apply the model to $\alpha$-syn monomer. $\alpha$-syn monomer, after being synthesized in the soma, is transported to the presynaptic terminal by slow axonal transport. Slow axonal transport is characterized by short rapid movements, which can be anterograde or retrograde, and are presumably powered by kinesin and dynein motors, respectively. Kinesin and dynein motors run along MTs. Rapid movements are interrupted by prolonged pauses, during which $\alpha$-syn monomers presumably maintain some association with MTs.

Since axonal transport is mostly one-dimensional (it occurs along the axon, Fig. 1), we characterized all concentrations in the axon by their linear number densities (number of cargoes in a certain kinetic state per unit length of the axon). The model includes two motor-driven states for $\alpha$-syn monomers with concentrations $n_{a}^{*}$ and $n_{r}^{*}$, respectively. Conservation of $\alpha$-syn residing in motor-driven states (Fig. 2a) gives the following equations:

$-v_{a}^{*} \frac{\partial n_{a}^{*}}{\partial x^{*}}-\gamma_{10}^{*} n_{a}^{*}+\gamma_{01}^{*} n_{a 0}^{*}=0$

$v_{r}^{*} \frac{\partial n_{r}^{*}}{\partial x^{*}}-\gamma_{10}^{*} n_{r}^{*}+\gamma_{01}^{*} n_{r 0}^{*}=0$

where $x^{*}$ is the Cartesian coordinate along the axon (Fig. 1). Various $\alpha$-syn concentrations are defined in Table 1 and various model parameters are defined in Tables 2 and 3.

The first terms on the left-hand sides of Eqs. (1) and (2) describe fast motions of $\alpha$-syn monomers in the anterograde (with a velocity $v_{a}^{*}$ ) and retrograde (with a velocity $v_{r}^{*}$ ) directions, respectively, while other terms describe transitions between motor-driven and pausing kinetic states. Fig. 2a shows various kinetic states and transitions between them described by kinetic rates $\gamma^{*} \mathrm{~s}$.

The model also includes equations for $\alpha$-syn monomers in two pausing states, with concentrations $n_{a 0}^{*}$ and $n_{r 0}^{*}$, respectively. It is assumed that despite pausing, $\alpha$-syn monomers maintain some connection with MTs but are ready to resume anterograde or retrograde motion. Equations expressing conservation of $\alpha$ syn monomers in the pausing states involve only terms that describe transitions to/from other kinetic states, since no motor-driven transport or diffusion occur in the pausing states (Fig. 2a): 


$$
\begin{aligned}
& -\left(\gamma_{01}^{*}+\gamma_{a r}^{*}+\gamma_{o f f, a}^{*}\right) n_{a 0}^{*}+\gamma_{10}^{*} n_{a}^{*}+\gamma_{r a}^{*} n_{r 0}^{*}+\gamma_{o n, a}^{*} n_{f r e e}^{*}=0 \\
& -\left(\gamma_{01}^{*}+\gamma_{r a}^{*}+\gamma_{o f f, r}^{*}\right) n_{r 0}^{*}+\gamma_{10}^{*} n_{r}^{*}+\gamma_{a r}^{*} n_{a 0}^{*}+\gamma_{o n, r}^{*} n_{f r e e}^{*}=0 .
\end{aligned}
$$

SCb-transported proteins have diffusible fractions [31]. Free (cytosolic) $\alpha$-syn monomers can thus be transported by diffusion. They also can be destroyed by degradation in proteasomes [32], which are present in various locations in the axon. Free $\alpha$-syn can also transition to anterograde or retrograde biased pausing states (Fig. 2a). Stating the conservation of free monomeric $\alpha$-syn gives the following equation:

$$
D_{n_{\text {free }}}^{*} \frac{\partial^{2} n_{\text {free }}^{*}}{\partial x^{* 2}}+\gamma_{\text {off }, a}^{*} n_{a 0}^{*}+\gamma_{\text {off }, r}^{*} n_{r 0}^{*}-\left(\gamma_{o n, a}^{*}+\gamma_{o n, r}^{*}\right) n_{\text {free }}^{*}-\frac{n_{\text {free }}^{*} \ln (2)}{T_{1 / 2, \text { free }}^{*}}=0,
$$

where the last term on the left-hand side of Eq. (5) simulates the destruction of free $\alpha$-syn monomers in proteasomes. In this term, the rate of decay of free $\alpha$-syn is assumed to be directly proportional to the concentration of the free $\alpha$-syn.

Eqs. (1)-(5) must be solved subject to the following boundary conditions:

At $x^{*}=0$ :

$n_{t o t}^{*}=n_{t o t, x=0}^{*}, \quad j_{t o t}^{*}=v_{a v, e s t i m a t e}^{*} n_{t o t, x=0}^{*}$,

where $n_{\text {tot }, x=0}^{*}$ is the total concentration of $\alpha$-syn monomers at the axon hillock (at $x=0$ ), which is assumed to be constant. We estimated its value in Table 2 .

In our model, all $\gamma^{*} \mathrm{~s}$ in Eqs. (1)-(5) are constants that are independent of the cargo concentration along the axon.

Eq. (6a) postulates the total concentration of $\alpha$-syn monomers at the axon hillock and Eq. (6b) postulates the total flux of newly synthesized $\alpha$-syn monomers entering the axon. In Eq. (6b)

$$
j_{\text {tot }}^{*}\left(x^{*}\right)=-D_{n_{\text {free }}^{*}}^{*} \frac{\partial n_{\text {free }}^{*}}{\partial x^{*}}+v_{a}^{*} n_{a}^{*}-v_{r}^{*} n_{r}^{*}
$$

is the total flux of $\alpha$-syn monomers due to diffusion in the cytosol (the first term of the right-hand side of Eq. (7)) and motor-driven anterograde (the second term) and retrograde (the third term) transport.

The total concentration of $\alpha$-syn monomers (in all five kinetic states displayed in Fig. 2a) is found as:

$$
n_{\text {tot }}^{*}=n_{a}^{*}+n_{r}^{*}+n_{a 0}^{*}+n_{r 0}^{*}+n_{\text {free }}^{*}
$$


As we suggested in ref. [33], the average velocity of a protein in slow axonal transport is defined as the ratio of the total protein flux to the total protein concentration:

$$
v_{a v}^{*}\left(x^{*}\right)=\frac{j_{t o t}^{*}}{n_{t o t}^{*}} .
$$

At the axon presynaptic terminal, we imposed the following boundary conditions:

At $x^{*}=L^{*}: \quad \frac{\partial n_{\text {free }}^{*}}{\partial x^{*}}=0, \quad n_{\text {tot }}^{*}=n_{\text {tot }, x=L}^{*}$

We defined the dimensionless concentration of $\alpha$-syn as:

$$
n=n^{*} / n_{x=L}^{*}
$$

This equation applies to the total $\alpha$-syn concentration and all $\alpha$-syn concentration components $\left(n_{a}, n_{r}\right.$, etc.). Eq. (10b) can then be recast as:

$$
n_{t o t, x=L}=1
$$

The dimensionless total flux of $\alpha$-syn is defined as:

$$
j_{\text {tot }}=\frac{j_{\text {tot }}^{*}}{n_{x=L}^{*} v_{a}^{*}} .
$$

\subsection{The model of fast anterograde (unidirectional) axonal transport of various organelles}

Fast anterograde axonal transport of various membranous organelles is simulated by the following equation:

$$
-v_{a}^{*} \frac{\partial n_{a}^{*}}{\partial x^{*}}-\frac{n_{a}^{*} \ln (2)}{T_{1 / 2, a}^{*}}=0 .
$$

In Eq. (14) we neglected the vesicles' diffusivity due to their large size. This equation must be solved subject to the following boundary condition:

$$
\text { At } x^{*}=0: \quad n_{a}^{*}=n_{t o t, x=0}^{*}
$$

To enable a comparison between slow and fast axonal transport simulations, we assumed the same protein concentration at $x^{*}=0$ for fast axonal transport as for slow axonal transport (compare with Eq. (6a)). 
The analytical solution of Eq. (14) with boundary condition (15) is

$$
n_{a}^{*}=n_{t o t, x=0}^{*} \exp \left(-\frac{\ln (2)}{V_{a}^{*} T_{1 / 2, a}^{*}} x^{*}\right) .
$$

Eq. (16) applies to the whole length of the axon, $0 \leq x^{*} \leq L^{*}$.

Ref. [34] has shown that neuropeptide delivery to en passant boutons in type Ib terminals of Drosophila motoneurons involves DCV circulation, in which DCVs that reached the most distal bouton in the terminal turn around and move back by retrograde transport. The concentration of retrogradely transported cargos can be modeled by the following equation:

$v_{r}^{*} \frac{\partial n_{r}^{*}}{\partial x^{*}}-\frac{n_{r}^{*} \ln (2)}{T_{1 / 2, r}^{*}}=0$.

This equation must be solved subject to the following boundary condition at the axon tip:

At $x^{*}=L^{*}: \quad j_{r}^{*}=v j_{a}^{*}$,

where $j_{a}^{*}=v_{a}^{*} n_{a}^{*}, j_{r}^{*}=v_{r}^{*} n_{r}^{*}$, and $v$ is the fraction of vesicles entering the presynaptic terminal that turn around and return to the axon, moved by dynein motors. Under steady-state conditions, the difference, $j_{a}^{*}-j_{r}^{*}$, must be destroyed in the presynaptic terminal (or released from it). Eq. (18) can be recast as:

At $x^{*}=L^{*}: \quad n_{r}^{*}=\frac{v v_{a}^{*}}{v_{r}^{*}} n_{a}^{*}$.

If $T_{1 / 2, a}^{*}$ is very large, then, from Eq. (16), $n_{a, x=0}^{*}=n_{a, x=L}^{*}=n_{t o t, x=0}^{*}$, and the solution of Eq. (17) with boundary condition (19) gives the following:

$$
n_{r}^{*}=n_{t o t, x=0}^{*} \frac{v v_{a}^{*}}{v_{r}^{*}} \exp \left(-\frac{\left(L^{*}-x^{*}\right) \ln (2)}{v_{r}^{*} T_{1 / 2, r}^{*}}\right) .
$$

Similarly to Eq. (16), Eq. (20) applies for $0 \leq x^{*} \leq L^{*}$.

\subsection{The model of slow axonal transport of cytosolic proteins with $15 \%$ fast component}


According to [8,9,14,31], 10-15\% of proteins transported in SCb are moved by fast axonal transport. In order to simulate this situation, we utilized the above models of fast and slow axonal transport, in which Eq. $(6 a, b)$ was modified as:

At $x^{*}=0: \quad n_{\text {tot }}^{*}=0.85 n_{\text {tot }, x=0}^{*}, \quad j_{\text {tot }}^{*}=0.85 v_{\text {av }, \text { stimate }}^{*} n_{\text {tot }, x=0}^{*}$,

and Eq. (15) is replaced with the following equation:

$$
x^{*}=0: n_{a}^{*}=0.15 n_{t o t, x=0}^{*} .
$$

\subsection{Axonal transport model that includes anterograde motor-driven transport with pausing and diffusion only}

In this section, we investigate the question of whether an anterograde transport model with pausing and diffusion in the free state can simulate transport against the concentration gradient (Fig. 2b). Consider cargo assembled in the cell body. It binds to kinesin which transports it along the MTs in the axon in the anterograde direction towards the terminal. The cargo may detach during its journey and diffuse along the axon before it binds again to kinesin to continue its journey to the axon terminal. After arriving at the nerve terminal, the cargo may detach from its kinesin motor and accumulate and degrade, building up a gradient similar to that shown in Figs. 4a, 6a, and 8a. In this case, the mathematical model given by Eqs. (1)-(5) reduces to the following equations:

$$
\begin{aligned}
& -v_{a}^{*} \frac{\partial n_{a}^{*}}{\partial x^{*}}-\gamma_{10}^{*} n_{a}^{*}+\gamma_{01}^{*} n_{a 0}^{*}=0, \\
& -\left(\gamma_{01}^{*}+\gamma_{\text {off }, a}^{*}\right) n_{a 0}^{*}+\gamma_{10}^{*} n_{a}^{*}+\gamma_{o n, a}^{*} n_{\text {free }}^{*}=0, \\
& D_{n_{\text {free }}^{*}}^{*} \frac{\partial^{2} n_{\text {free }}^{*}}{\partial x^{* 2}}+\gamma_{\text {off }, a}^{*} n_{a 0}^{*}-\gamma_{\text {on }, a}^{*} n_{\text {free }}^{*}-\frac{n_{\text {free }}^{*} \ln (2)}{T_{1 / 2, \text { free }}^{*}}=0 .
\end{aligned}
$$

Eqs. (23)-(25) must be solved subject to the following boundary conditions:

$$
\text { At } x^{*}=0: \quad n_{\text {tot }}^{*}=n_{\text {tot }, x=0}^{*}, \quad j_{\text {tot }}^{*}=v_{a v, e s t i m a t e}^{*} n_{\text {tot }, x=0}^{*} .
$$

At $x^{*}=L^{*}: \quad n_{t o t}^{*}=n_{t o t, x=L}^{*}$. 


\subsection{Axonal transport model that includes anterograde and retrograde motor-driven transport without diffusion}

In this section we investigate the situation when diffusion and pausing states are dropped from the model described in section 2.1, and only motor-driven states are retained (Fig. 2c). Eqs. (1)-(5) in this case reduce to:

$$
\begin{aligned}
& -v_{a}^{*} \frac{\partial n_{a}^{*}}{\partial x^{*}}-\gamma_{a r}^{*} n_{a}^{*}+\gamma_{r a}^{*} n_{r}^{*}=0, \\
& v_{r}^{*} \frac{\partial n_{r}^{*}}{\partial x^{*}}-\gamma_{r a}^{*} n_{r}^{*}+\gamma_{a r}^{*} n_{a}^{*}=0 .
\end{aligned}
$$

Eqs. (28) and (29) must be solved subject to the following boundary conditions:

$$
\begin{array}{ll}
\text { At } x^{*}=0: & n_{t o t}^{*}=n_{t o t, x=0}^{*}, \\
\text { At } x^{*}=L^{*}: & n_{t o t}^{*}=n_{t o t, x=L}^{*} .
\end{array}
$$

The total flux of cargo in this case is calculated as:

$$
j_{\text {tot }}^{*}\left(x^{*}\right)=v_{a}^{*} n_{a}^{*}-v_{r}^{*} n_{r}^{*}
$$

and the total cargo concentration is found as:

$$
n_{t o t}^{*}=n_{a}^{*}+n_{r}^{*}
$$

\subsection{Axonal transport model that includes anterograde transport with pausing only}

In this section we investigate what happens if diffusion is dropped out of the model presented in section 2.4, and whether in this situation the model can still correctly predict transport against the concentration gradient (Fig. 2d). Eqs. (23)-(25) in this case reduce to:

$$
\begin{aligned}
& -v_{a}^{*} \frac{\partial n_{a}^{*}}{\partial x^{*}}-\gamma_{10}^{*} n_{a}^{*}+\gamma_{01}^{*} n_{a 0}^{*}-\frac{n_{a}^{*} \ln (2)}{T_{1 / 2, a}^{*}}=0, \\
& -\gamma_{01}^{*} n_{a 0}^{*}+\gamma_{10}^{*} n_{a}^{*}=0 .
\end{aligned}
$$

Similar to Eq. (14), we added a term in Eq. (34), which describes a possible cargo decay in the motordriven state. Without this term, the equations exhibit a trivial (constant concentration) solution. 
Eqs. (34) and (35) must be solved subject to the following boundary condition:

At $x^{*}=0: \quad n_{\text {tot }}^{*}=n_{\text {tot }, x=0}^{*}$.

By adding Eqs (34) and (35), Eq. (14) is obtained. The solution of Eq. (14) in this case is

$$
n_{a}^{*}=n_{a, x=0}^{*} \exp \left(-\frac{\ln (2)}{v_{a}^{*} T_{1 / 2, a}^{*}} x^{*}\right) .
$$

Using Eq. (35) and $n_{\text {tot }}^{*}=n_{a}^{*}+n_{a 0}^{*}$ results in

$$
n_{t o t}^{*}=n_{a}^{*}\left(1+\frac{\gamma_{10}^{*}}{\gamma_{01}^{*}}\right)
$$

Utilizing Eq. (38), Eq. (37) is recast as:

$$
n_{t o t}^{*}=n_{t o t, x=0}^{*} \exp \left(-\frac{\ln (2)}{v_{a}^{*} T_{1 / 2, a}^{*}} x^{*}\right) .
$$

Eq. (39) means that anterograde transport with pausing cannot capture transport against the concentration gradient correctly. Note that modulating values of kinetic constants $\gamma_{10}^{*}$ and $\gamma_{01}^{*}$ (allowing them to depend on $x^{*}$ ) cannot fix this problem. The issue with this model is that it simulates transport in only one (anterograde) direction, and thus it cannot simulate the propagation of information regarding the cargo concentration in the retrograde direction. In order to correctly simulate the physical situation (a given high cargo concentration at the axon tip), the model must allow for the imposition of the second boundary condition at the tip, which is not possible because the highest order derivative in the governing equations is of the first order $\left(\frac{\partial n_{a}^{*}}{\partial x^{*}}\right.$, Eq. (34)).

The analysis above shows that the case with cargos that are anterogradely transported by motors and can also pause is reduced to the case of anterogradely motor-driven cargos. The reason why the unidirectional anterograde motor-driven transport model cannot simulate cargo transport against the concentration gradient is further explained in Fig. 3. Under steady-state-conditions (due to a long duration of human life, most of the time axonal transport can be assumed to operate at steady-state), the balance of cargos entering and leaving a control volume $(\mathrm{CV})$ can be stated as follows: 


$$
\underbrace{v_{a}^{*} n_{a}^{*}\left(x^{*}\right)}_{\begin{array}{c}
\text { rate at which cargo } \\
\text { enters the } \mathrm{CV}
\end{array}}=\underbrace{v_{a}^{*} n_{a}^{*}\left(x^{*}+d x^{*}\right)+\frac{n_{a}^{*} \ln (2)}{T_{1 / 2, a}^{*}} d x^{*}}_{\text {rate at which cargo leaves the } \mathrm{CV}} .
$$

From Eq. (40) it follows that

$$
n_{a}^{*}\left(x^{*}+d x^{*}\right) \leq n_{a}^{*}\left(x^{*}\right)
$$

Equality is for the case of $T_{1 / 2, a}^{*} \rightarrow \infty$.

\subsection{Finding values of kinetic constants by least square regression}

In order to solve the problem numerically, values of eight kinetic constants given in Table 3 are needed. These values can be found by using multi-objective optimization (see, for example, [35-39]). The following objective (penalty) function was minimized:

$$
e r r=\sum_{j=1}^{N_{f t t}}\left(n_{t o t, j}-n_{\text {tot }, \text { estimate }, j}\right)^{2}+\omega_{1} \sum_{j=1}^{N_{f i t}}\left(v_{a v, j}^{*}-v_{a v, e s t i m a t e}^{*}\right)^{2}+\omega_{2} .
$$

For the most general slow axonal transport model formulated in section 2.1, the objective function defined by Eq. (42) depends on eight parameters: $\gamma_{10}^{*}, \gamma_{01}^{*}, \gamma_{a r}^{*}, \gamma_{r a}^{*}, \gamma_{o n, a}^{*}, \gamma_{o n, r}^{*}, \gamma_{o f f, a}^{*}$, and $\gamma_{o f f, r}^{*}$. The best-fit values of these parameters were determined by finding a set that gives the minimum value of the objective function.

The objective function defined by Eq. (42) combines three different effects. The first term on the righthand side of Eq. (42) estimates how well the $\alpha$-syn concentration predicted by the model, $n_{\text {tot }, j}$, fits the estimated concentration of $\alpha$-syn given by the following sigmoid curve, which we obtained by modifying a logistic function:

$$
n_{\text {tot }, e s t i m a t e, j}=n_{\text {tot }, x=0}+\left(1-n_{\text {tot }, x=0}\right)(1-\tanh [k(L-x)]) .
$$

Although synthetic data given by Eq. (43) simulate $\alpha$-syn monomer distribution that would require $\alpha$-syn transport against the concentration gradient, this gradient is not uniform along the axon length; most of the increase is assumed to occur near the presynaptic terminal.

The second term on the right-hand side of Eq. (42) estimates how well the average velocity of $\alpha$-syn predicted by the model, $v_{a v, j}^{*}$, fits the estimated average $\alpha$-syn velocity, $v_{a v, e s t i m a t e}^{*}$. We used three values 
for $v_{a v, e s t i m a t e}^{*}$, which are in the range of average velocities of SCb (2-8 mm/day [3]): 0.02, 0.05, and 0.1 $\mu \mathrm{m} / \mathrm{s}$. We used $\omega_{1}=1 \mathrm{~s}^{2} / \mu \mathrm{m}^{2}$. This value was selected by numerical experimentation to avoid overfit in terms of either $\alpha$-syn concentration or average velocity, as described in [40].

Physically, $\alpha$-syn concentrations in various kinetic states must be non-negative. Therefore, we set $\omega_{2}=10^{8}$ if any of $n_{a, j}, n_{r, j}, n_{a 0, j}, n_{r 0, j}$, and $n_{\text {free }, j}\left(j=1, \ldots, N_{\text {fit }}\right)$ are negative. If the half-life of $\alpha$-syn monomers is infinitely large, its flux under steady-state conditions must stay constant. However, if the half-life of $\alpha$-syn is finite, its flux decreases as $x^{*}$ increases. However, since the presynaptic terminal must be supplied with $\alpha$-syn monomers, physically the flux must remain positive. Therefore, we also set $\omega_{2}=10^{8}$ if $j_{\text {tot }}\left(j=1, \ldots, N_{\text {fit }}\right)$ becomes negative.

Examples of the best fit-values of model parameters for models presented in sections 2.1, 2.4, and 2.5 are given in Tables S1, S2, and S3, respectively.

Table 1. Dependent variables in the model of $\alpha$-syn monomers transport from the soma to the presynaptic terminal.

\begin{tabular}{|l|l|l|}
\hline Symbol & Definition & Units \\
\hline$j_{\text {tot }}^{*}$ & $\begin{array}{l}\text { Total flux of } \alpha \text {-syn monomers through a given } \\
\text { cross-section in the axon }\end{array}$ & $\mathrm{s}^{-1}$ \\
\hline$n_{a}^{*}$ & $\begin{array}{l}\text { Concentration of on-track } \alpha \text {-syn monomers } \\
\text { moving along MTs anterogradely, propelled by } \\
\text { molecular motors }\end{array}$ & $\mu \mathrm{m}^{-1}$ \\
\hline$n_{r}^{*}$ & $\begin{array}{l}\text { Concentration of on-track } \alpha \text {-syn monomers } \\
\text { moving along MTs retrogradely, propelled by } \\
\text { molecular motors }\end{array}$ & $\mu \mathrm{m}^{-1}$ \\
\hline$n_{a 0}^{*}$ & $\begin{array}{l}\text { Concentration of pausing on-track } \alpha \text {-syn } \\
\text { monomers that are still associated with } \\
\text { molecular motors and can resume their } \\
\text { anterograde motion }\end{array}$ & $\mu \mathrm{m}^{-1}$ \\
\hline$n_{r 0}^{*}$ & $\begin{array}{l}\text { Concentration of pausing on-track } \alpha \text {-syn } \\
\text { monomers that are still associated with } \\
\text { molecular motors and can resume their } \\
\text { retrograde motion }\end{array}$ & $\mu \mathrm{m}^{-1}$ \\
\hline$n_{\text {free }}^{*}$ & $\begin{array}{l}\text { Concentration of free (off-track) } \alpha \text {-syn } \\
\text { monomers in the cytosol }\end{array}$ & $\mu \mathrm{m}^{-1}$ \\
\hline
\end{tabular}


Table 2. Parameters characterizing transport of $\alpha$-syn monomers in the axon taken from published data or assumed on physical grounds.

\begin{tabular}{|c|c|c|c|c|c|}
\hline Symbol & Definition & Units & $\begin{array}{l}\text { Value or } \\
\text { range }\end{array}$ & Reference(s) & $\begin{array}{l}\text { Value(s) used in } \\
\text { computations }\end{array}$ \\
\hline$D_{n_{\text {free }}}^{*}$ & $\begin{array}{l}\text { Diffusivity of } \alpha \text {-syn } \\
\text { monomers in the cytosolic } \\
\text { state }\end{array}$ & $\mu \mathrm{m}^{2} / \mathrm{s}$ & $114^{\mathrm{a}}$ & [41] & 114 \\
\hline$k$ & $\begin{array}{l}\text { The logistic growth rate, } \\
\text { which characterizes the } \\
\text { steepness of the } S \text {-shaped } \\
\text { curve used in approximating } \\
\text { the distribution of } \alpha \text {-syn } \\
\text { along the axon length }\end{array}$ & & & & $10^{-3}$ \\
\hline$L^{*}$ & Length of the axon & $\mu \mathrm{m}$ & $\begin{array}{l}\text { up to } 10^{6} \text { in } \\
\text { humans }\end{array}$ & [27] & $5 \times 10^{4} b$ \\
\hline$n_{t o t, x=0}^{*}$ & $\begin{array}{l}\text { Concentration of } \alpha \text {-syn } \\
\text { monomers at the axon hillock }\end{array}$ & $\mu \mathrm{M}$ & $10^{-3 \mathrm{c}}$ & [42] & $10^{-3}$ \\
\hline$n_{t o t, x=L}^{*}$ & $\begin{array}{l}\text { Concentration of } \alpha \text {-syn } \\
\text { monomers at the presynaptic } \\
\text { terminal }\end{array}$ & $\mu \mathrm{M}$ & $3.5^{\mathrm{c}}$ & [43] & 3.5 \\
\hline$N_{\text {fit }}$ & $\begin{array}{l}\text { Number of points uniformly } \\
\text { distributed along the axon } \\
\text { length in which } \alpha \text {-syn } \\
\text { concentration is matched with } \\
\text { the assumed } S \text {-shaped } \\
\text { distribution }\end{array}$ & & & & 50 \\
\hline$T_{1 / 2, a}^{*}$ & $\begin{array}{l}\text { Half-life of } 15 \% \text { portion } \alpha- \\
\text { syn monomers transported } \\
\text { anterogradely by fast axonal } \\
\text { transport }\end{array}$ & $\mathrm{S}$ & $\begin{array}{l}6.62 \times 10^{3}- \\
1.73 \times 10^{5} \mathrm{~d}\end{array}$ & [44-47] & $\begin{array}{l}5.76 \times 10^{4} \\
5.76 \times 10^{5} \\
5.76 \times 10^{6} \\
5.76 \times 10^{10}\end{array}$ \\
\hline$T_{1 / 2, \text { free }}^{*}$ & $\begin{array}{l}\text { Half-life of free } \alpha \text {-syn } \\
\text { monomers }\end{array}$ & $\mathrm{S}$ & $\begin{array}{l}6.62 \times 10^{3}- \\
1.73 \times 10^{5} \mathrm{~d}\end{array}$ & [44-47] & $\begin{array}{l}5.76 \times 10^{4} \\
5.76 \times 10^{5} \\
5.76 \times 10^{6} \\
5.76 \times 10^{10}\end{array}$ \\
\hline$v_{a}^{*}, v_{r}^{*}$ & $\begin{array}{l}\text { Velocities of rapid motions of } \\
\alpha \text {-syn monomers on MTs } \\
\text { propelled by kinesin and }\end{array}$ & $\mu \mathrm{m} \mathrm{s}^{-1}$ & 0.7 & [48] & 0.7 \\
\hline
\end{tabular}




\begin{tabular}{|c|c|c|c|c|c|}
\hline & $\begin{array}{l}\text { dynein motors, respectively, } \\
\text { in slow axonal transport }\end{array}$ & & & & \\
\hline$v_{a v, \text { stimate }}^{*}$ & $\begin{array}{l}\text { Estimated average velocity of } \\
\alpha \text {-syn monomers in slow } \\
\text { axonal transport }\end{array}$ & $\mu \mathrm{m} \mathrm{s}^{-1}$ & $0.023-0.093^{\mathrm{e}}$ & {$[3,49,50]$} & $0.02,0.05,0.1$ \\
\hline$v$ & $\begin{array}{l}\text { Fraction of vesicles entering } \\
\text { the presynaptic terminal, } \\
\text { moved by fast axonal } \\
\text { transport, that turn around } \\
\text { and return to the axon moved } \\
\text { by dynein motors }\end{array}$ & & $0-1$ & & 0.5 \\
\hline$\omega_{1}$ & Weighting factor in Eq. (42) & $\mathrm{s}^{2} / \mu \mathrm{m}^{2}$ & & $\begin{array}{l}\text { Numerical } \\
\text { experimentation }\end{array}$ & 1 \\
\hline$\omega_{2}$ & Weighting factor in Eq. (42) & & & $\begin{array}{l}\text { Numerical } \\
\text { experimentation }\end{array}$ & $10^{8}$ \\
\hline
\end{tabular}

a The large diffusivity of $\alpha$-syn monomers is explained by its small molecular weight of $\sim 14 \mathrm{kDa}$ [51].

${ }^{\mathrm{b}}$ In computations, we used a representative axon length of $50 \mathrm{~mm}$ [27].

${ }^{c}$ Cellular $\alpha$-syn concentration in presynaptic terminals is expected to be in micromolar range, while in other parts of the cell it can be as low as nanomolar range [42]. Ref. [43] estimated the concentration of $\alpha$-syn in the presynaptic terminal to be $3.5 \mu \mathrm{M}$.

${ }^{\mathrm{d}}$ The cellular environment is quite hostile to most proteins. A possible reason for this is damage to proteins by reactive oxygen species. Cytosolic proteins could be degraded in proteasomes, which are present in various locations in the axon. The typical half-life of cytosolic proteins is days or weeks at the most [2].

Monomeric $\alpha$-syn is most likely degraded in proteasomes [44,52]. Various estimates are found in the literature; the reported values are $1.84 \mathrm{hrs}$ [44], $16 \mathrm{hrs}$ [45], and $48 \mathrm{hrs}$ [46]. Following [45,47], we used 16 hours $\left(5.76 \times 10^{4} \mathrm{~s}\right)$ as an estimate of the half-life of an unprotected monomeric $\alpha$-syn.

In large neurons, the time that it takes for a protein to travel from the soma to the synapse may exceed the lifetime of the protein. Therefore, it is likely that proteins are somehow protected from degradation during their transit in the axon [50,53]. As a result, the half-life of $\alpha$-syn monomers undergoing slow axonal transport may be much larger than 16 hours. For that reason, in computations we used four estimates for 
$\alpha$-syn monomers half-life: $5.76 \times 10^{4} \mathrm{~s}(16$ hours $), 5.76 \times 10^{5} \mathrm{~s}(160$ hours $), 5.76 \times 10^{6} \mathrm{~s}(1,600$ hours $)$, and $5.76 \times 10^{10} \mathrm{~s}\left(1.6 \times 10^{7}\right.$ hours $)$.

${ }^{\mathrm{e}}$ There are different estimates of the average velocity of $\alpha$-syn monomers transport from the soma to the presynaptic terminal: 0.022-0.028 $\mu \mathrm{m} / \mathrm{s}(1.9-2.4 \mathrm{~mm} /$ day) [49] and 0.035-0.12 $\mu \mathrm{m} / \mathrm{s} \mathrm{(3-10} \mathrm{mm/day)} \mathrm{[50].}$

Since $\alpha$-syn monomers are transported in SCb, we are using an estimate of $0.023-0.093 \mu \mathrm{m} / \mathrm{s}(2-8$ $\mathrm{mm} /$ day) reported in [3].

Table 3. Kinetic constants characterizing transition of $\alpha$-syn monomers between different kinetic states in slow axonal transport, which are displayed in Fig. 2a. Values of these kinetic constants were obtained by finding values that give the best fit with respect to different objectives: getting the best fit (i) between the assumed concentration (given by Eq. (43)) and computed $\alpha$-syn concentration and (ii) between the value of the average $\alpha$-syn transport velocity reported in the literature (we used three values, $0.02,0.05$, and 0.1 $\mu \mathrm{m} / \mathrm{s}$ ) and its computed value. These objectives were weighted in defining the objective (penalty) function, see Eq. (42). For optimizing the fit, the Least Square Regression (LSR) was utilized, as described in $[40,54,55]$.

\begin{tabular}{|l|l|l|l|}
\hline Symbol & Definition & Units & $\begin{array}{l}\text { Initial guess } \\
\text { used in the } \\
\text { optimization } \\
\text { procedure }\end{array}$ \\
\hline$\gamma_{10}^{*}$ & $\begin{array}{l}\text { Kinetic constant describing } \\
\text { the rate of transitions } \\
n_{a}^{*} \rightarrow n_{a 0}^{*} \text { and } n_{r}^{*} \rightarrow n_{r 0}^{*} \text { (Fig. } \\
2 \mathrm{a})\end{array}$ & $\mathrm{s}^{-1}$ & $7.19 \times 10^{-3}$ \\
\hline$\gamma_{01}^{*}$ & $\begin{array}{l}\text { Kinetic constant describing } \\
\text { the rate of transitions } \\
n_{a 0}^{*} \rightarrow n_{a}^{*} \text { and } n_{r 0}^{*} \rightarrow n_{r}^{*}(\text { Fig. } \\
2 \mathrm{a})\end{array}$ & $\mathrm{s}^{-1}$ & $4.01 \times 10^{-3}$ \\
\hline$\gamma_{a r}^{*}$ & $\begin{array}{l}\text { Kinetic constant describing } \\
\text { the rate of transitions } \\
n_{a 0}^{*} \rightarrow n_{r 0}^{*} \text { (Fig. 2a) }\end{array}$ & $\mathrm{s}^{-1}$ & $4.59 \times 10^{-3}$ \\
\hline$\gamma_{r a}^{*}$ & $\begin{array}{l}\text { Kinetic constant describing } \\
\text { the rate of transitions } \\
n_{r 0}^{*} \rightarrow n_{a 0}^{*} \text { (Fig. 2a) }\end{array}$ & $\mathrm{s}^{-1}$ & $6.76 \times 10^{-3}$ \\
\hline
\end{tabular}




\begin{tabular}{|l|l|l|l|}
\hline$\gamma_{\text {on }, a}^{*}$ & $\begin{array}{l}\text { Kinetic constant describing } \\
\text { the rate of transitions } \\
n_{\text {free }}^{*} \rightarrow n_{a 0}^{*} \text { (Fig. 2a) }\end{array}$ & $\mathrm{s}^{-1}$ & $9.43 \times 10^{-2}$ \\
\hline$\gamma_{o n, r}^{*}$ & $\begin{array}{l}\text { Kinetic constant describing } \\
\text { the rate of transitions } \\
n_{\text {free }}^{*} \rightarrow n_{r 0}^{*} \text { (Fig. 2a) }\end{array}$ & $\mathrm{s}^{-1}$ & $5.90 \times 10^{-2}$ \\
\hline$\gamma_{\text {off }, a}^{*}$ & $\begin{array}{l}\text { Kinetic constant describing } \\
\text { the rate of transitions } \\
n_{a 0}^{*} \rightarrow n_{\text {free }}^{*} \text { (Fig. 2a) }\end{array}$ & $\mathrm{s}^{-1}$ & $5.29 \times 10^{-3}$ \\
\hline$\gamma_{\text {off }, r}^{*}$ & $\begin{array}{l}\text { Kinetic constant describing } \\
\text { the rate of transitions } \\
n_{r 0}^{*} \rightarrow n_{\text {free }}^{*} \text { (Fig. 2a) }\end{array}$ & $\mathrm{s}^{-1}$ & $5.40 \times 10^{-3}$ \\
\hline
\end{tabular}

\subsection{Numerical solution}

We eliminated $n_{a 0}^{*}\left(x^{*}\right)$ and $n_{r 0}^{*}\left(x^{*}\right)$ from Eqs. (1)-(5) using Eqs. (3) and (4). This led to a system of ordinary differential equations of the fourth order, which was solved using Matlab's BVP5C solver (Matlab R2019a, MathWorks, Natick, MA, USA). The inverse problem, which involves a determination of values of kinetic constants (Table 3), was solved by using MULTISTART with the local solver FMINCON; these routines are included in Matlab's Optimization Toolbox. 1000 random points plus the initial point given in Table 3 were utilized as starting points in the search for the global minimum. The numerical procedure is described in detail in [25].

\section{Results}

\subsection{Effect of the average velocity of $\alpha$-syn monomers}

A bidirectional transport model (in particular, a slow axonal transport model) can fit a protein distribution characterized by a uniform low protein concentration in the axon and a sharp concentration increase at the presynaptic terminal. For the simulated case of slow axonal transport of $\alpha$-syn, the fitting is done by adjusting values of the kinetic constants characterizing protein transfer rates between different kinetic states. The best-fit values of the rate constants for $v_{a v, e s t i m a t e}^{*}=0.05 \mu \mathrm{m} \mathrm{s}^{-1}$ are given in Table S1. The model can fit such a distribution for any average velocity of $\alpha$-syn transport within the SCb range (the total concentration is shown in Fig. 4a, the components of the total concentration are shown in Figs. S1S3). This is because the bidirectional axonal transport model is described by a higher order system of 
differential equations (second when diffusion of free proteins in the cytosol is neglected and fourth when it is accounted for), and thus allows for the imposition of boundary conditions at the axon hillock and at the presynaptic terminal. Because the model includes both anterogradely and retrogradely transported protein populations, information about the cargo concentration in this model can propagate in both anterograde and retrograde directions, which allows a bidirectional axonal transport model to account for the imposed protein concentration at the presynaptic terminal. This enables a bidirectional axonal transport to move proteins against their concentration gradient, unlike pure diffusion (without any other kinetic states but the free state) or unidirectional fast axonal transport.

Unlike bidirectional axonal transport, unidirectional axonal transport cannot simulate the increase of protein concentration near the presynaptic terminal. If the protein half-life is infinitely large, the protein concentration is uniform and constant (Fig. 4a). This is explained by the fact that the system of governing equations simulating unidirectional (in the simulated case, anterograde) axonal transport is of the first order, and thus can only include one boundary condition, which in the case of anterograde transport has to be imposed at the axon hillock. This is because the model of unidirectional fast anterograde axonal transport includes only transport by anterograde motors, and thus information about the cargo concentration can only propagate in the anterograde direction. Diffusion is neglected in the model of unidirectional transport because this mode of transport usually applies to fast axonal transport, in which case cargos are moved inside vesicles, which are usually too large to exhibit a significant diffusivity.

The slow axonal transport model can simulate various cargo distributions. Possible distributions are not limited by a distribution with a constant concentration of cargo along most of the axon, which is followed by a gradient at the terminal (as in the curves shown in Fig. 4a). The distribution in Fig. 4a is a consequence of using a modified logistic function, given by Eq. (43), to fit our model. For example, Fig. 3(b) in [25] and Fig. 3(a) in [22] show that the slow axonal transport model can fit a cargo distribution that changes along the whole length of the axon, not only near the tip.

In some situations, cargos participating in fast axonal transport can turn around at the end of the axon and then move backward by retrograde transport, propelled by cytoplasmic dynein. This situation may lead to cargo circulation [34]. However, without cargo transitions between the anterograde and retrograde states, this situation does not allow for the imposition of a higher cargo concentration at the end of the axon. This is because only a fraction of anterogradely transported cargos can turn around, and due to the conservation of cargos this fraction cannot exceed unity. The red dashed curve in Fig. $4 \mathrm{~b}$ shows the retrograde flux for the situation when half of anterogradely transported cargos turn around at the end of 
the axon. The velocities of fast anterograde and retrograde axonal transport components are the same (Fig. 5a).

Our model shows that $\alpha$-syn flux along the axon is constant and uniform if $\alpha$-syn destruction during its axonal transport is neglected. Since $\alpha$-syn concentration at the entrance to the axon is assumed constant, the constant value of $\alpha$-syn flux increases with an increase of the average $\alpha$-syn velocity. For the same $\alpha$ syn concentration at the axon entrance, fast axonal transport can deliver a much larger $\alpha$-syn flux due to larger average velocity (Fig. 4b).

The velocity along most of the axon length remains constant, but it decreases close to the presynaptic terminal (Fig. 5a), in the region where the average $\alpha$-syn concentration increases (Fig. 4a). The increase of $\alpha$-syn concentration near the axon tip is explained by the increase of both anterograde and retrograde components of axonal transport; the diffusion component remains relatively small (Fig. 5b).

\subsection{Effect of the half-life of $\alpha$-syn monomers}

If the $\alpha$-syn half-life is varied, the slow axonal transport model can still fit an $\alpha$-syn concentration profile with a sharp concentration increase at the presynaptic terminal (the total concentration is shown in Fig. 6a, the components of the total concentration are shown in Figs. S4-S6). The fast axonal transport model predicts a decreasing concentration toward the presynaptic terminal due to protein degradation. The decrease becomes faster for shorter protein half-life (Fig. S4b vs Figs. S5b and S6b).

For the slow axonal transport model, the $\alpha$-syn flux remains almost constant along most of the axon (Fig. $6 b)$. This is because in the slow axonal transport model we assumed that $\alpha$-syn is destroyed only in the free (cytosolic) kinetic state (see Eq. (5)), and the concentration of $\alpha$-syn in this kinetic state is very low in most of the axon (Fig. S4, S5, S6). Close to the presynaptic terminal the flux decreases, which is due to a sharp increase in the concentration of $\alpha$-syn (including in the free state, in which $\alpha$-syn can be destroyed) near the presynaptic terminal (Fig. 6a and Figs. S4b, S5b, S6b). For the fast anterograde axonal transport model, $\alpha$-syn degradation during its transport along the axon results in a decrease of the $\alpha$-syn flux because of $\alpha$-syn destruction (Fig. 6b), see Eq. (14).

It is interesting that even if the $\alpha$-syn half-life is decreased, the slow axonal transport model is capable of simulating a constant velocity along most of the axon, with the velocity decreasing close to the presynaptic terminal (Fig. 7a). The diffusion component of the total flux is much smaller than the anterograde and retrograde components (Fig. 7b). 


\subsection{Effect of a $15 \%$ fraction of $\alpha$-syn monomers moved by fast axonal transport}

To investigate whether transport of a fraction of $\alpha$-syn by fast axonal transport may affect the $\alpha$-syn distribution, we combined the slow and fast components of axonal transport and modified the boundary conditions in such way that $85 \%$ of $\alpha$-syn enters the axon in slow component and $15 \%$ enters the axon by axonal transport [9,31], see Eqs. (21) and (22). The combined $15 \%$ fast plus $85 \%$ slow axonal transport model is still able to fit the $\alpha$-syn concentration characterized by a uniform concentration in most of the axon, with a concentration increase only at the presynaptic terminal (Fig. 8a).

The $\alpha$-syn flux in the case of combined fast plus slow axon transport is slightly (by $\sim 17 \%$ ) larger because fast axonal transport is much more efficient than slow axonal transport; even 15\% makes a difference (Fig. 8b). The average velocity of $\alpha$-syn transport is also slightly (by $\sim 15 \%$ ) larger when a fraction of $\alpha$ syn is transported in the fast component (Fig. 9a). Cargo transport is governed by the balance of anterograde and retrograde motor-driven transport, with diffusion-driven transport being negligible (Fig. $9 b)$.

\subsection{Effect of removing retrograde motor-driven transport from the model (and leaving only anterograde motor-driven transport, pausing, and diffusion in the free state)}

If cargo is transported only by anterograde motor-driven transport and diffusion in the free state (Fig. 2b), the model can still fit the concentration profile with the peak at the axon tip (Fig. S7a). The best-fit values of the rate constants for $v_{a v, \text { estimate }}^{*}=0.05 \mu \mathrm{m} \mathrm{s}^{-1}$ are given in Table S2. The fit does not require modulation of the values of kinetic constants, as their best-fit values are independent of $x^{*}$. This is because diffusion allows for the transport of information about the cargo concentration in both anterograde and retrograde directions (which is described by the second derivative with respect to $x^{*}$ in Eq. (25)). In fact, due to the increase of cargo concentration toward the axon tip, diffusion transports cargo in the retrograde direction, from the tip toward the soma. The system given by Eqs. (23)-(25) thus allows for information flow in both anterograde and retrograde directions and makes it possible to impose a high concentration of cargo condition at the tip of the axon. However, it should be noted that during their axonal transport many proteins are transported as multi-protein complexes or as vesicular components [56], which, due to their large size, are characterized by small diffusivity. If cargo diffusivity is negligible, motor-driven 
anterograde and retrograde transport is the only option to allow for bidirectional transport of information about the cargo concentration in the axon.

Since computations are performed assuming a large cargo half-life $\left(T_{1 / 2, \text { free }}^{*}=5.76 \times 10^{10}\right)$, the cargo fluxes are independent of $x^{*}$ (Fig. S7b). The fluxes in Fig. S7b are the same as those for slow (bidirectional) axonal transport in Fig. 4b. Average velocity distributions in Fig. S8a are similar to velocity distributions in Fig. 5a for the case of slow axonal transport, with almost a constant value over most of the axon and a velocity decrease near the axon tip. It is interesting that although for the cases displayed in Figs. 5b, 7b, and $9 \mathrm{~b}$ anterograde and retrograde motor-driven fluxes competed near the axonal tip and the diffusiondriven flux was negligible, this is not the situation for the case displayed in Fig. S8b. Since in the case displayed in Fig. S8b the model does not include retrograde transport, the only mechanism that can compete with anterograde transport in the vicinity of the axonal tip is diffusion. Therefore, in Fig. S8b diffusion's magnitude is significant and the direction of the cargo flux caused by it is opposite to the direction of anterograde axonal transport.

\subsection{Effect of leaving only anterograde and retrograde motor-driven transport in the model}

If cargo is transported only by anterogradely and retrogradely moving motors, with no free or pausing states (Fig. 2c), the results presented in Figs. S9 and S10 show that the model can still fit the prescribed concentration profile (Fig. S9a) as well as reproduce the prescribed average cargo velocity (Fig. S10a). This is explained by the fact that in this case cargo transport is bidirectional, although cargo diffusion is neglected, and Eqs. (28) and (29) allow for the imposition of given cargo concentrations both at the axon hillock and the axon tip (Eqs. (30) and (31)). The best-fit values of kinetic constants for $v_{a v, e s t i m a t e}^{*}=0.05$ $\mu \mathrm{m} \mathrm{s}^{-1}$ are given in Table S3. These values are constant; no modulation of the kinetic constants is required. The cargo fluxes displayed in Fig. S9b are identical to those displayed in Fig. 3b for the three slow axonal transport cases. This is because the total cargo flux equals the average cargo velocity times the total cargo concentration (Eq. (9)). The anterograde and retrograde cargo fluxes both increase at the axon tip (Fig. S10b).

\section{Discussion, limitations of the model and future directions}

In this paper, we compared bidirectional and unidirectional axonal transport models with respect to information about the cargo concentration that these models allow us to impose on the boundaries of the 
domain. The presented analysis uncovers an important feature of propagation of information about the cargo concentration in bidirectional and unidirectional axonal transport processes. Bidirectional axonal transport includes both anterograde and retrograde components, and hence information about the cargo concentration can propagate in both directions. This allows for the imposition of protein concentration not only at the axon hillock, but also at the presynaptic terminal. Since any value of protein concentration can be imposed at the presynaptic terminal, bidirectional axonal transport is capable of transporting protein against its concentration gradient, allowing for a situation when the protein concentration in the beginning of the axon is low and at the presynaptic terminal is high. It should be noted that in the case of increasing cargo concentration along the axon length, retrograde transport can occur not only by the motor-driven mechanism (dynein motors) but also by diffusion, which can move cargos in the direction opposite to their concentration gradient, from the axon tip to the soma. However, due to the small diffusivity of large cargos and the large length of the axon, diffusion is usually insufficient for long-range transport [33]. Contrary to this, the unidirectional anterograde axonal transport (without diffusion) accounts only for anterograde flow of information about the cargo concentration and thus allows for the imposition of a boundary condition specifying the protein concentration only at the axon hillock. Since no boundary condition can be imposed at the presynaptic terminal, the information about the cargo concentration at the terminal cannot be supplied in the unidirectional anterograde axonal transport model. This results in the inability of unidirectional axonal transport to move protein against its concentration gradient. However, bidirectional axonal transport is capable of transporting proteins against their concentration gradient. The presented results suggest why bidirectional transport, despite its much less efficient utilization of molecular motors and larger energy cost, is used by neurons to transport presynaptic proteins from the soma, where these proteins are synthesized, to the presynaptic terminal. The concentration of such proteins is much higher at the presynaptic terminal, and the utilization of bidirectional axonal transport, with its ability to transmit information about the cargo concentration both ways, allows for transport of these proteins from locations where their concentration is low (the soma and proximal axon) to locations where their concentration is high (the presynaptic terminal). We should note that to have information about the cargo concentration travel in both anterograde and retrograde directions, it is not enough to have cargos that make bidirectional movements occasionally. It is necessary to have separate populations of anterogradely and retrogradely moving cargos, which happens, for example, in slow axonal transport. We compared different components of the cargo flux in the axon. In the region with a sharp increase of cargo concentration the anterograde motor-driven flux increases. Since under steady-state conditions with a very large cargo half-life the total flux must remain constant; the increase of anterograde flux must be 
compensated by an increase of the retrograde flux. This leads to an increase of the motor-driven retrograde flux near the tip of the axon. However, if there is no retrograde motor-driven flux in the model, the retrograde flux occurs due to the diffusion component.

Our simulations show that if the pausing and diffusion-driven (free) states are removed from the model and only anterograde and retrograde motor-driven states are included in the model, the model is still capable of predicting cargo transport against the concentration gradient (sections 2.5 and 3.5). Why then do cargos moved by slow axonal transport spend most of their time pausing, if the cargo can be moved with a much larger average velocity, without pausing? Our explanation is that relying on fast axonal transport would be energetically much more expensive since cargos would have to be moved continuously in a circulation loop, similar to the transport of dense core vesicles in Drosophila motoneurons [34]. The utilization of pauses in cargo transport saves energy because it eliminates the need for long-range circulation driven by energy-consuming molecular motors. The circulation may be repeated many times for the same cargo.

In our simulations, we used constant values of kinetic constants, which are independent of cargo concentration. This means that a single cargo does not see what the other cargos are doing. This does not change the conclusions from our modeling. It does not matter whether the coefficients in differential equations are constants or functions of dependent variables (concentrations). One needs the ability to impose cargo concentrations at both the axon hillock $\left(x^{*}=0\right)$ and the axon tip $\left(x^{*}=L^{*}\right)$ to inform the model of what the cargo concentrations at the boundaries are. If governing equations allow only for the imposition of the concentration at the hillock, the model does not know what concentration it should satisfy at the axon tip. This is the case of the unidirectional axonal transport model without diffusion (section 2.6).

Finally, a note about the ability of diffusion alone to simulate cargo transport against the cargo concentration gradient. Ref. [33] studied a cargo (tau protein) diffusion model with a finite cargo half-life in the free state. Cargo can transition from a free state, where it is moved by diffusion, to a pausing state, where it does not move. Figs. $4 \mathrm{~b}$ and $4 \mathrm{~d}$ in [33] show a perfect curve-fit of the total cargo concentration with experimental data, while Figs. $4 \mathrm{a}$ and $4 \mathrm{c}$ show how the kinetic constant characterizing the rate of cargo attachment to MTs must be modulated to achieve this fit. The results suggest that although a reaction-diffusion model can simulate cargo transport against the concentration gradient, it requires quite an unphysical increase in a value of a kinetic constant along the axon length. This variation of the kinetic constant value with the axon length heavily depends on how long the axon is (compare Figs. 4a and 4c in [33]). 
Future work should include experimental testing of the slow axonal transport model of $\alpha$-syn monomers transport, which is described in section 2.1, including the calibration of model parameters that we presented. Unlike the model developed in [28] for neurofilament transport, the model developed in section 2.1 has not been experimentally tested yet.

Future research should also address models in which kinetic constants depend on cargo concentration gradients, such as the model developed in [57]. In such situations the differential equations become nonlinear.

The mechanistic insight that could be obtained from understanding axonal transport of proteins associated with neurodegenerative diseases, in particular PD, could be used to develop novel methods for treating and managing these diseases $[4,58,59]$.

Acknowledgment. IAK acknowledges the fellowship support of the Paul and Daisy Soros Fellowship for New Americans and the NIH/National Institute of Mental Health (NIMH) Ruth L. Kirchstein NRSA (F30 MH122076-01). AVK acknowledges the support of the National Science Foundation (award CBET2042834) and the Alexander von Humboldt Foundation through the Humboldt Research Award. 


\section{References}

[1] T. Misgeld, T.L. Schwarz, Mitostasis in neurons: Maintaining mitochondria in an extended cellular architecture, Neuron 96 (2017) 651-666.

[2] A. Goldberg, Protein degradation and protection against misfolded or damaged proteins, Nature 426 (2003) 895-899.

[3] S. Roy, M.J. Winton, M.M. Black, J.Q. Trojanowski, V.M.Y. Lee, Cytoskeletal requirements in axonal transport of slow component-b, Journal of Neuroscience 28 (2008) 5248-5256.

[4] D. Charvin, R. Medori, R.A. Hauser, O. Rascol, Therapeutic strategies for Parkinson disease: Beyond dopaminergic drugs, Nature Reviews Drug Discovery 17 (2018) 804-822.

[5] S.H. Shahmoradian, A.J. Lewis, C. Genoud, J. Hench, T.E. Moors, P.P. Navarro, D. Castano-Diez, G. Schweighauser, A. Graff-Meyer, K.N. Godie, R. Sutterlin, E. Huisman, A. Ingrassia, Y. de Gier, A.J.M. Rozemuller, J. Wang, A. De Paepe, J. Erny, A. Staempfli, J. Hoernschemeyer, F. Grosserueschkamp, D. Niedieker, S.F. El-Mashtoly, M. Quadri, W.F.J. Van IJcken, V. Bonifati, K. Gerwert, B. Bohrmann, S. Frank, M. Britschgi, H. Stahlberg, W.D.J. Van de Berg, M.E. Lauer, Lewy pathology in Parkinson's disease consists of crowded organelles and lipid membranes, Nature Neuroscience 22 (2019) 1099-1109. [6] H.A. Lashuel, C.R. Overk, A. Oueslati, E. Masliah, The many faces of alpha-synuclein: From structure and toxicity to therapeutic target, Nature Reviews Neuroscience 14 (2013) 38-48.

[7] P. Jensen, M. Nielsen, R. Jakes, G. Dotti, M. Goedert, Binding of alpha-synuclein to brain vesicles is abolished by familial Parkinson's disease mutation, Journal of Biological Chemistry 273 (1998) 2629226294.

[8] P. Jensen, J. Li, A. Dahlstrom, C. Dotti, Axonal transport of synucleins is mediated by all rate components, European Journal of Neuroscience 11 (1999) 3369-3376.

[9] Y. Tang, U. Das, D.A. Scott, S. Roy, The slow axonal transport of alpha-synuclein-mechanistic commonalities amongst diverse cytosolic cargoes, Cytoskeleton 69 (2012) 506-513.

[10] J.Y. Li, P.H. Jensen, A. Dahlstrom, Differential localization of alpha-, beta- and gamma-synucleins in the rat CNS, Neuroscience 113 (2002) 463-478.

[11] D. Fortin, V. Nemani, S. Voglmaier, M. Anthony, T. Ryan, R. Edwards, Neural activity controls the synaptic accumulation of alpha-synuclein, Journal of Neuroscience 25 (2005) 10913-10921.

[12] J. Burre, The synaptic function of alpha-synuclein, Journal of Parkinsons Disease 5 (2015) 699-713. 
[13] M. Yang, L. Hasadsri, W.S. Woods, J.M. George, Dynamic transport and localization of alphasynuclein in primary hippocampal neurons, Molecular Neurodegeneration 5 (2010) 9.

[14] M. Utton, W. Noble, J. Hill, B. Anderton, D. Hanger, Molecular motors implicated in the axonal transport of tau and alpha-synuclein, Journal of Cell Science 118 (2005) 4645-4654.

[15] S. Roy, Dynein's life in the slow lane, Neuron 90 (2016) 907-909.

[16] S. Maday, A.E. Twelvetrees, A.J. Moughamian, E.L.F. Holzbaur, Axonal transport: Cargo-specific mechanisms of motility and regulation, Neuron 84 (2014) 292-309.

[17] D.A. Scott, I. Tabarean, Y. Tang, A. Cartier, E. Masliah, S. Roy, A pathologic cascade leading to synaptic dysfunction in alpha-synuclein-induced neurodegeneration, Journal of Neuroscience 30 (2010) 8083-8095.

[18] W.O. Hancock, Bidirectional cargo transport: Moving beyond tug of war, Nature Reviews Molecular Cell Biology 15 (2014) 615-628.

[19] A. Brown, Axonal Transport, in: D. Pfaff, N. Volkow (Eds.), Neuroscience in the 21st Century, Springer, 2016, pp. 379.

[20] T. Scholz, E. Mandelkow, Transport and diffusion of tau protein in neurons, Cellular and Molecular Life Sciences 71 (2014) 3139-3150.

[21] X. Li, Y. Kumar, H. Zempel, E.M. Mandelkow, J. Biernat, E. Mandelkow, Novel diffusion barrier for axonal retention of tau in neurons and its failure in neurodegeneration, Embo Journal 30 (2011) 48254837.

[22] I.A. Kuznetsov, A. Kuznetsov V., Modeling tau transport in the axon initial segment, Mathematical Biosciences 329 (2020) 108468.

[23] M.M. Black, T. Slaughter, S. Moshiach, M. Obrocka, I. Fischer, Tau is enriched on dynamic microtubules in the distal region of growing axons, Journal of Neuroscience 16 (1996) 3601-3619.

[24] I.A. Kuznetsov, A.V. Kuznetsov, How the formation of amyloid plaques and neurofibrillary tangles may be related - A mathematical modelling study, Proceedings of the Royal Society A 474 (2018) 20170777.

[25] I.A. Kuznetsov, A.V. Kuznetsov, Simulating the effect of formation of amyloid plaques on aggregation of tau protein, Proceedings of the Royal Society A-Mathematical Physical and Engineering Sciences 474 (2018) 20180511. 
[26] A.E. Twelvetrees, S. Pernigo, A. Sanger, P. Guedes-Dias, G. Schiavo, R.A. Steiner, M.P. Dodding, E.L.F. Holzbaur, The dynamic localization of cytoplasmic dynein in neurons is driven by kinesin-1, Neuron 90 (2016) 1000-1015.

[27] S. Roy, Finding order in slow axonal transport, Current Opinion in Neurobiology 63 (2020) 87-94.

[28] P. Jung, A. Brown, Modeling the slowing of neurofilament transport along the mouse sciatic nerve, Physical Biology 6 (2009) 046002.

[29] A.V. Kuznetsov, A.A. Avramenko, D.G. Blinov, Effect of protein degradation in the axon on the speed of the bell-shaped concentration wave in slow axonal transport, International Communications in Heat and Mass Transfer 36 (2009) 641-645.

[30] A.V. Kuznetsov, A.A. Avramenko, D.G. Blinov, Macroscopic modeling of slow axonal transport of rapidly diffusible soluble proteins, International Communications in Heat and Mass Transfer 36 (2009) 293-296.

[31] S. Roy, Seeing the unseen: The hidden world of slow axonal transport, Neuroscientist 20 (2014) 7181.

[32] A. Raichur, S. Vali, F. Gorin, Dynamic modeling of alpha-synuclein aggregation for the sporadic and genetic forms of Parkinson's disease, Neuroscience 142 (2006) 859-870.

[33] I.A. Kuznetsov, A.V. Kuznetsov, A comparison between the diffusion-reaction and slow axonal transport models for predicting tau distribution along an axon, Mathematical Medicine and Biology 32 (2015) 263-283.

[34] M.Y. Wong, C. Zhou, D. Shakiryanova, T.E. Lloyd, D.L. Deitcher, E.S. Levitan, Neuropeptide delivery to synapses by long-range vesicle circulation and sporadic capture, Cell 148 (2012) 1029-1038.

[35] J.B. Kool, J.C. Parker, M.T. van Genuchten, Parameter estimation for unsaturated flow and transport models - A review, Journal of Hydrology 91 (1987) 255-293.

[36] K.S. Zadeh, Parameter estimation in flow through partially saturated porous materials, Journal of Computational Physics 227 (2008) 10243-10262.

[37] K.S. Zadeh, S.B. Shah, Mathematical modeling and parameter estimation of axonal cargo transport, Journal of Computational Neuroscience 28 (2010) 495-507.

[38] K.S. Zadeh, A synergic simulation-optimization approach for analyzing biomolecular dynamics in living organisms, Computers in Biology and Medicine 41 (2011) 24-36. 
[39] K.S. Zadeh, H.J. Montas, Parametrization of flow processes in porous media by multiobjective inverse modeling, Journal of Computational Physics 259 (2014) 390-401.

[40] I.A. Kuznetsov, A.V. Kuznetsov, Utilization of the bootstrap method for determining confidence intervals of parameters for a model of MAP1B protein transport in axons, Journal of Theoretical Biology 419 (2017) 350-361.

[41] S. Nath, J. Meuvis, J. Hendrix, S.A. Carl, Y. Engelborghs, Early aggregation steps in alpha-synuclein as measured by FCS and FRET: Evidence for a contagious conformational change, Biophysical Journal 98 (2010) 1302-1311.

[42] J.K. Hannestad, S. Rocha, B. Agnarsson, V.P. Zhdanov, P. Wittung-Stafshede, F. Hook, Singlevesicle imaging reveals lipid-selective and stepwise membrane disruption by monomeric alpha-synuclein, Proceedings of the National Academy of Sciences of the United States of America 117 (2020) 1417814186.

[43] S.M.L. Banks, A.T. Medeiros, M. McQuillan, D.J. Busch, A.S. Ibarraran-Viniegra, R. Sousa, E.M. Lafer, J.R. Morgan, Hsc70 ameliorates the vesicle recycling defects caused by excess alpha-synuclein at synapses, Eneuro 7 (2020) 0448-19.2020.

[44] M.C. Bennett, J.F. Bishop, Y. Leng, P.B. Chock, T.N. Chase, M.M. Mouradian, Degradation of alpha-synuclein by proteasome, Journal of Biological Chemistry 274 (1999) 33855-33858.

[45] A.H.V. Schapira, A.E.T. Lang, S. Fahn (Eds.), Movement Disorders 4: Blue Books of Neurology Series, Volume 35, Saunders, Philadelphia, PA, 2010.

[46] J.L. George, S. Mok, D. Moses, S. Wilkins, A.I. Bush, R.A. Cherny, D.I. Finkelstein, Targeting the progression of Parkinson's disease, Current Neuropharmacology 7 (2009) 9-36.

[47] A. Gupta, T.M. Dawson, Chapter 10 - pathogenesis of Parkinson's disease, Blue Books of Neurology 34 (2010) 155-169.

[48] S. Toba, M. Jin, M. Yamada, K. Kumamoto, S. Matsumoto, T. Yasunaga, Y. Fukunaga, A. Miyazawa, S. Fujita, K. Itoh, S. Fushiki, H. Kojima, H. Wanibuchi, Y. Arai, T. Nagai, S. Hirotsune, Alpha-synuclein facilitates to form short unconventional microtubules that have a unique function in the axonal transport, Scientific Reports 7 (2017) 16386.

[49] A. Saha, J. Hill, M. Utton, A. Asuni, S. Ackerley, A. Grierson, C. Miller, A. Davies, V. Buchman, B. Anderton, D. Hanger, Parkinson's disease alpha-synuclein mutations exhibit defective axonal transport in cultured neurons, Journal of Cell Science 117 (2004) 1017-1024. 
[50] W.X. Li, P.N. Hoffman, W. Stirling, D.L. Price, M.K. Lee, Axonal transport of human alphasynuclein slows with aging but is not affected by familial Parkinson's disease-linked mutations, Journal of Neurochemistry 88 (2004) 401-410.

[51] A. Iyer, M.M.A.E. Claessens, Disruptive membrane interactions of alpha-synuclein aggregates, Biochimica Et Biophysica Acta-Proteins and Proteomics 1867 (2019) 468-482.

[52] C. Kim, S. Lee, Controlling the mass action of alpha-synuclein in Parkinson's disease, Journal of Neurochemistry 107 (2008) 303-316.

[53] T. Rosenberg, S. Gal-Ben-Ari, D.C. Dieterich, M.R. Kreutz, N.E. Ziv, E.D. Gundelfinger, K. Rosenblum, The roles of protein expression in synaptic plasticity and memory consolidation, Frontiers in Molecular Neuroscience 7 (2014) 86.

[54] J.V. Beck, K.J. Arnold, Parameter Estimation in Science and Engineering, Wiley, New York, 1977.

[55] I.A. Kuznetsov, A.V. Kuznetsov, Simulating tubulin-associated unit transport in an axon: Using bootstrapping for estimating confidence intervals of best fit parameter values obtained from indirect experimental data, Proceedings of the Royal Society A 473 (2017) 20170045.

[56] S.V. Puthanveettil, F.J. Monje, M.C. Miniaci, Y. Choi, K.A. Karl, E. Khandros, M.A. Gawinowicz, M.P. Sheetz, E.R. Kandel, A new component in synaptic plasticity: Upregulation of kinesin in the neurons of the gill-withdrawal reflex, Cell 135 (2008) 960-973.

[57] M. Ciocanel, P. Jung, A. Brown, A mechanism for neurofilament transport acceleration through nodes of ranvier, Molecular Biology of the Cell 31 (2020) 640-654.

[58] E. Kosari, K. Vafai, Chapter seven - thermal stimulation of targeted neural circuits via remotely controlled nano-transducers: A therapy for neurodegenerative disorders, Advances in Heat Transfer 52 (2020) 543-581.

[59] E. Kosari, K. Vafai, Thermal tissue damage analysis for magnetothermal neuromodulation and lesion size minimization, Brain Multiphysics 1 (2020) 100014. 


\section{Figure captions}

Fig. 1. A diagram showing the coordinate system adopted in the model.

Fig. 2. A kinetic diagram showing various kinetic states in our model of $\alpha$-syn transport in the axon and transitions between these kinetic states. Degradation of free monomeric $\alpha$-syn due to its destruction in proteasomes is also shown (in the model illustrated in Fig. $2 \mathrm{~d}$ the degradation process is added in the anterograde state because there is no free state in this model). (a). The diagram is based on the model of SCa transport of neurofilaments developed in [28] with modification to this model suggested in [29,30] to extend this model to SCb-transported proteins. Figs. 2(b),(c),(d) show various versions of the model with some of the transport modes and kinetic states removed. This is done to investigate what transport modes are minimally required to simulate cargo transport against its concentration gradient.

Fig. 3. A schematic diagram showing a control volume (CV) in the axon. Anterogradely transported cargo can enter and leave the $\mathrm{CV}$; the cargo can also decay in the $\mathrm{CV}$.

Fig. 4. Slow (bidirectional) and fast (unidirectional) axonal transport. $T_{1 / 2, \text { free }}^{*}=5.76 \times 10^{10} \mathrm{~s}$, the fraction of $\alpha$-syn monomers conveyed in the fast component of axonal transport is assumed to be zero. (a) Total concentration of $\alpha$-syn monomers (the sum of $\alpha$-syn concentrations in motor-driven, pausing, and diffusing states). (b) Total flux of $\alpha$-syn monomers due to action of molecular motors and diffusion in the cytosol.

Fig. 5. Slow (bidirectional) and fast (unidirectional) axonal transport. $T_{1 / 2}^{*}$,free $=5.76 \times 10^{10} \mathrm{~s}$, the fraction of $\alpha$-syn monomers conveyed in the fast component of axonal transport is assumed to be zero. (a) Average velocity of $\alpha$-syn monomers in slow axonal transport along the axon. (b) Anterograde motordriven, retrograde motor-driven, and diffusion-driven components of the total $\alpha$-syn flux.

Fig. 6. Slow (bidirectional) and fast (unidirectional) axonal transport. $v_{a v, \text { estimate }}^{*}=0.05 \mu \mathrm{m} \mathrm{s}^{-1}$, the fraction of $\alpha$-syn monomers conveyed in the fast component of axonal transport is assumed to be zero. (a) Total concentration of $\alpha$-syn monomers (the sum of $\alpha$-syn concentrations in motor-driven, pausing, and diffusing states). (b) Total flux of $\alpha$-syn monomers due to action of molecular motors and diffusion in the cytosol.

Fig. 7. Slow (bidirectional) and fast (unidirectional) axonal transport. $v_{a v, \text { estimate }}^{*}=0.05 \mu \mathrm{m} \mathrm{s}^{-1}$, the fraction of $\alpha$-syn monomers conveyed in the fast component of axonal transport is assumed to be zero. (a) 
Average velocity of $\alpha$-syn monomers in slow axonal transport along the axon. (b) Anterograde motordriven, retrograde motor-driven, and diffusion-driven components of the total $\alpha$-syn flux.

Fig. 8. Slow (bidirectional) and fast (unidirectional) axonal transport. $T_{1 / 2, \text { free }}^{*}=T_{1 / 2, a}^{*}=5.76 \times 10^{10} \mathrm{~s}$, $v_{a v, e s t i m a t e}^{*}=0.05 \mu \mathrm{m} \mathrm{s}^{-1}$, the fraction of $\alpha$-syn monomers conveyed in the fast component of axonal transport is assumed to be $15 \%$. (a) Total concentration of $\alpha$-syn monomers (the sum of $\alpha$-syn concentrations in motor-driven, pausing, and diffusing states). (b) Total flux of $\alpha$-syn monomers due to action of molecular motors and diffusion in the cytosol.

Fig. 9. Slow (bidirectional) and fast (unidirectional) axonal transport. $T_{1 / 2, \text { free }}^{*}=T_{1 / 2, a}^{*}=5.76 \times 10^{10} \mathrm{~s}$, $v_{a v, e s t i m a t e}^{*}=0.05 \mu \mathrm{m} \mathrm{s}^{-1}$, the fraction of $\alpha$-syn monomers conveyed in the fast component of axonal transport is assumed to be $15 \%$. (a) Average velocity of $\alpha$-syn monomers in slow (bidirectional) and fast (unidirectional) axonal transport along the axon. (b) Anterograde motor-driven, retrograde motor-driven, and diffusion-driven components of the total $\alpha$-syn flux. $n_{a}$ and $n_{a \text {,fast }}$ are scaled in such a way so that $85 \%$ of $\alpha$-syn monomers are transported in slow component and $15 \%$ are transported in fast component. 


\section{Bidirectional axonal}

$\underset{x^{*}=0}{\stackrel{\text { Axon hillock }}{\longrightarrow}} \stackrel{x^{*}=L^{*}}{\longrightarrow} x^{*}$


(a)

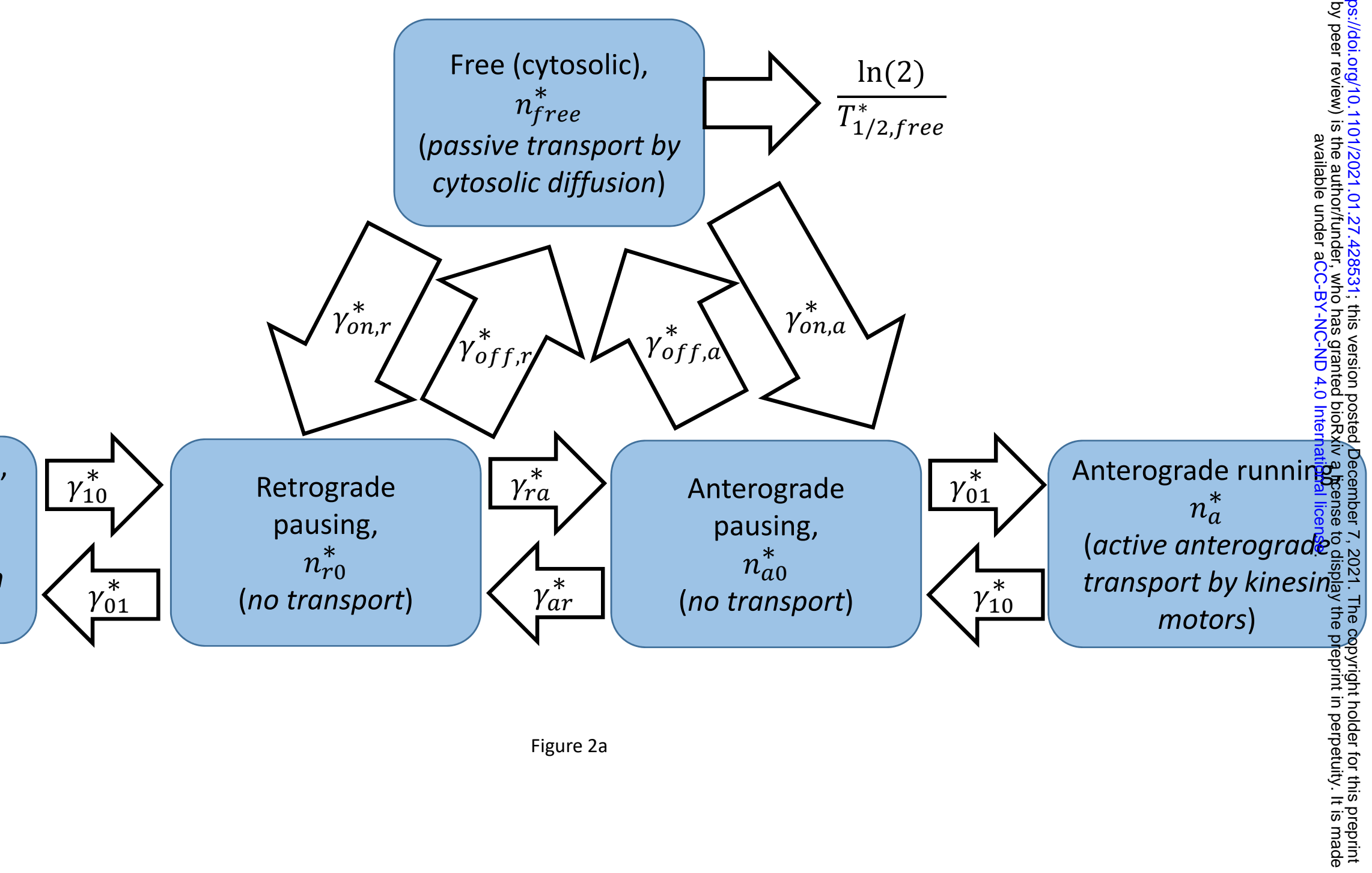




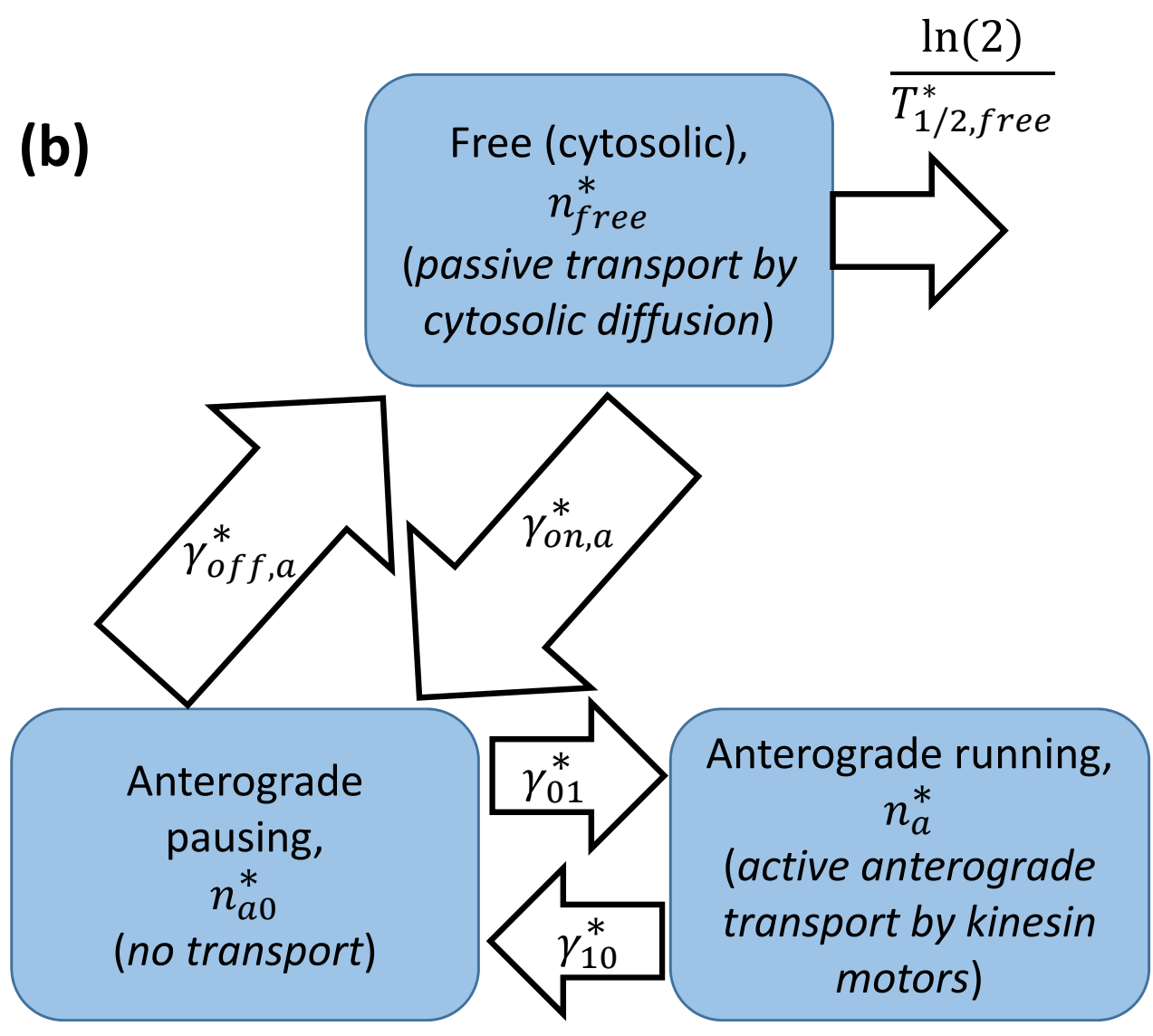

(c)

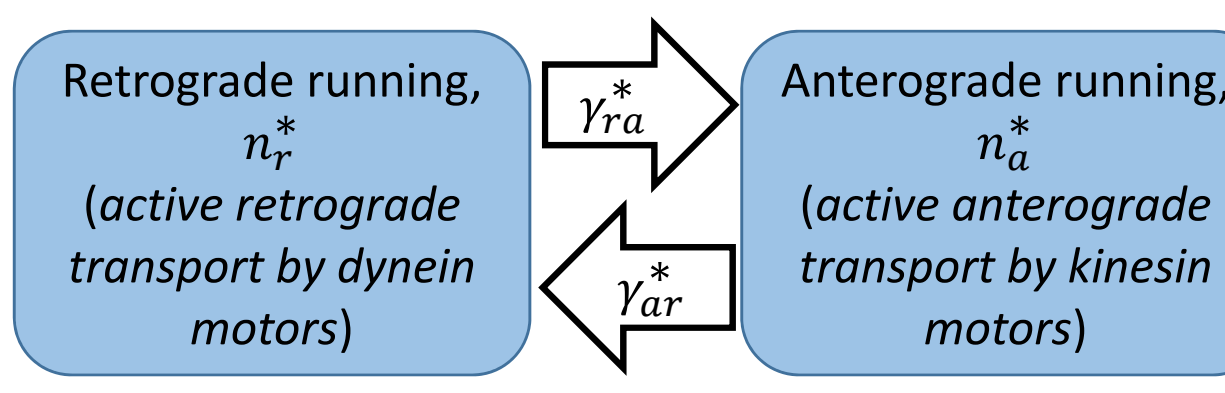

(d)

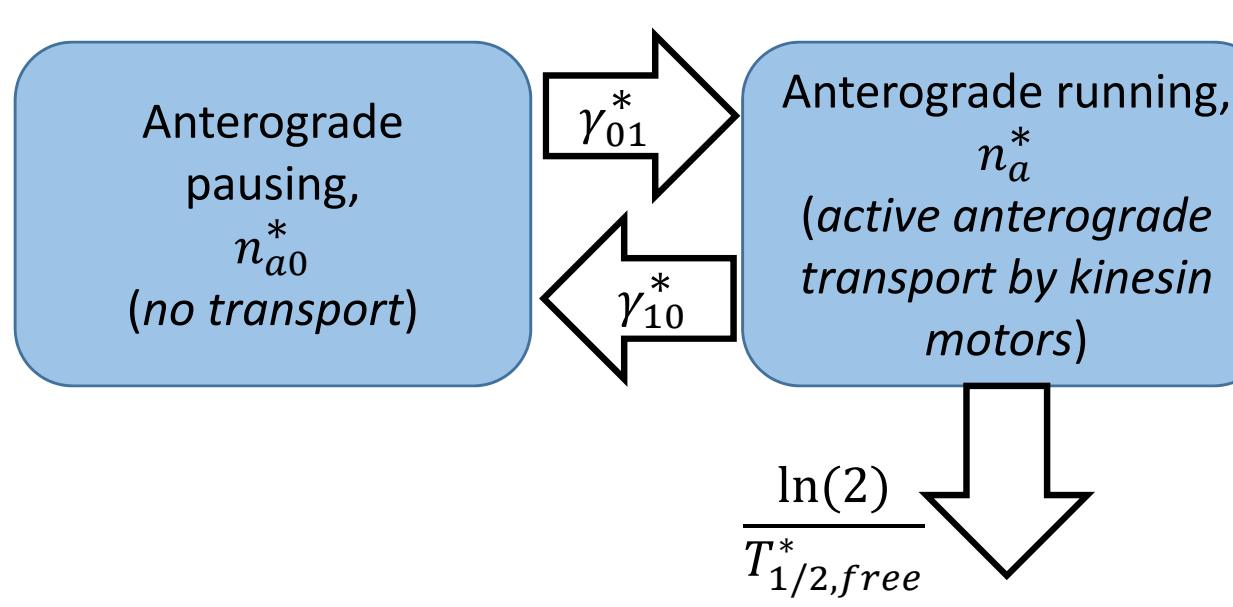

Figure $2 b, c, d$ 


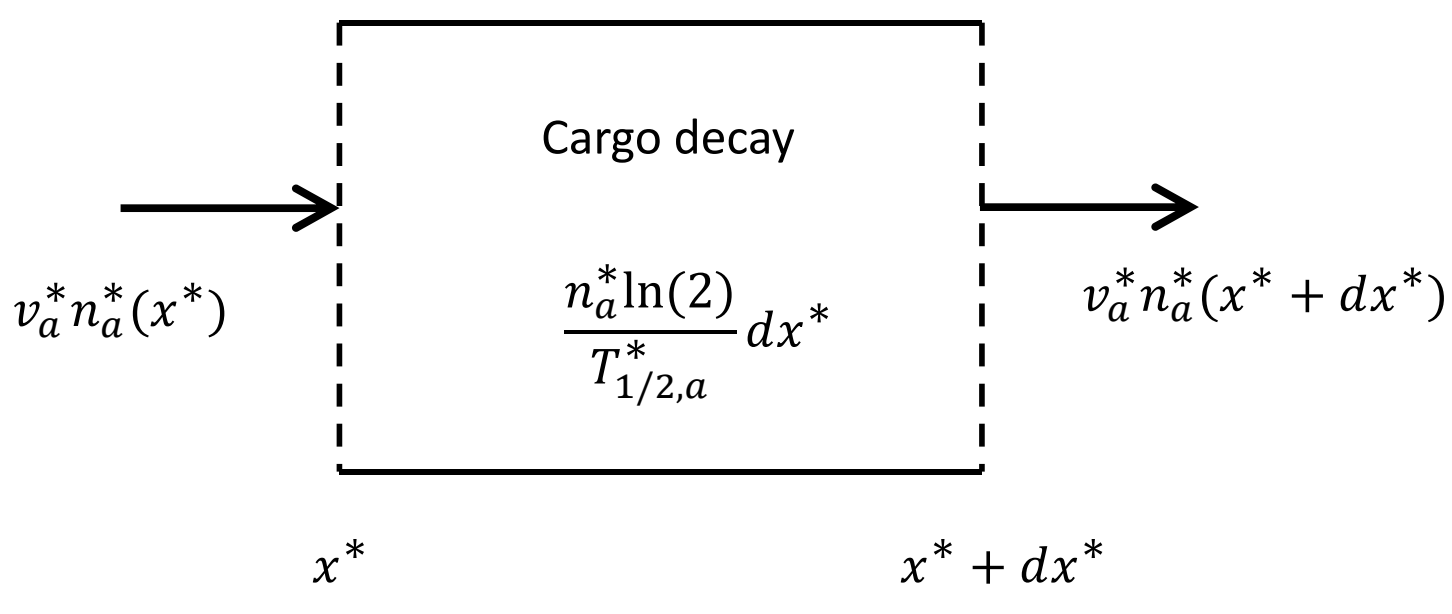

Figure 3 
(a)

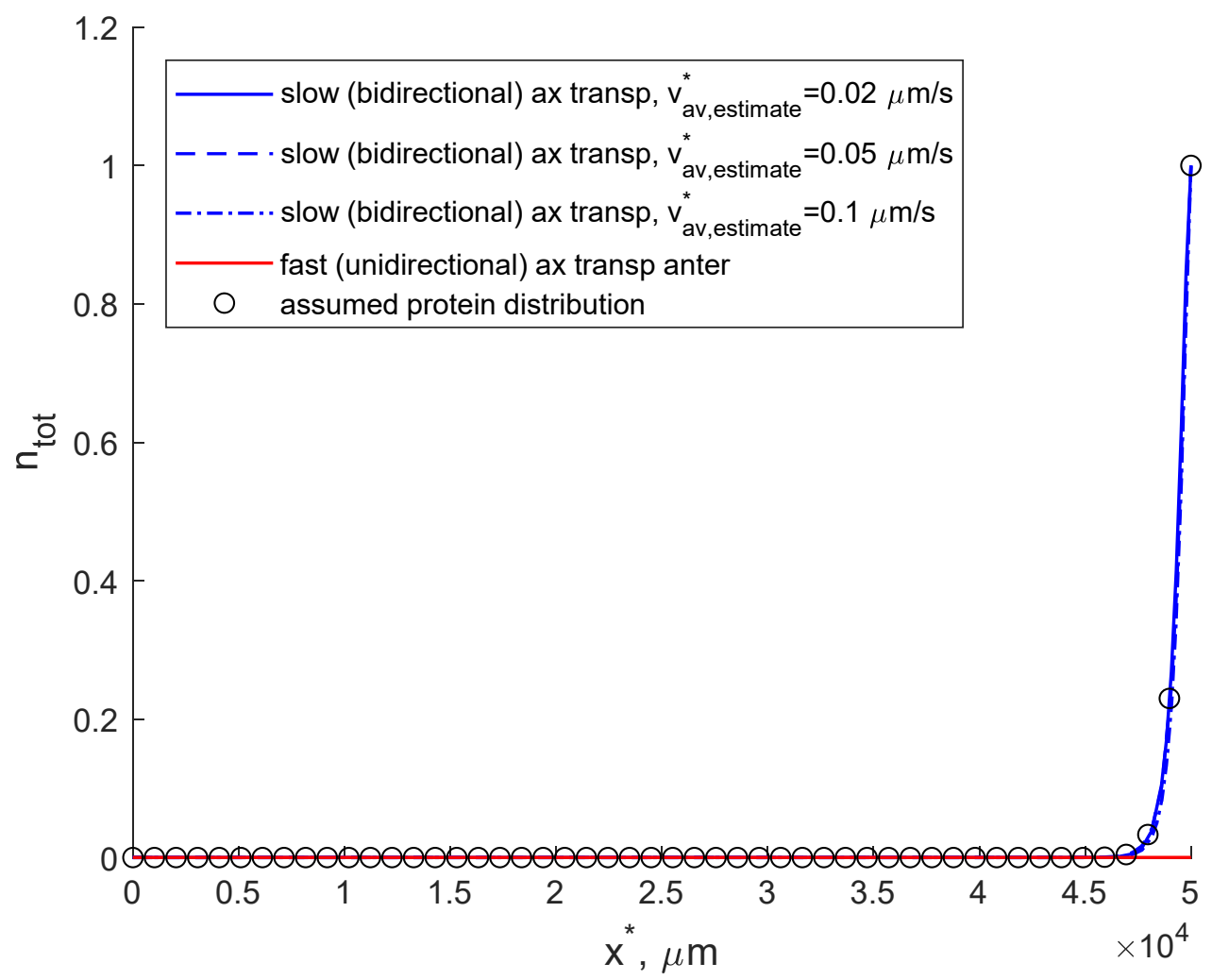

(b)

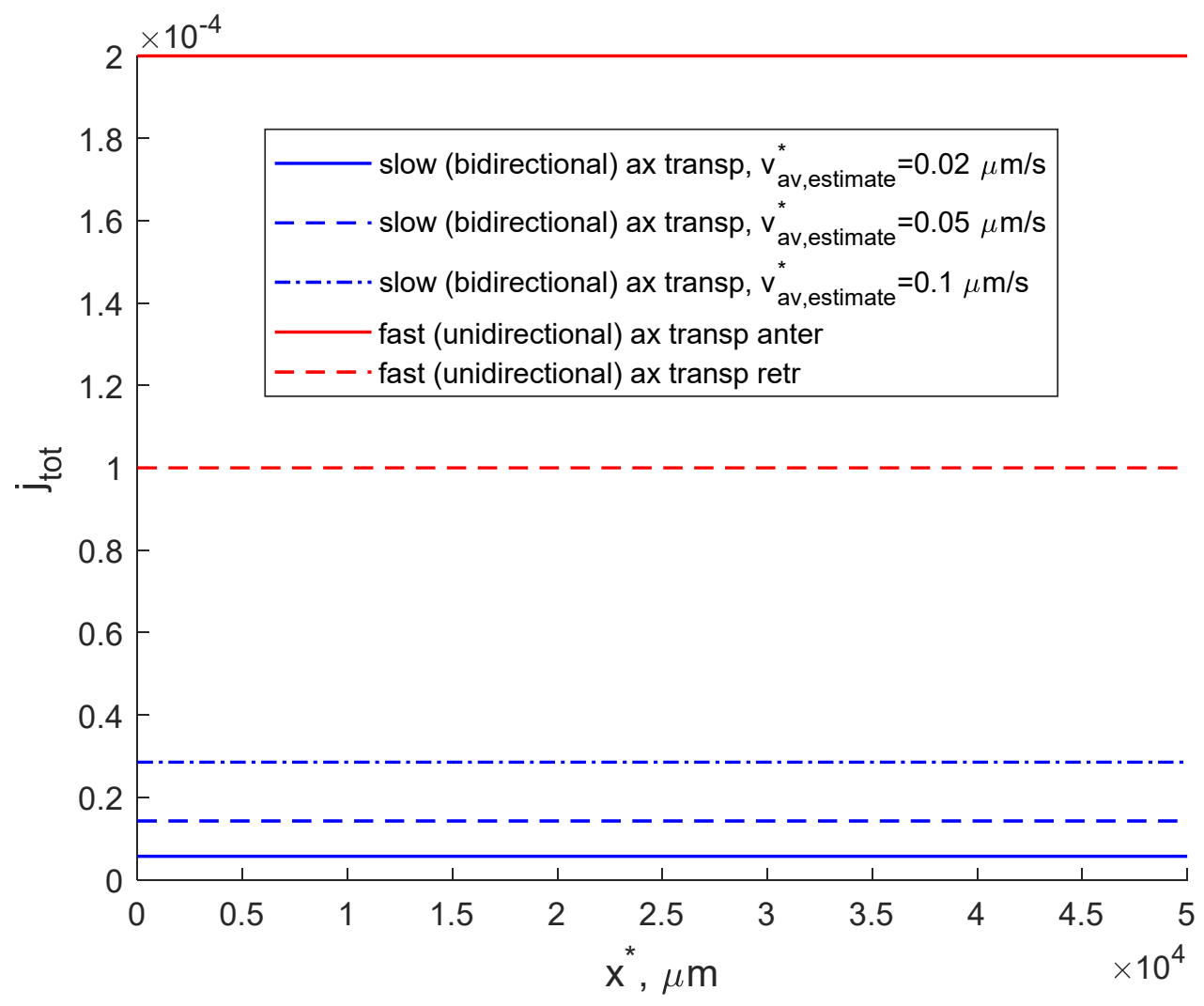


(a)

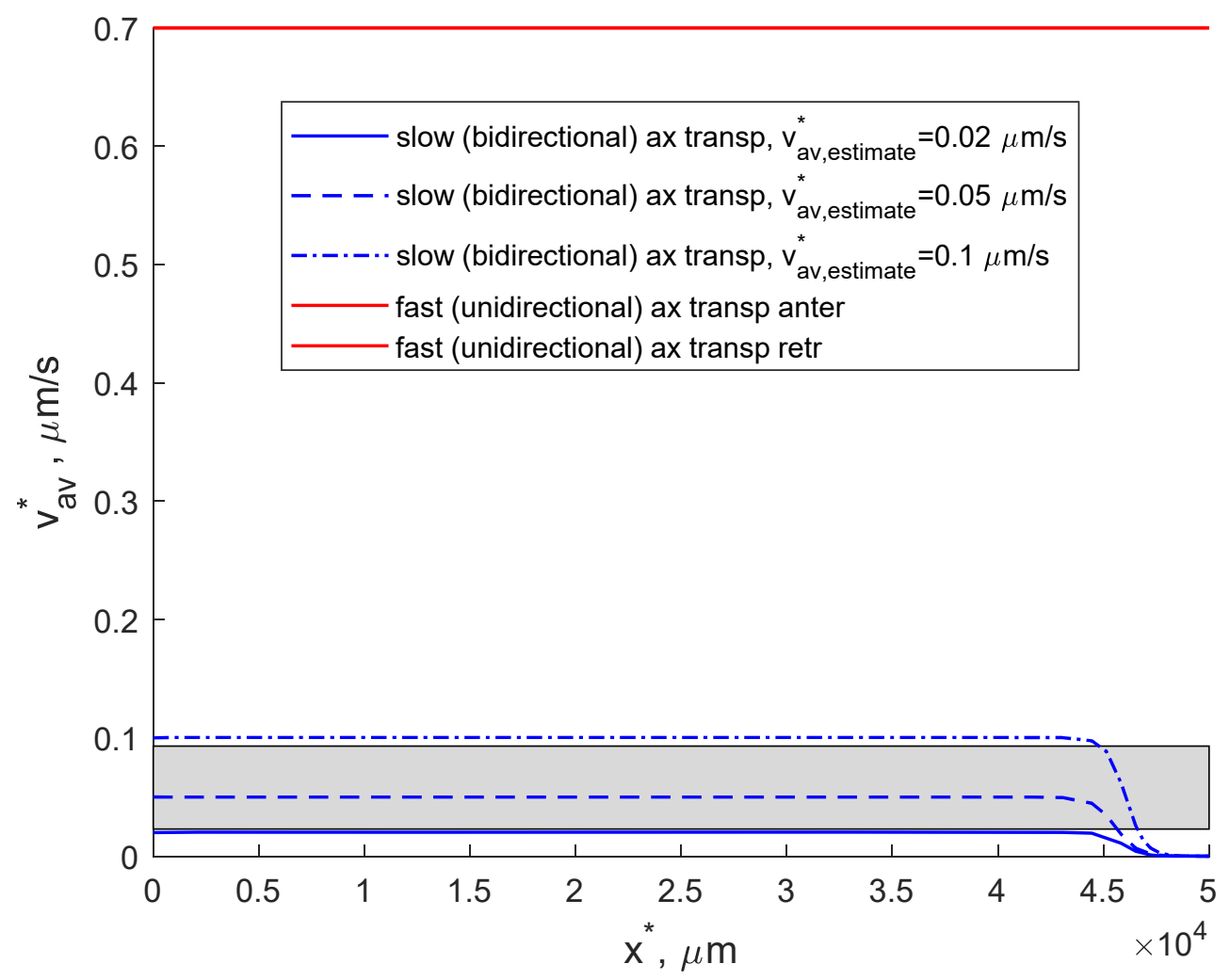

(b)

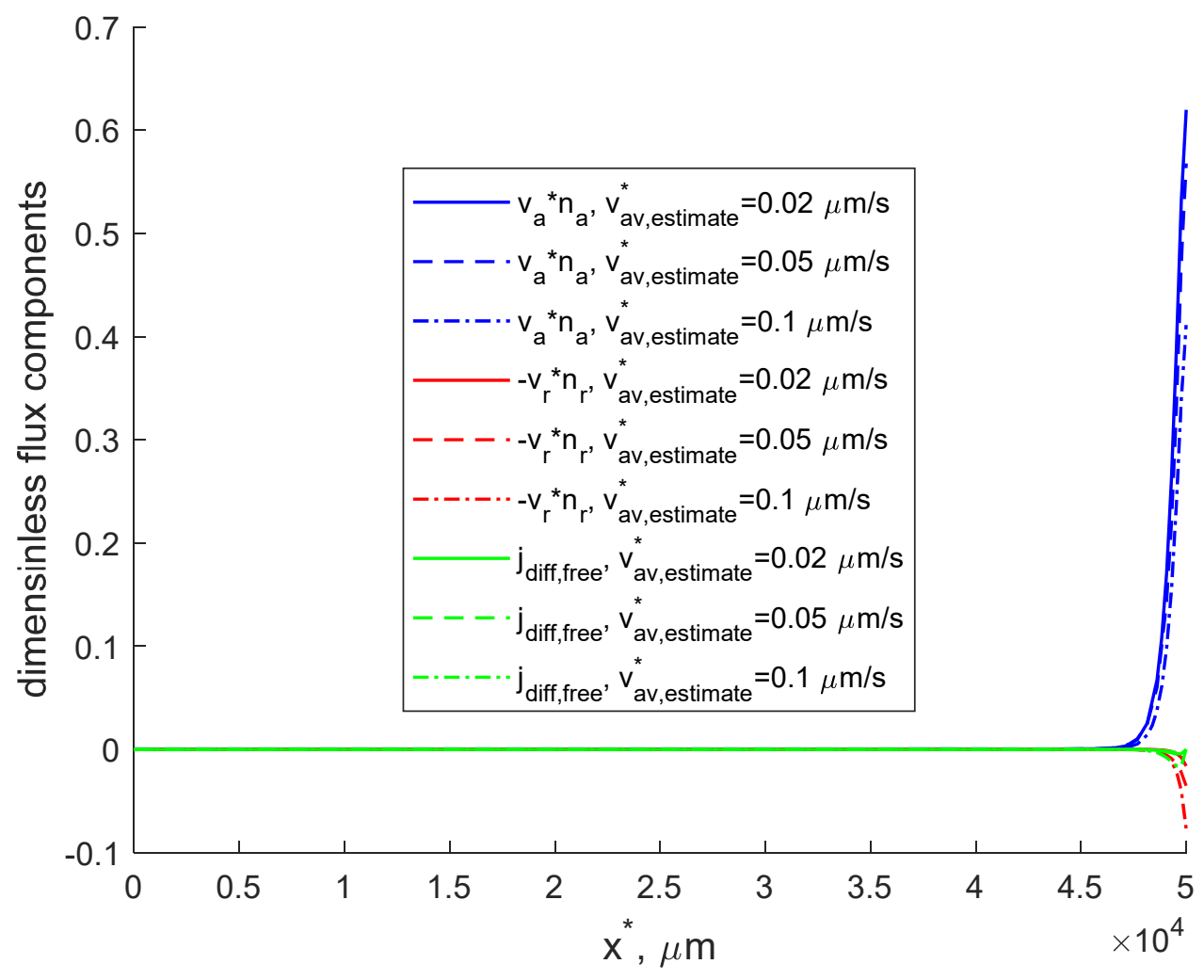

Figure 5 
(a)

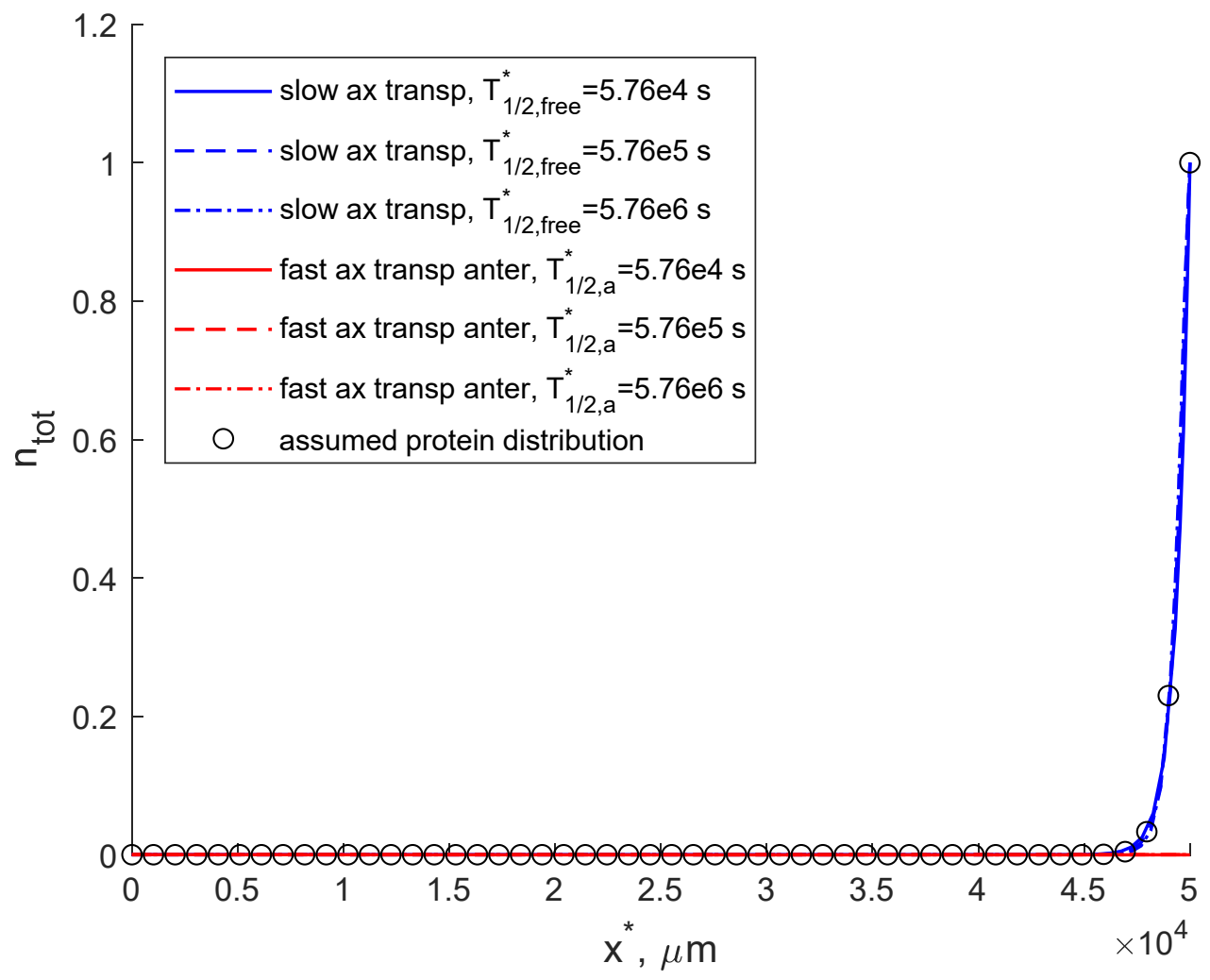

(b)

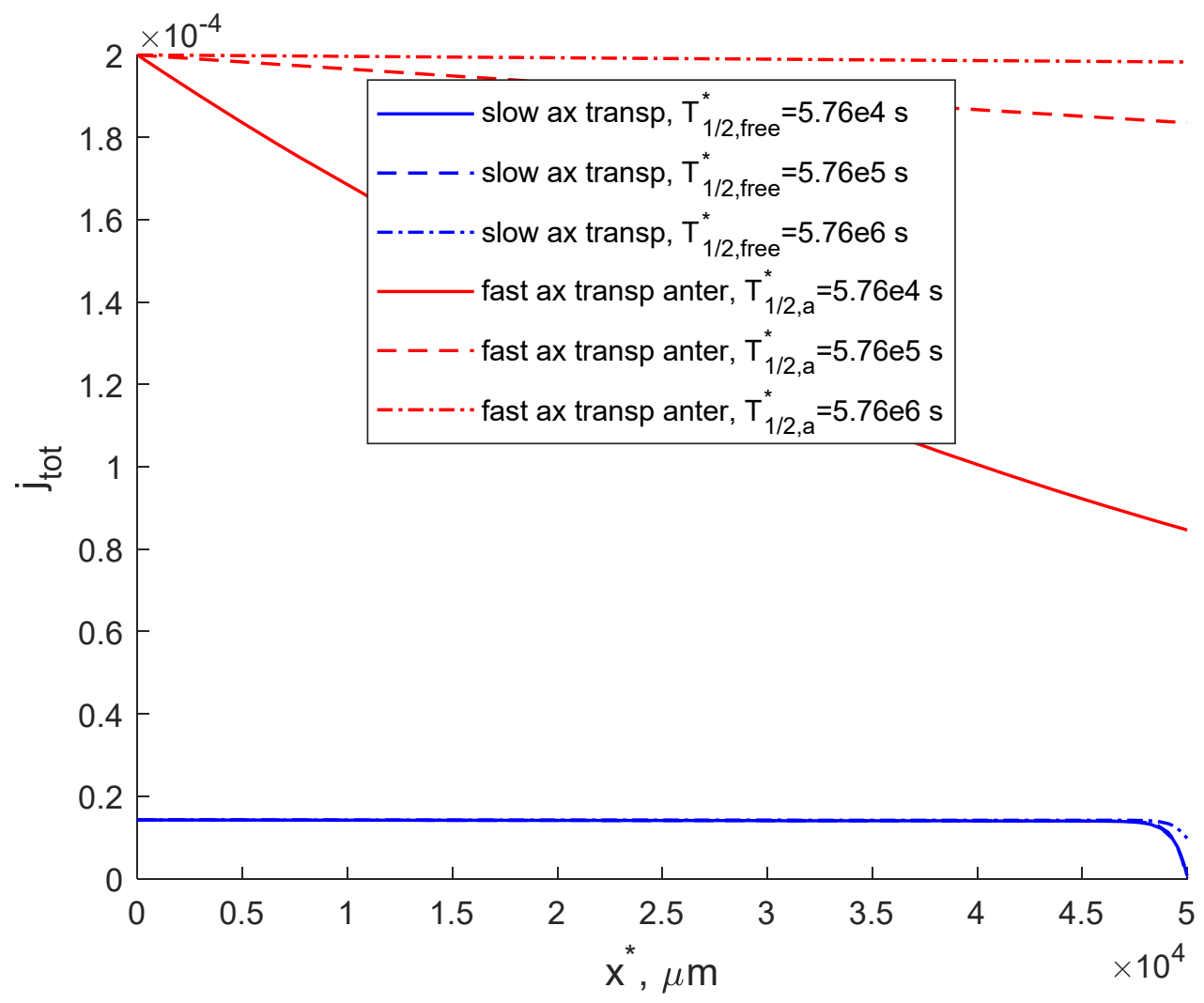


(a)

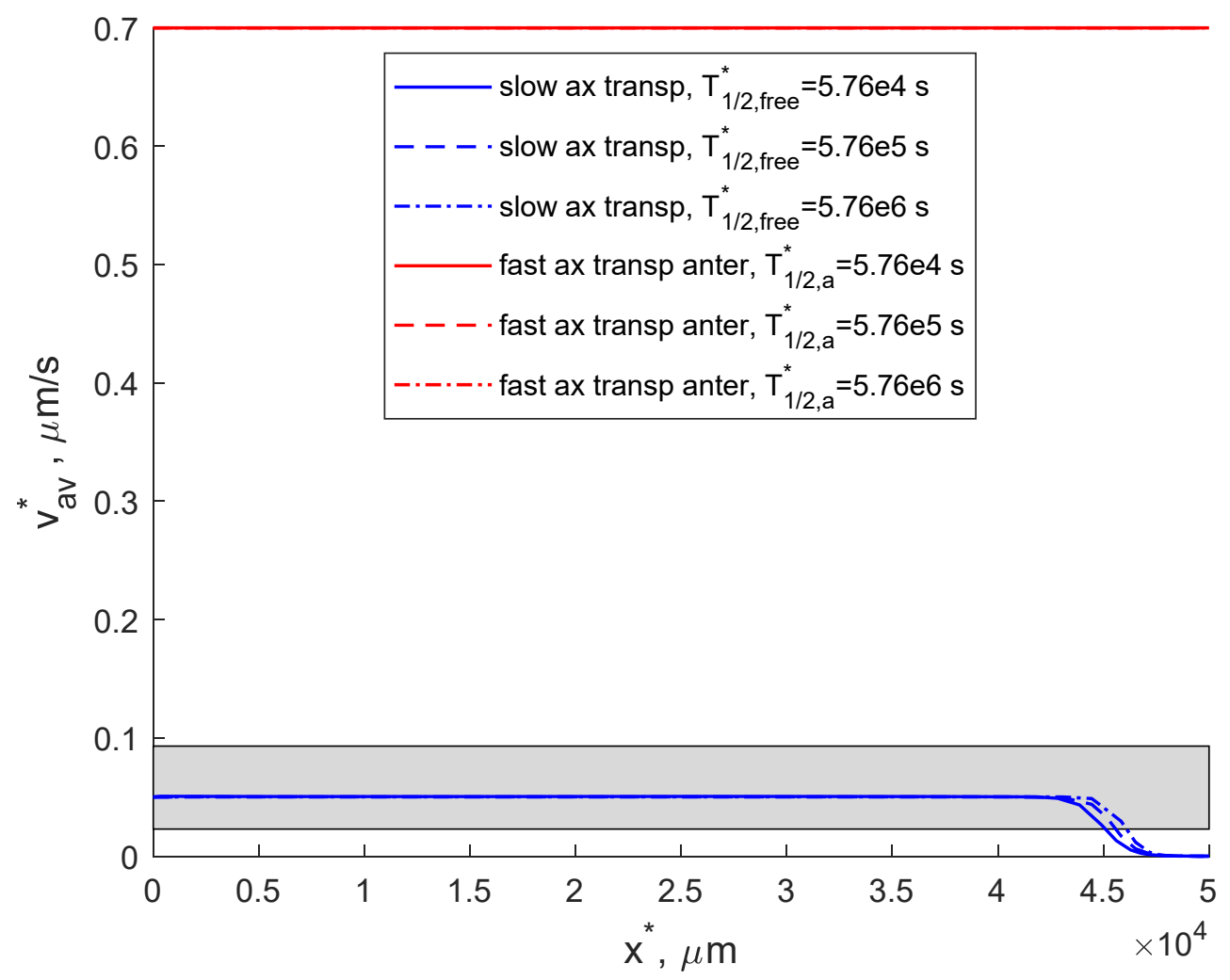

(b)

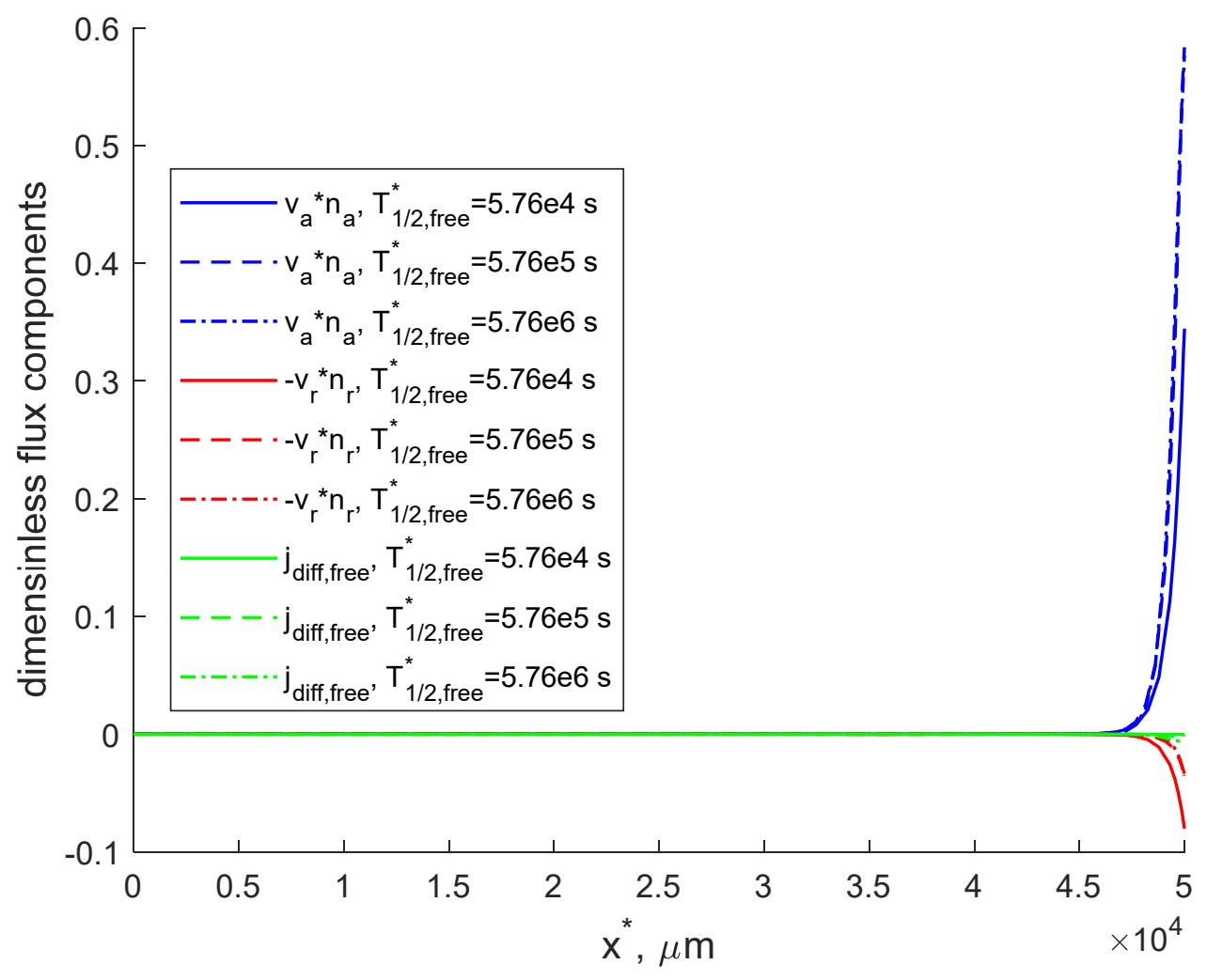


(a)

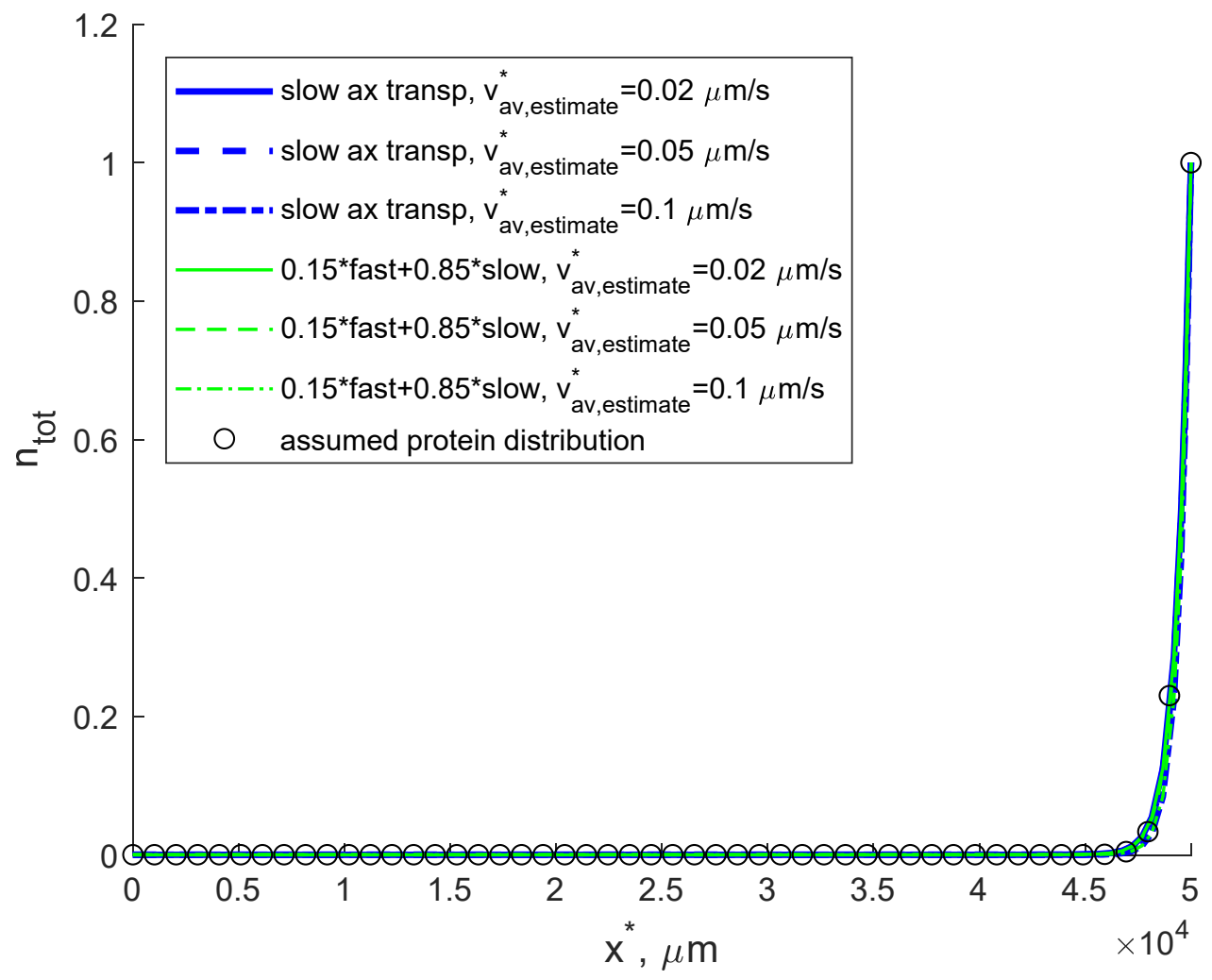

(b)

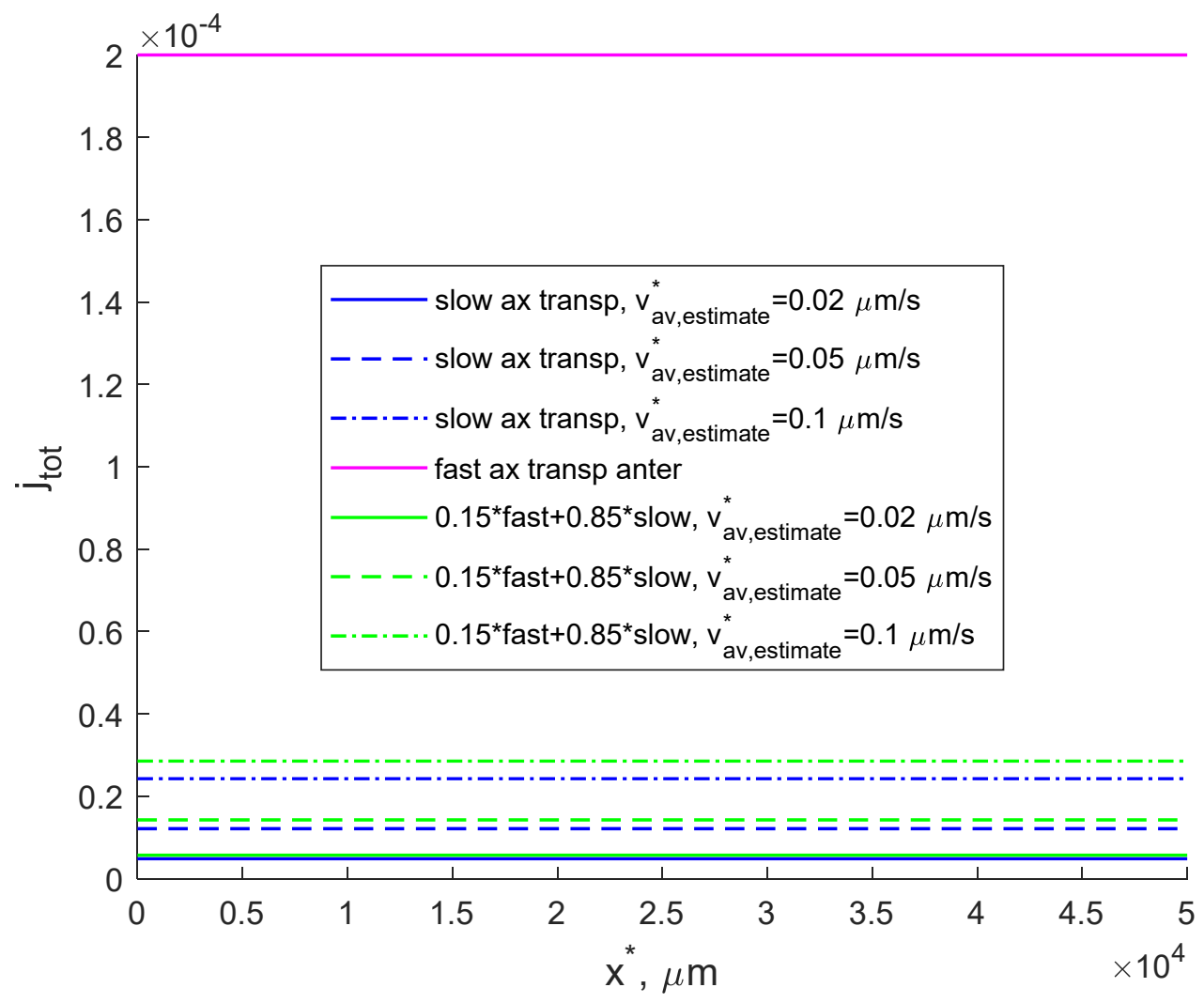


(a)

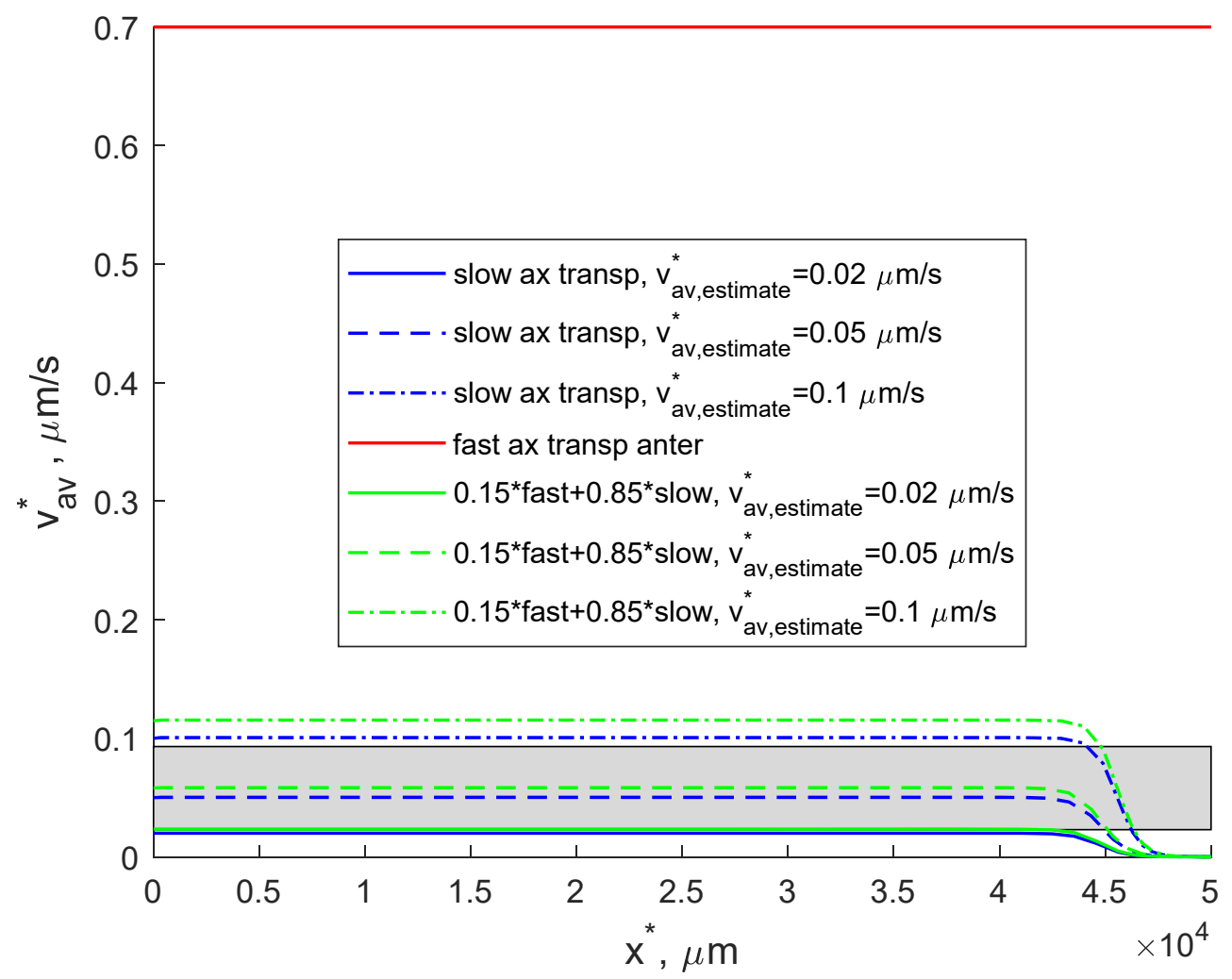

(b)

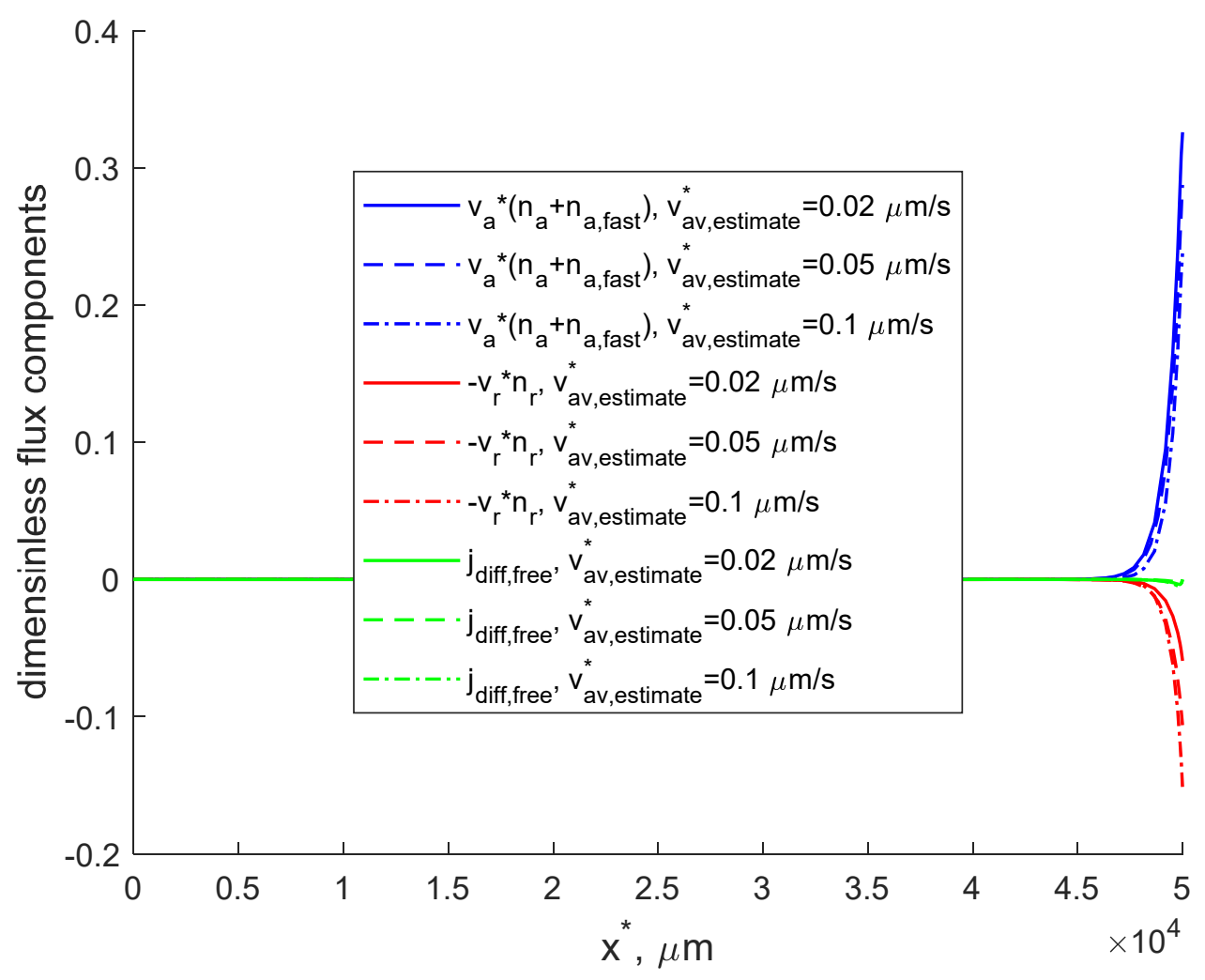

Figure 9 


\title{
Bidirectional, unlike unidirectional transport, allows transporting axonal cargos against their concentration gradient
}

\author{
I. A. Kuznetsov ${ }^{(a),(b)}$ and A. V. Kuznetsov ${ }^{(c)}$

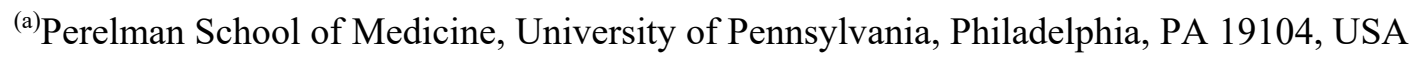

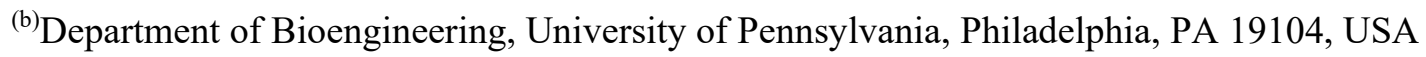 \\ ${ }^{(c)}$ Dept. of Mechanical and Aerospace Engineering, North Carolina State University, \\ Raleigh, NC 27695-7910, USA; e-mail: avkuznet@ncsu.edu
}

\section{$\underline{\text { Supplemental Materials }}$}

\section{S1. Supplementary tables}

Table S1. Kinetic constants characterizing the transition of $\alpha$-syn monomers between different kinetic states in slow axonal transport. $T_{1 / 2, \text { free }}^{*}=T_{1 / 2, a}^{*}=5.76 \times 10^{10} \mathrm{~s}$ and $v_{a v, \text { estimate }}^{*}=0.05 \mu \mathrm{m} \mathrm{s}^{-1}$ (one of the cases displayed in Figs. 4 and 5, other cases in these figures correspond to $v_{a v, e s t i m a t e}^{*}=0.02$ and $v_{a v, e s t i m a t e}^{*}=0.1$ $\left.\mu \mathrm{m} \mathrm{s}^{-1}\right)$. Note that since these kinetic constants are found as best-fit parameters by minimizing the objective function defined Eq. (42), the values of these constants depend on parameter values (such as $v_{a v, e s t i m a t e}^{*}$. A different set of parameter values would give a different set of kinetic constants. 1000 random points plus the initial point given in Table 3 were utilized as starting points in the search for the global minimum. All kinetic constants in Table $\mathrm{S} 1$ have dimensions $\mathrm{s}^{-1}$.

\begin{tabular}{|l|l|l|l|l|l|l|l|}
\hline$\gamma_{10}^{*}$ & $\gamma_{01}^{*}$ & $\gamma_{a r}^{*}$ & $\gamma_{r a}^{*}$ & $\gamma_{\text {on }, a}^{*}$ & $\gamma_{\text {on }, r}^{*}$ & $\gamma_{\text {off }, a}^{*}$ & $\gamma_{\text {off }, r}^{*}$ \\
\hline $1.90 \times 10^{-3}$ & $1.99 \times 10^{-4}$ & $7.91 \times 10^{-4}$ & $8.58 \times 10^{-3}$ & $1.75 \times 10^{-1}$ & $2.42 \times 10^{-2}$ & $9.36 \times 10^{-3}$ & $9.81 \times 10^{-3}$ \\
\hline
\end{tabular}

Table S2. Kinetic constants characterizing transition of $\alpha$-syn monomers between different kinetic states in an axonal transport model that includes anterograde motor-driven transport and diffusion only. $T_{1 / 2, \text { free }}^{*}=T_{1 / 2, a}^{*}=5.76 \times 10^{10} \mathrm{~s}$ and $v_{a v, e s t i m a t e}^{*}=0.05 \mu \mathrm{m} \mathrm{s}^{-1}$. The computational procedure used to obtain these constants was similar to that used for Table S1. All kinetic constants in Table S2 have dimensions $\mathrm{s}^{-1}$. 


\begin{tabular}{|l|l|l|l|}
\hline$\gamma_{10}^{*}$ & $\gamma_{01}^{*}$ & $\gamma_{\text {on,a }}^{*}$ & $\gamma_{\text {off }, a}^{*}$ \\
\hline $3.23 \times 10^{-4}$ & $2.69 \times 10^{-5}$ & $1.34 \times 10^{-1}$ & $9.89 \times 10^{-3}$ \\
\hline
\end{tabular}

Table S3. Kinetic constants characterizing transition of $\alpha$-syn monomers between different kinetic states in an axonal transport model that includes anterograde and retrograde motor-driven transport but no diffusion. $v_{a v, \text { estimate }}^{*}=0.05 \mu \mathrm{m} \mathrm{s}^{-1}$. The computational procedure used to obtain these constants was similar to that used for Table S1. All kinetic constants in Table S3 have dimensions $\mathrm{s}^{-1}$.

\begin{tabular}{|l|l|}
\hline$\gamma_{a r}^{*}$ & $\gamma_{r a}^{*}$ \\
\hline $7.02 \times 10^{-3}$ & $8.12 \times 10^{-3}$ \\
\hline
\end{tabular}

\section{S2. Supplementary figures}

\section{S2.1. Effect of the average velocity of $\alpha$-syn monomers}

If $\alpha$-syn is somehow protected from degradation during its axonal transport and its half-life is very large, the components of the total concentration are constant along the axon length and increase sharply only near the presynaptic terminal (Fig. S1a). $n_{a 0}$ is the largest component, followed by $n_{r 0}, n_{a}, n_{r}$, and $n_{\text {free }} . n_{a 0}$ and $n_{r 0}$ are the largest because in slow axonal transport the protein spends most of its time in the pausing states (Fig. S1b, $v_{a v, \text { estimate }}^{*}=0.02 \mu \mathrm{m} / \mathrm{s}$ ). An increase of the average protein velocity results in an increase of the concentration of kinesin-driven protein, $n_{a}$, and an increase in the difference between kinesin (anterograde) and dynein (retrograde)-driven protein concentrations, $n_{a}-n_{r}$ (Figs. S2b and S3b). 
bioRxiv preprint doi: https://doi. org/10.1101/2021.0127,428531; this version posted December 7, 2021. The copyright holder for this preprint (which was not certified by peer review) is the author/funder, who has granted bioRxiv a license to display the preprint in perpetuity. It is made available under aCC-BY-NC-ND 4.0 International license.

(a)

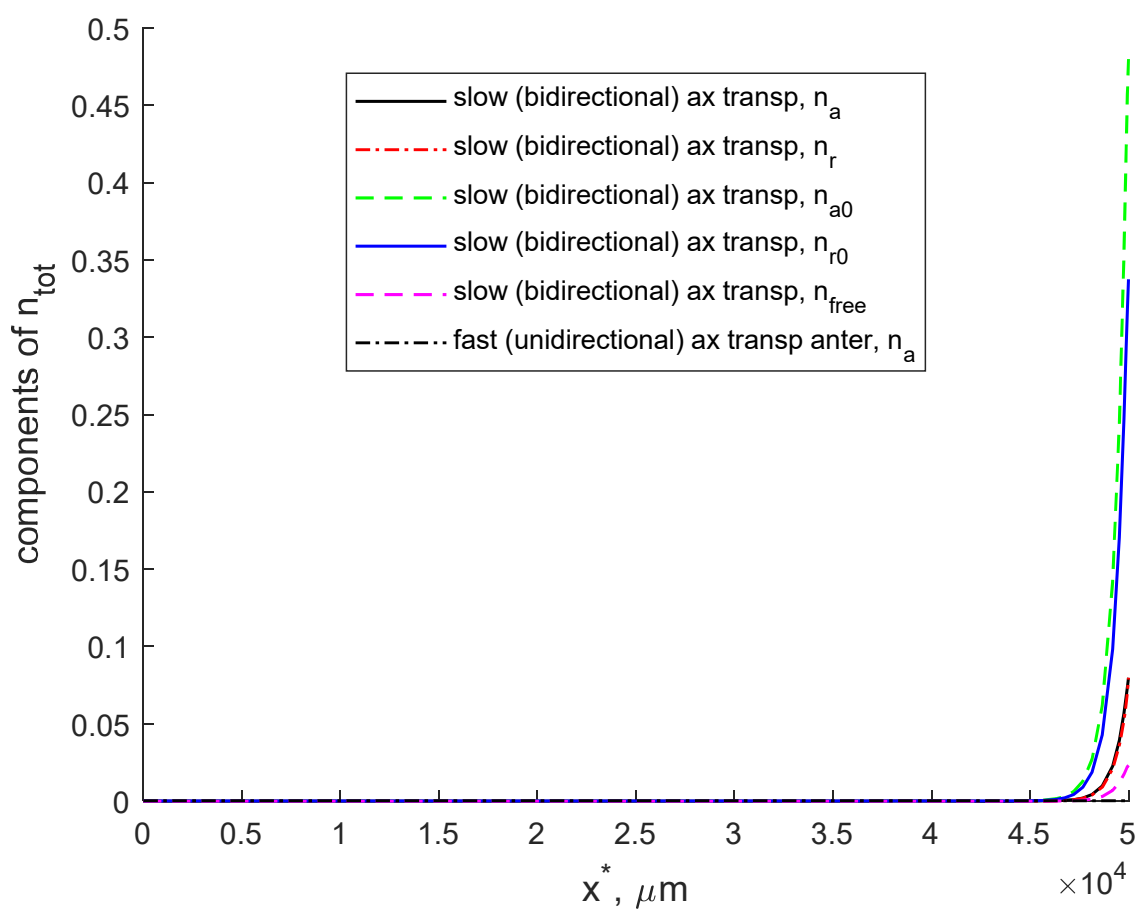

(b)

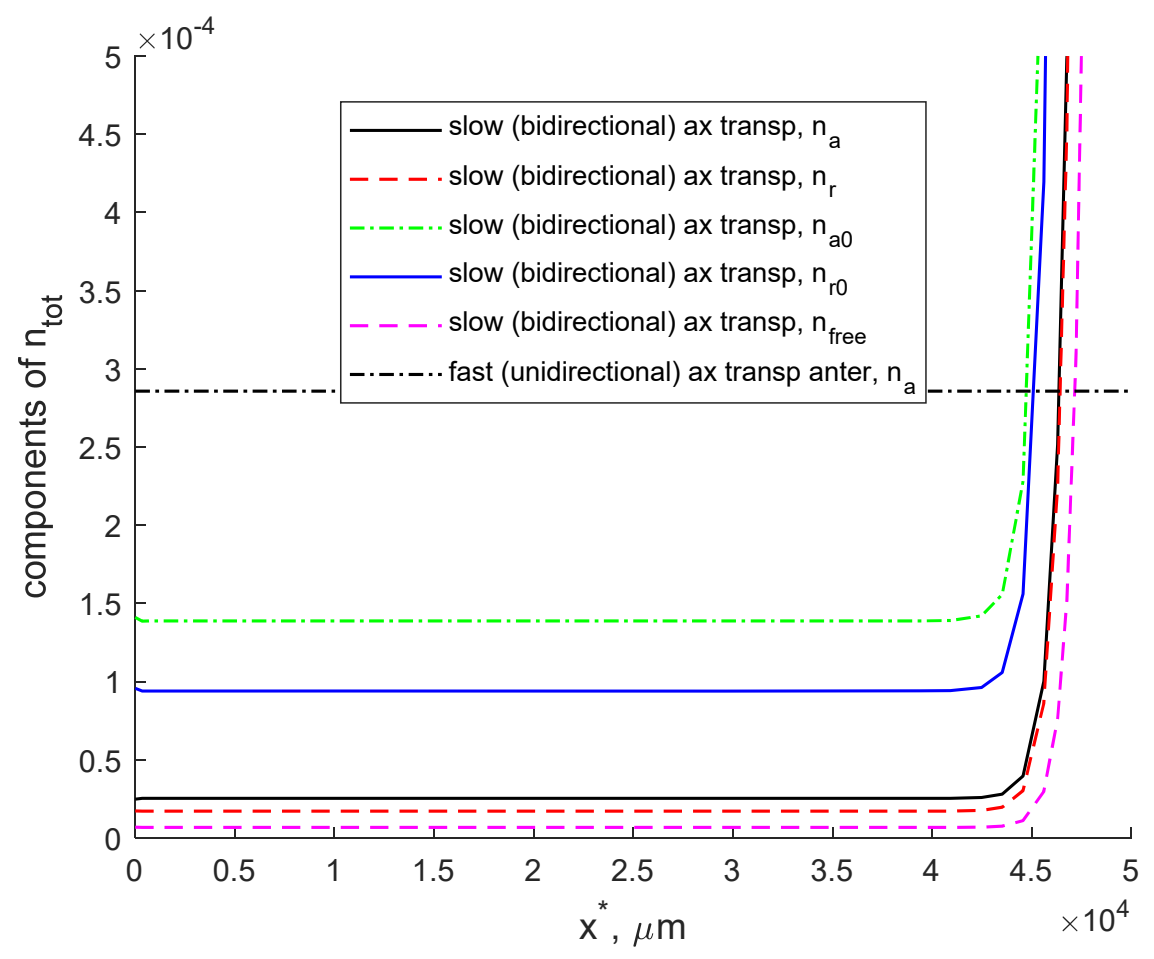


Fig. S1. (a) Components of the total concentration of $\alpha$-syn: $n_{a}, n_{r}, n_{a 0}, n_{r 0}$, and $n_{\text {free }}$. (b) Same as Fig. S1a, but with a magnified $y$-axis scale. $v_{a v, e s t i m a t e}^{*}=0.02 \mu \mathrm{m} / \mathrm{s}, T_{1 / 2, \text { free }}^{*}=5.76 \times 10^{10} \mathrm{~s}$, the fraction of $\alpha$-syn monomers conveyed in the fast component of axonal transport is assumed to be zero.

(a)

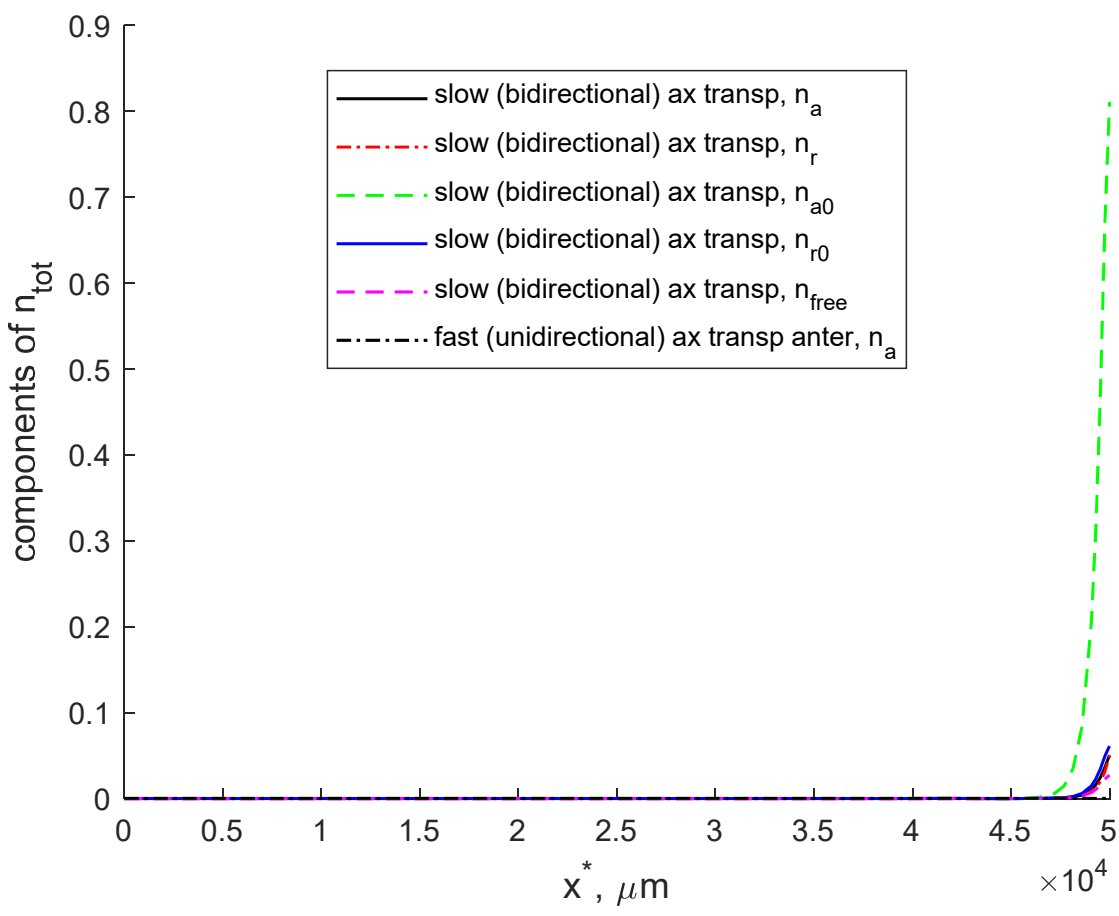


(b)

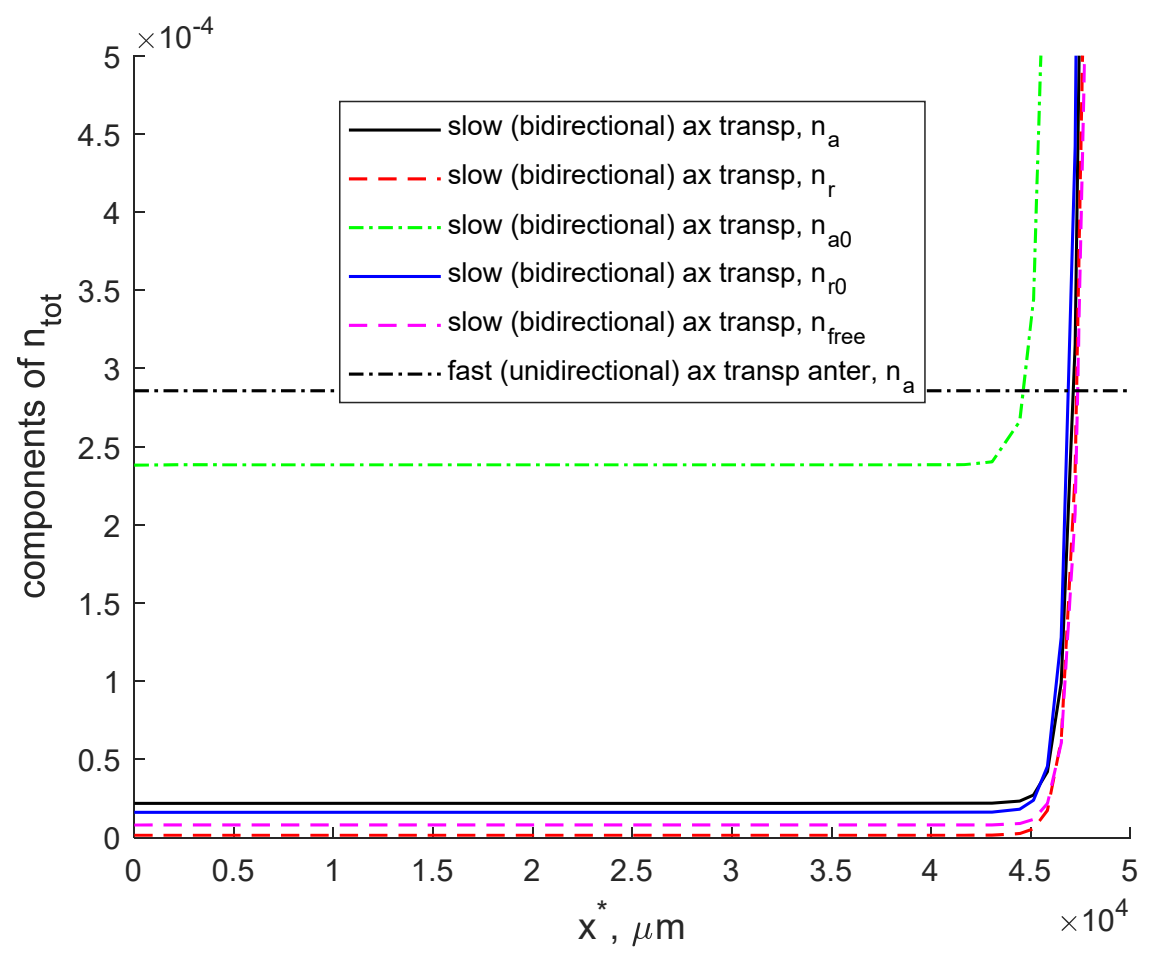

Fig. S2. (a) Components of the total concentration of $\alpha$-syn: $n_{a}, n_{r}, n_{a 0}, n_{r 0}$, and $n_{\text {free }}$. (b) Same as Fig. S2a, but with a magnified $y$-axis scale. $v_{a v, e s t i m a t e}^{*}=0.05 \mu \mathrm{m} / \mathrm{s}, T_{1 / 2, \text { free }}^{*}=5.76 \times 10^{10} \mathrm{~s}$, the fraction of $\alpha$-syn monomers conveyed in the fast component of axonal transport is assumed to be zero. 
bioRxiv preprint doi: https://doi. org/10.1101/2021.01.27,428531; this version posted December 7, 2021. The copyright holder for this preprint (which was not certified by peer review) is the author/funder, who has granted bioRxiv a license to display the preprint in perpetuity. It is made available under aCC-BY-NC-ND 4.0 International license.

(a)

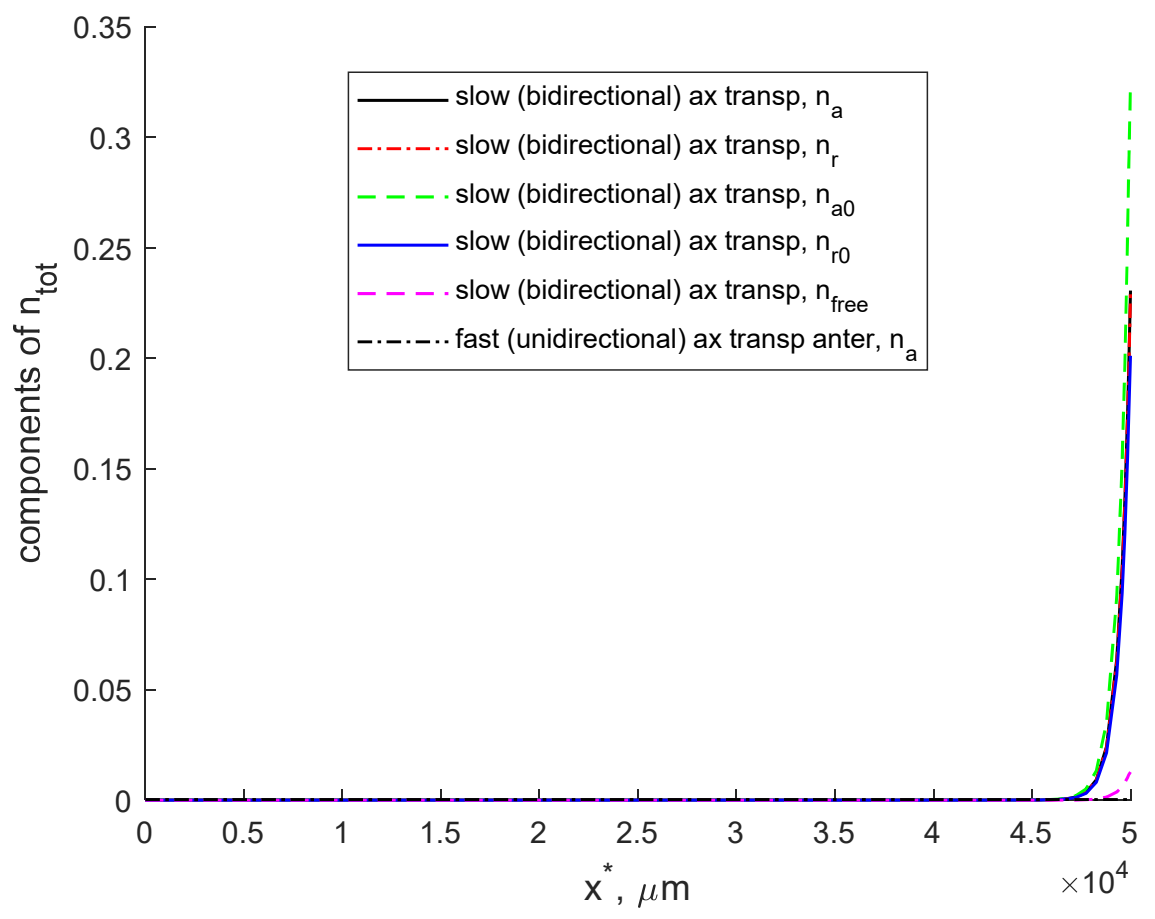

(b)

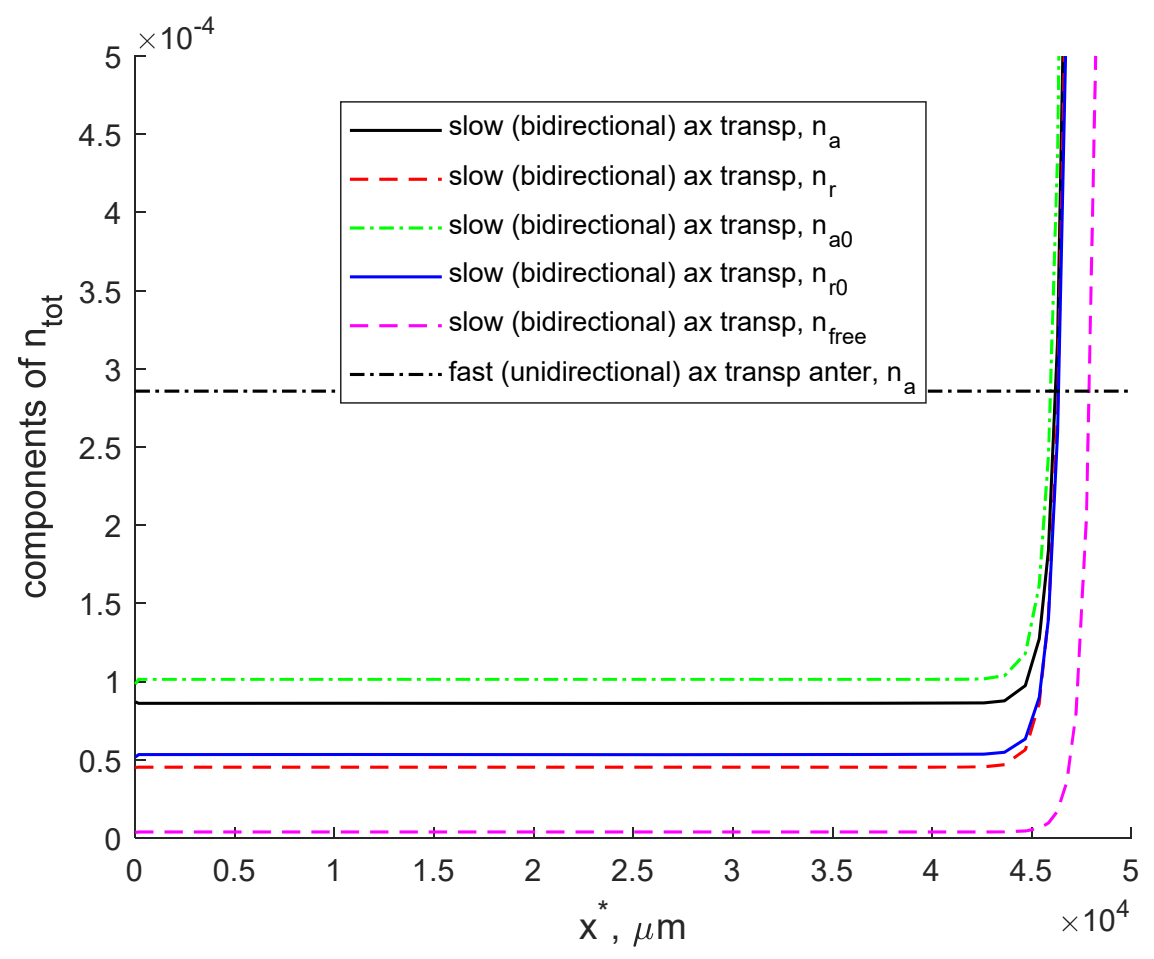


Fig. S3. (a) Components of the total concentration of $\alpha$-syn: $n_{a}, n_{r}, n_{a 0}, n_{r 0}$, and $n_{\text {free }}$. (b) Same as Fig. S3a, but with a magnified $y$-axis scale. $v_{a v, \text { estimate }}^{*}=0.1 \mu \mathrm{m} / \mathrm{s}, T_{1 / 2, \text { free }}^{*}=5.76 \times 10^{10} \mathrm{~s}$, the fraction of $\alpha$-syn monomers conveyed in the fast component of axonal transport is assumed to be zero.

\section{S2.2. Effect of the half-life of $\alpha$-syn monomers}

If $\alpha$-syn half-life during its axonal transport is finite, the concentration components slightly decrease as $x^{*}$ increases, except in the region close to the presynaptic terminal, where the concentrations sharply increase (Fig. S4b). The decrease along $x^{*}$ is more visible for smaller protein half-life (compare Fig. S4b with Figs. S5b and S6b).

(a)

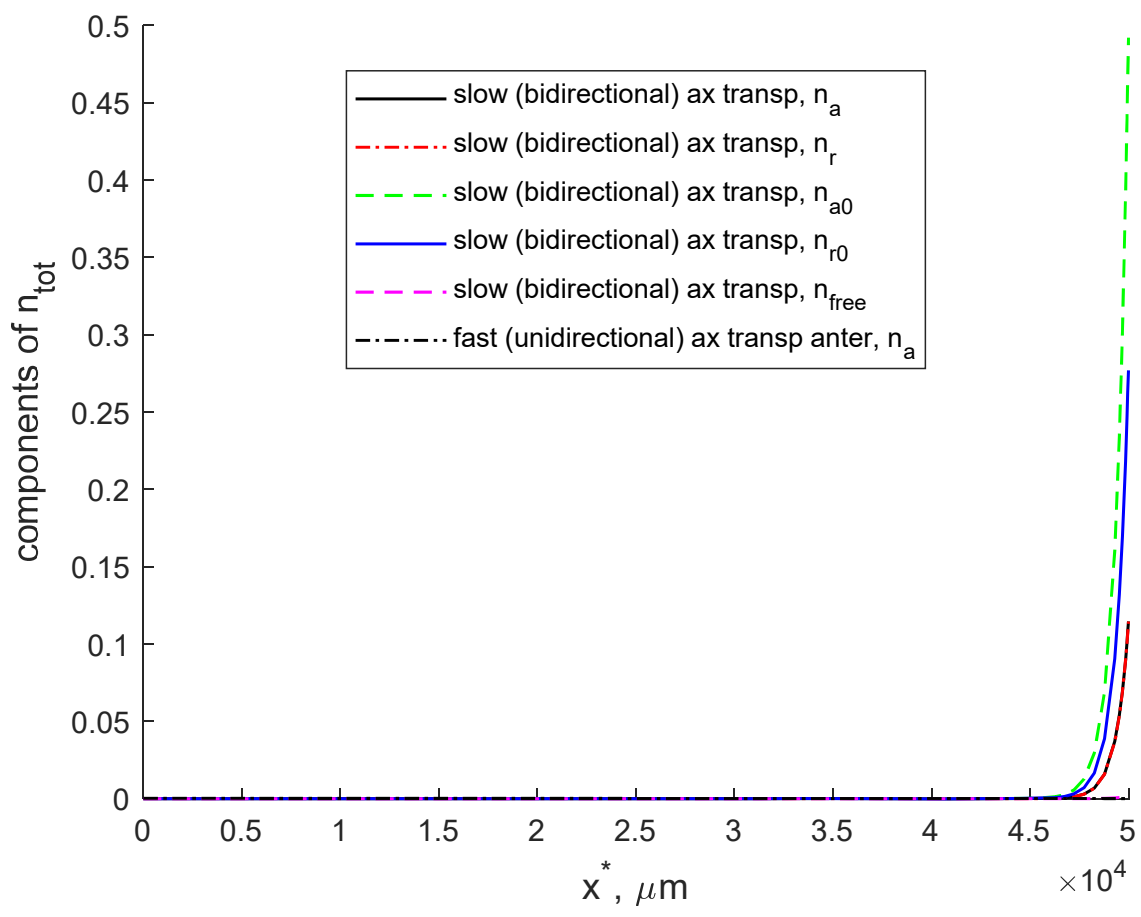


(b)

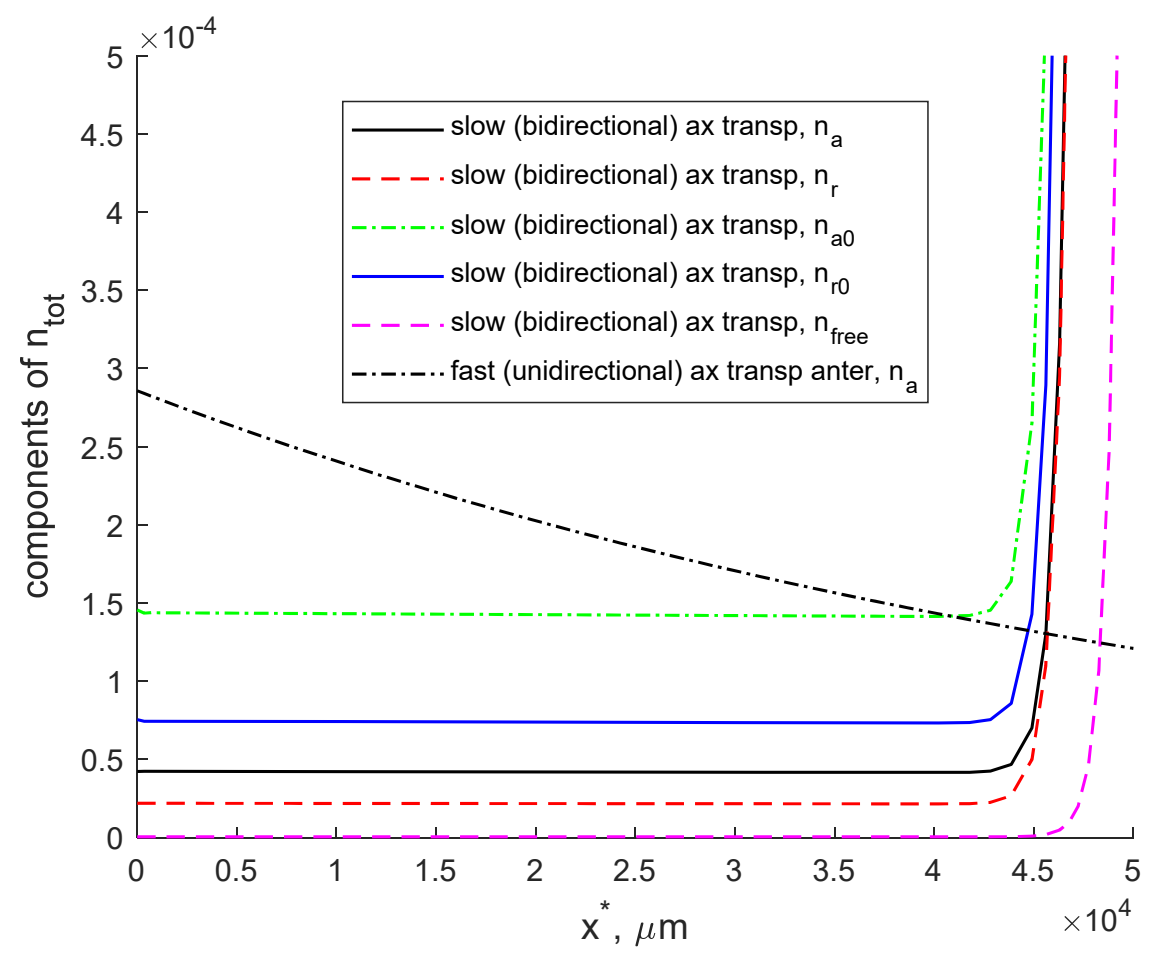

Fig. S4. (a) Components of the total concentration of $\alpha$-syn: $n_{a}, n_{r}, n_{a 0}, n_{r 0}$, and $n_{\text {free }}$. (b) Same as Fig. S4(a), but with a magnified $y$-axis scale. $T_{1 / 2, \text { free }}^{*}=5.76 \times 10^{4} \mathrm{~s}, v_{a v, \text { estimate }}^{*}=0.05 \mu \mathrm{m} \mathrm{s}^{-1}$, the fraction of $\alpha$ syn monomers conveyed in the fast component of axonal transport is assumed to be zero. 
bioRxiv preprint doi: https://doi. org/10.1101/2021.0127.428531; this version posted December 7, 2021. The copyright holder for this preprint (which was not certified by peer review) is the author/funder, who has granted bioRxiv a license to display the preprint in perpetuity. It is made available under aCC-BY-NC-ND 4.0 International license.

(a)

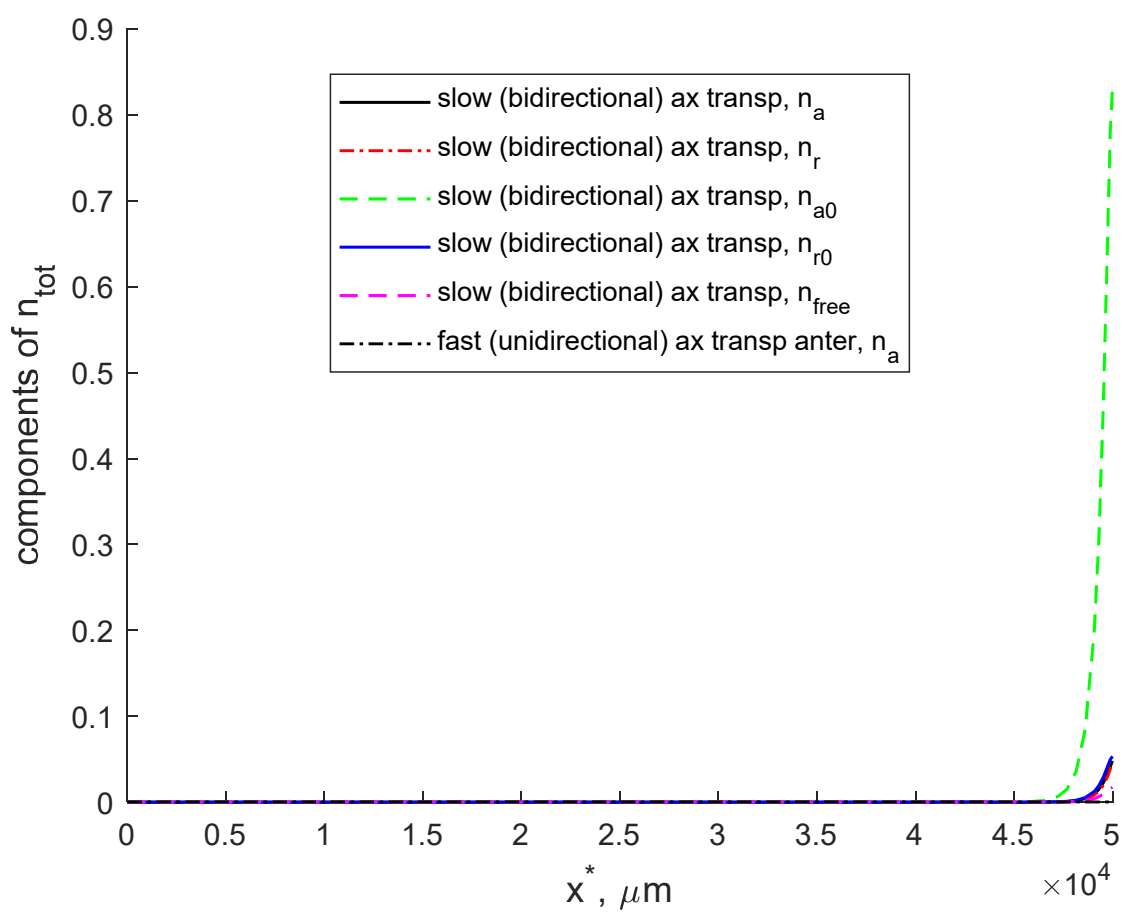

(b)

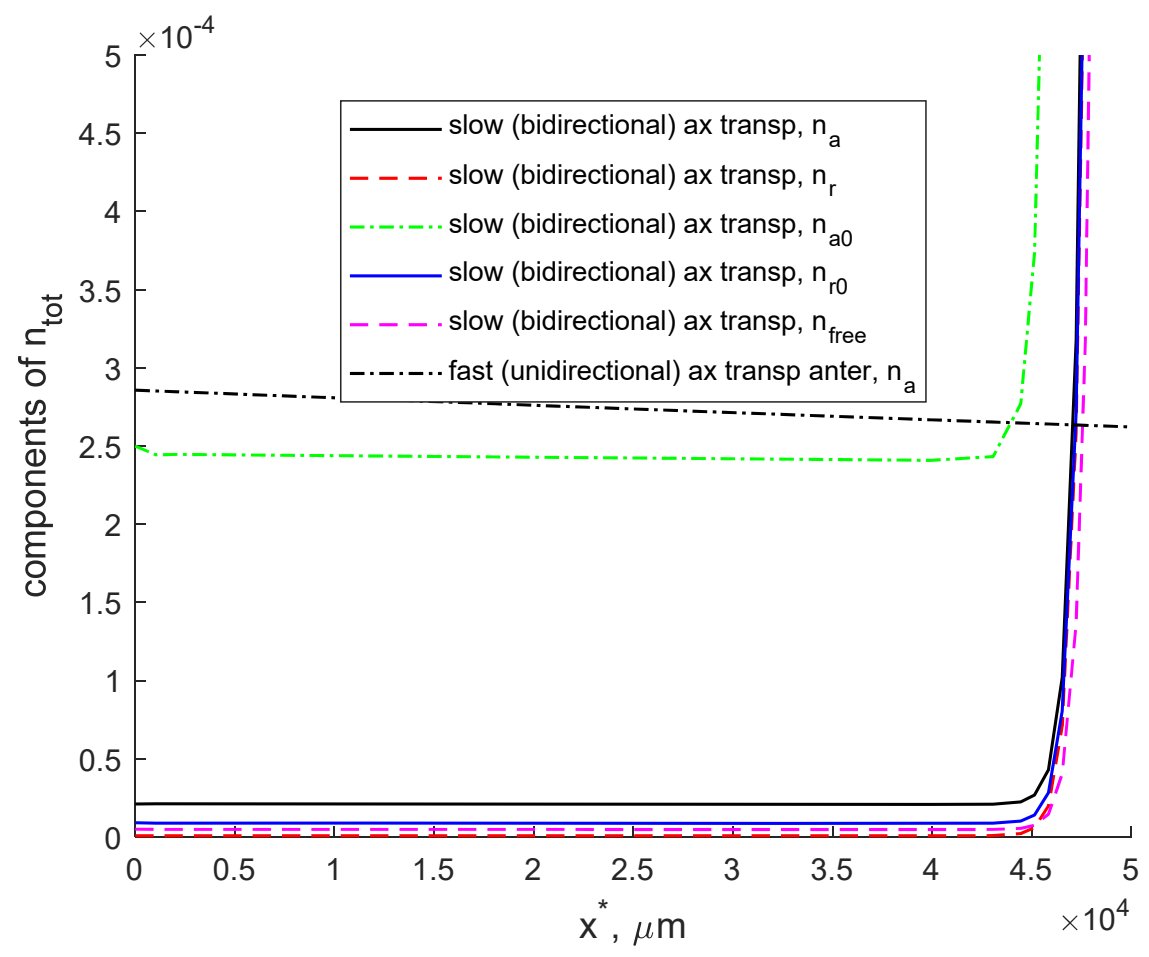


Fig. S5. (a) Components of the total concentration of $\alpha$-syn: $n_{a}, n_{r}, n_{a 0}, n_{r 0}$, and $n_{\text {free }}$. (b) Same as Fig. S5(a), but with a magnified $y$-axis scale. $T_{1 / 2, \text { free }}^{*}=5.76 \times 10^{5} \mathrm{~s}, v_{a v, \text { estimate }}^{*}=0.05 \mu \mathrm{m} \mathrm{s}^{-1}$, the fraction of $\alpha$ syn monomers conveyed in the fast component of axonal transport is assumed to be zero.

(a)

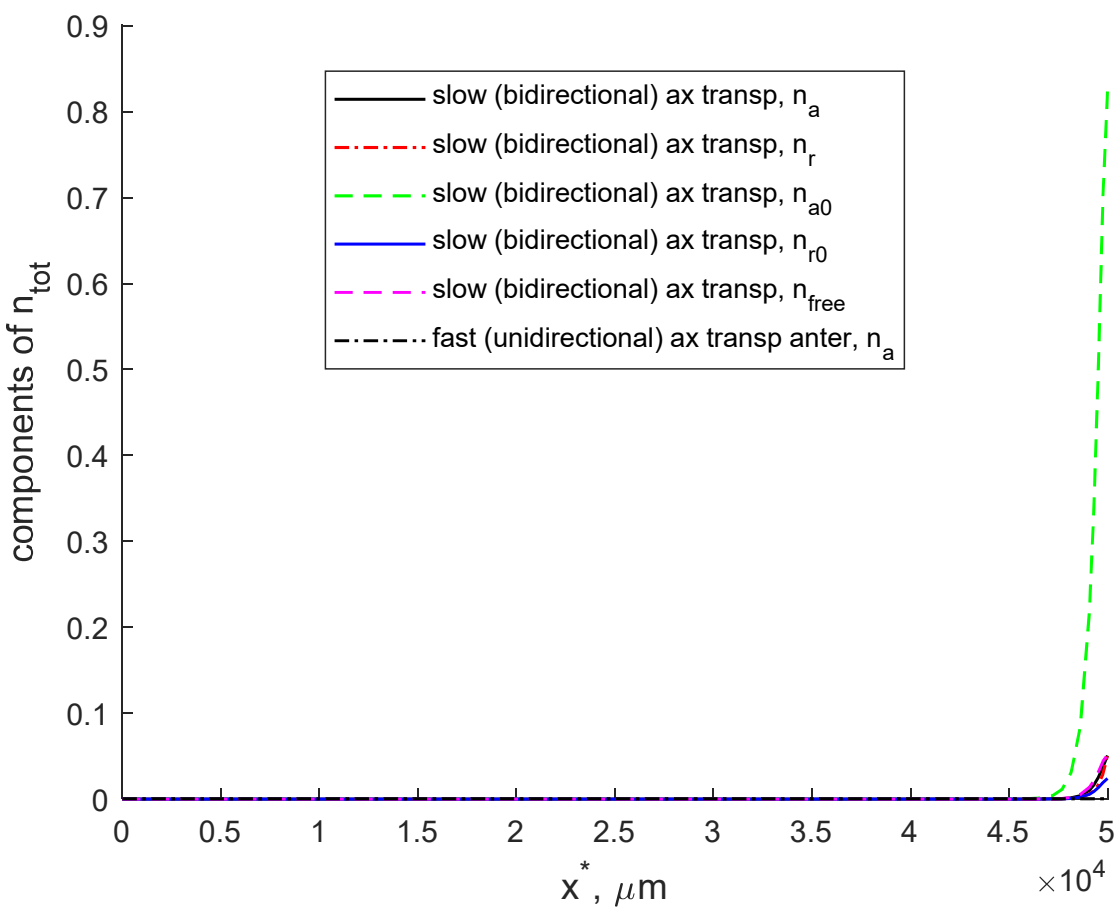


(b)

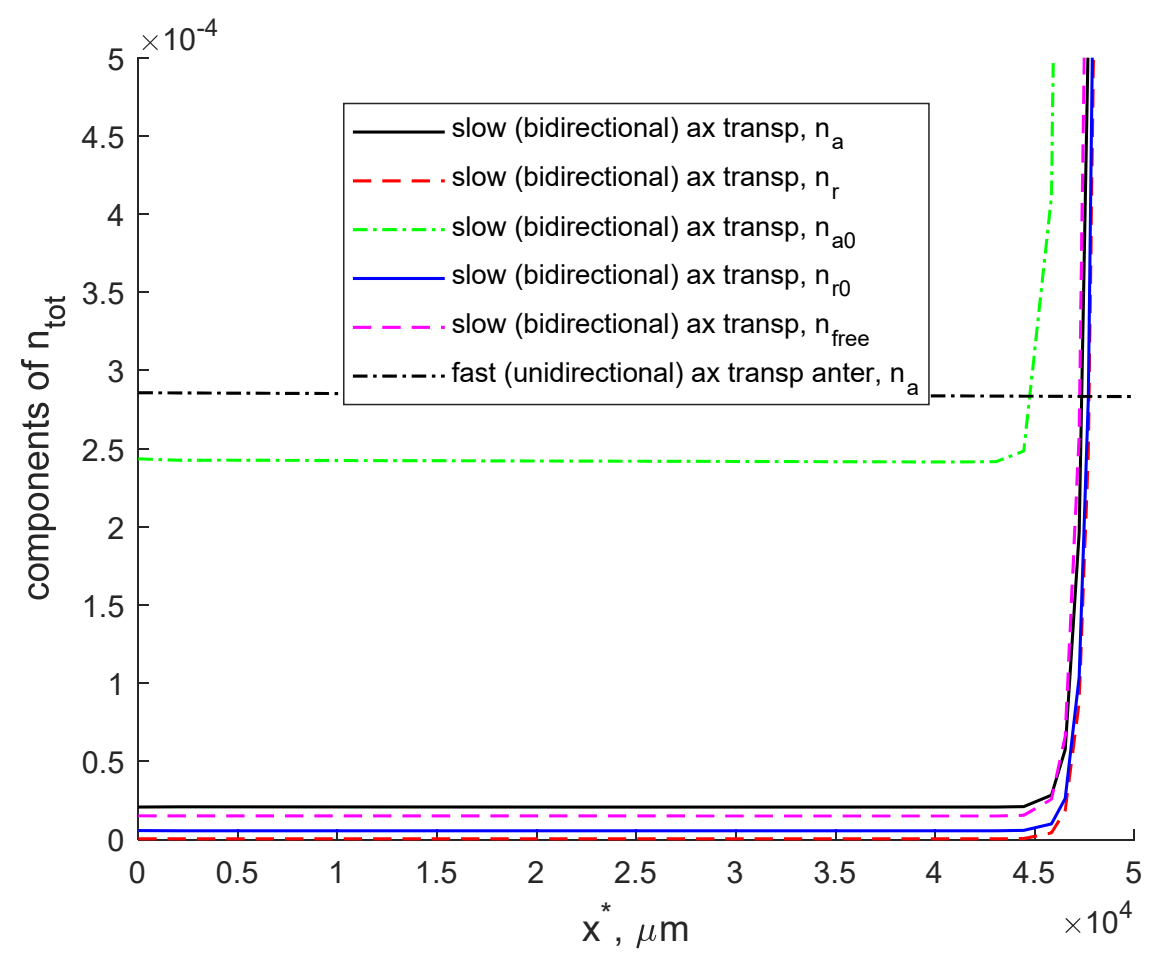

Fig. S6. (a) Components of the total concentration of $\alpha$-syn: $n_{a}, n_{r}, n_{a 0}, n_{r 0}$, and $n_{\text {free }}$. (b) Same as Fig. S6(a), but with a magnified $y$-axis scale. $T_{1 / 2, \text { free }}^{*}=5.76 \times 10^{6} \mathrm{~s}, v_{a v, e s t i m a t e}^{*}=0.05 \mu \mathrm{m} \mathrm{s}^{-1}$, the fraction of $\alpha$ syn monomers conveyed in the fast component of axonal transport is assumed to be zero.

\section{S2.3. Simulations using a model that accounts for anterograde motor-driven transport, pausing, and diffusion in the free state}

Figs. S7 and S8 show that retrograde motor-driven transport can be removed from the model without affecting its ability to fit a prescribed cargo concentration with a maximum concentration at the axon tip and a prescribed cargo average velocity. 
(a)

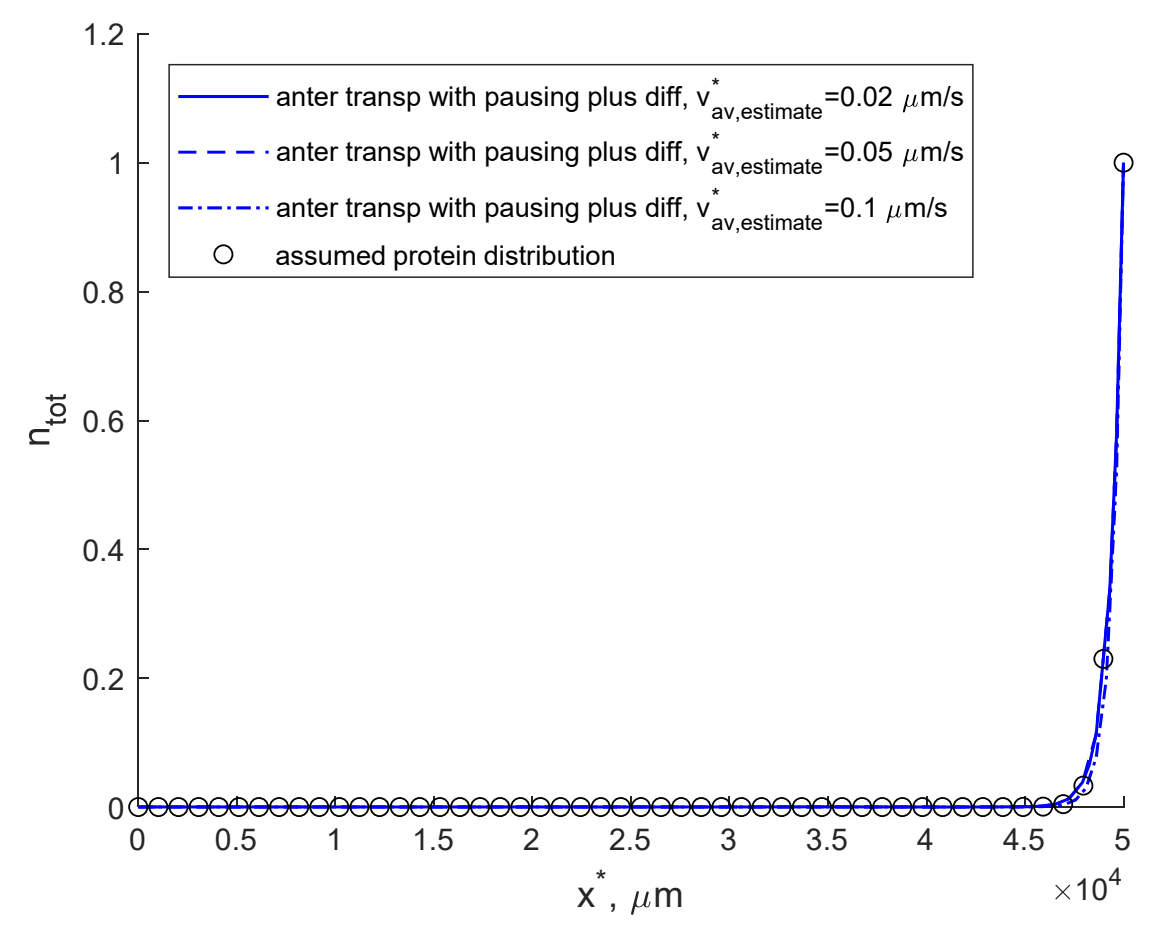

(b)

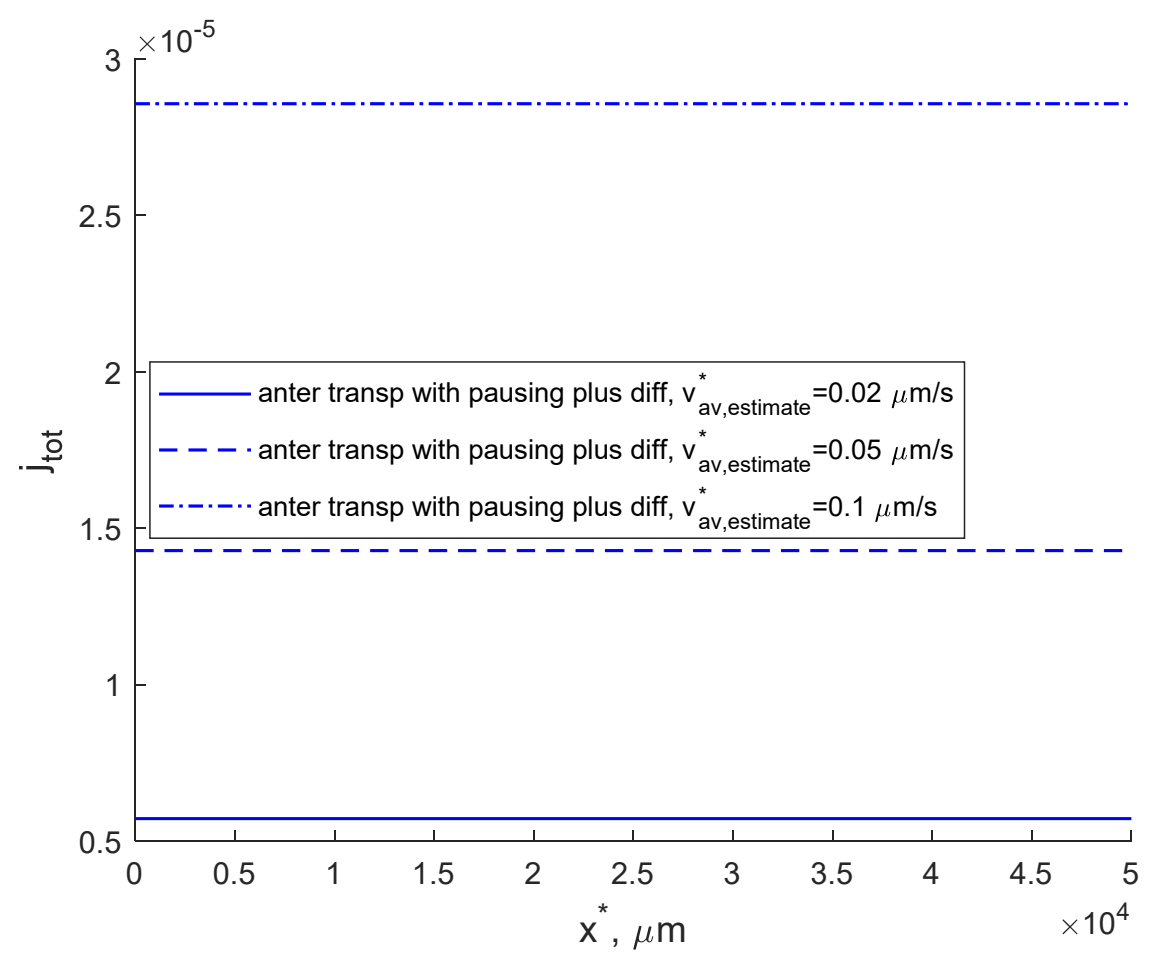

Fig. S7. Axonal transport model that includes anterograde transport with pausing and diffusion only. $T_{1 / 2, \text { free }}^{*}=5.76 \times 10^{10} \mathrm{~s}$. (a) Total cargo concentration (the sum of cargo concentrations in anterograde 
motor-driven, pausing, and diffusing states). (b) Total flux of cargo due to action of anterograde motors and diffusion in the cytosol.

(a)

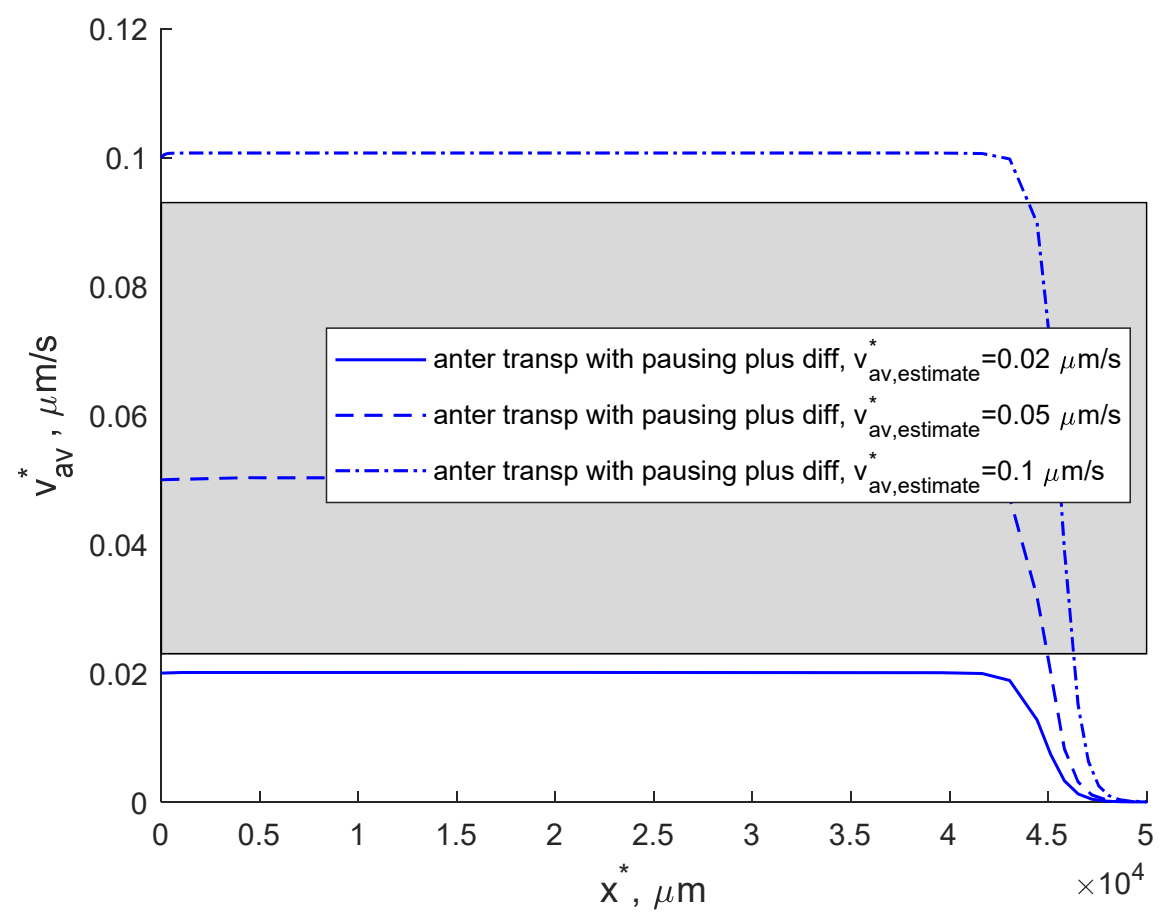

(b)

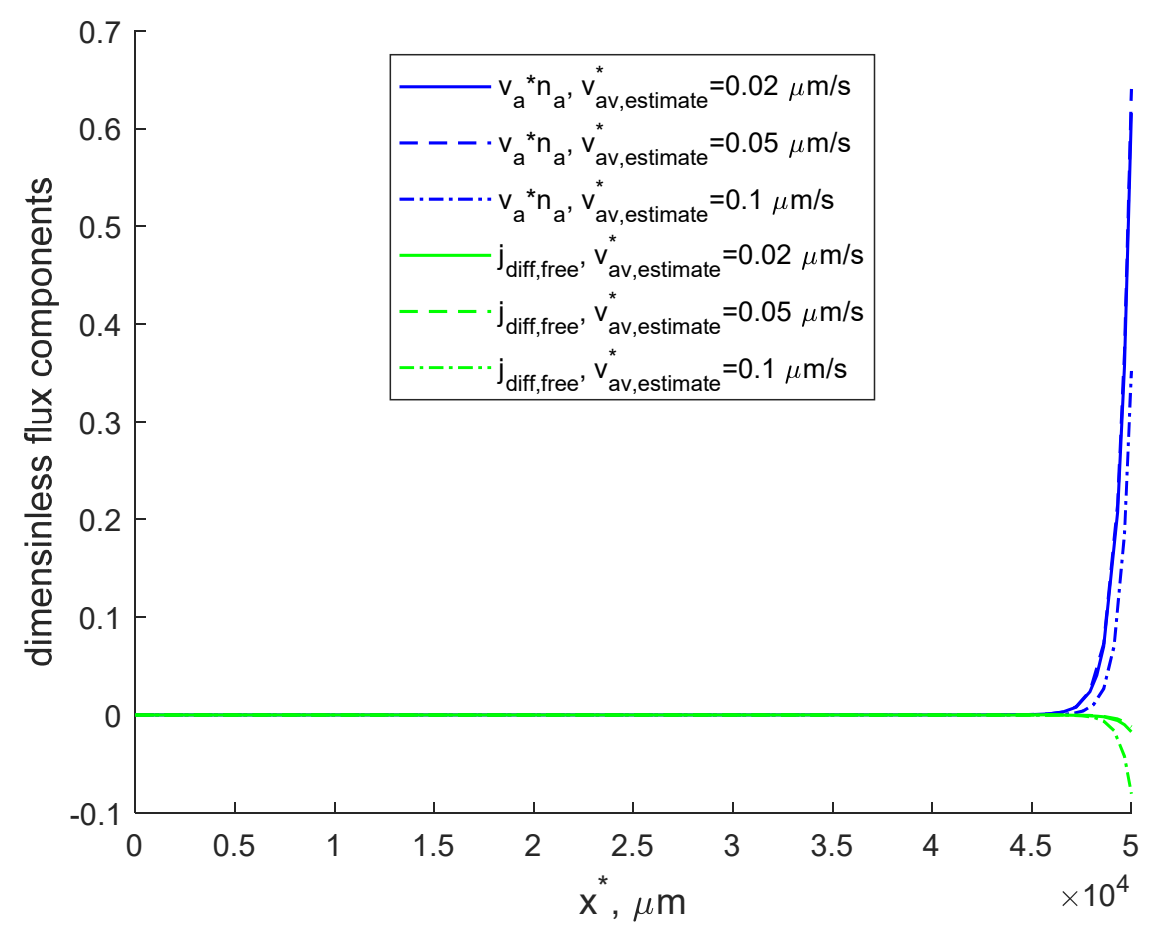

13 
Fig. S8. Axonal transport model that includes anterograde transport with pausing and diffusion only. $T_{1 / 2, \text { free }}^{*}=5.76 \times 10^{10}$ s. (a) Average cargo velocity. (b) Anterograde motor-driven and diffusion-driven components of the total $\alpha$-syn flux.

\section{S2.4. Simulations using a model that accounts only for anterograde and retrograde motor-driven transport in the axon, without cargo diffusion}

Figs. S9 and S10 show that including the diffusivity of cargo is not required to simulate axonal transport against the concentration gradient. A model that accounts for motor-driven transport in both directions but does not include cargo diffusion can simulate cargo transport toward the axon tip with a higher cargo concentration at the tip of the axon than at the hillock.

(a)

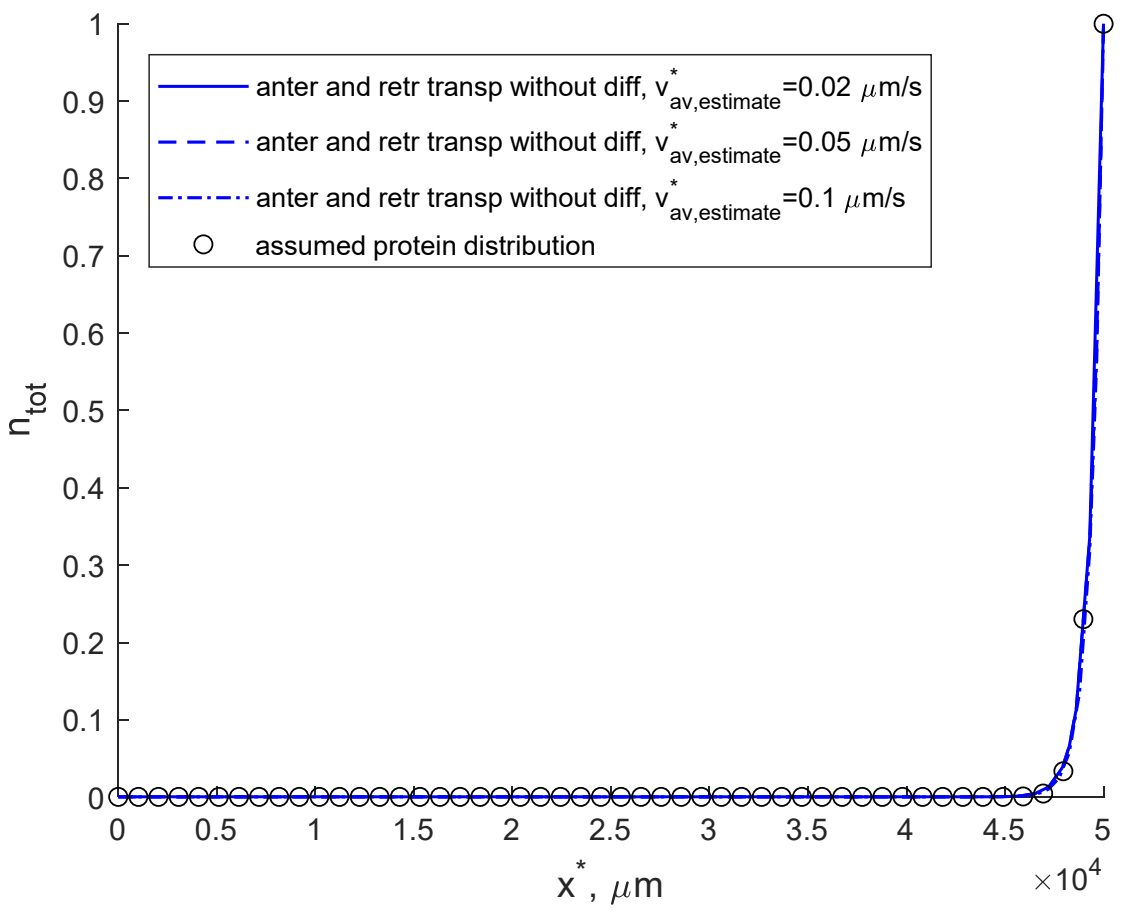


(b)

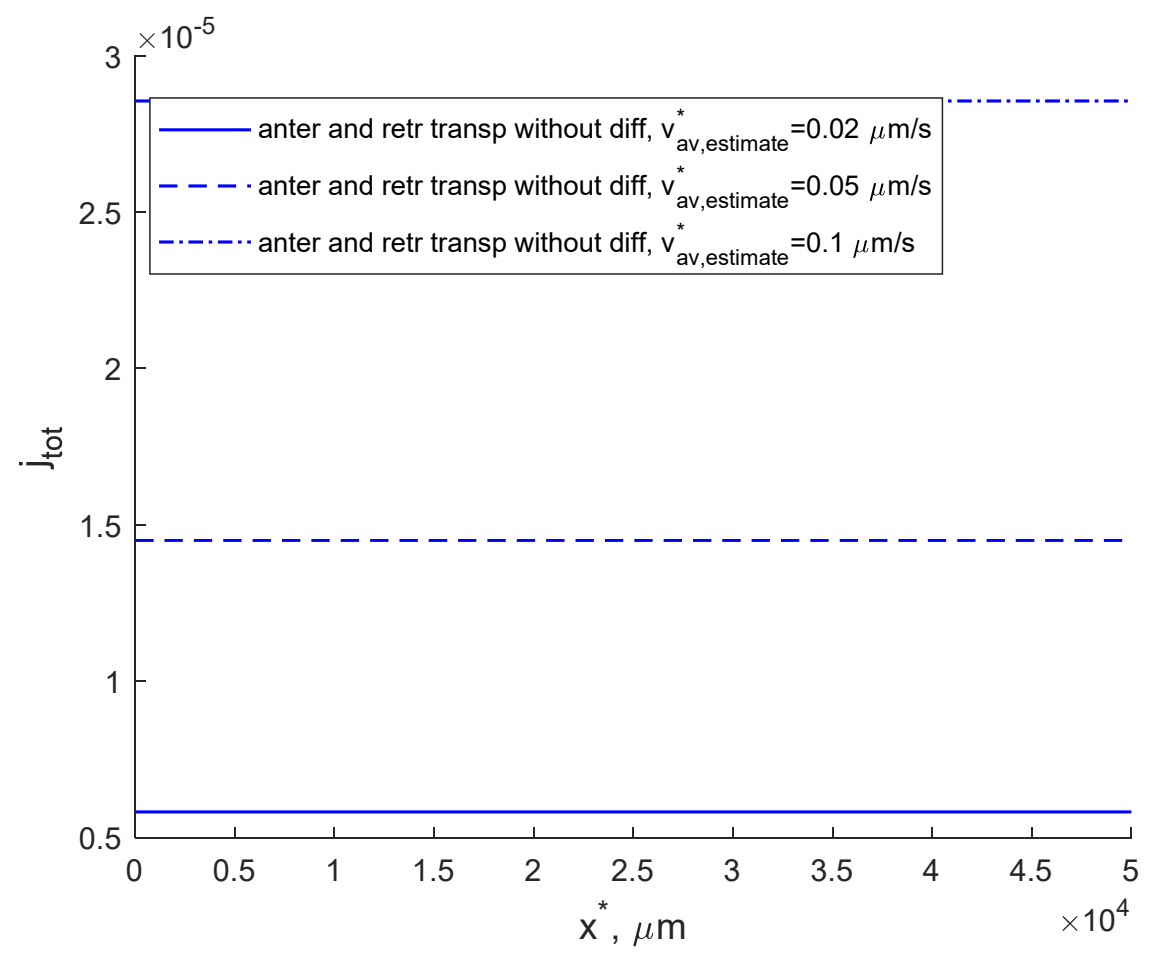

Fig. S9. Anterograde and retrograde axonal transport model without pausing states and diffusion. (a) Total cargo concentration (the sum of cargo concentrations in anterograde motor-driven, pausing, and diffusing states). (b) Total flux of cargo due to action of anterograde and retrograde motors. 
bioRxiv preprint doi: https://doi.org/10.1101/2021.01.27.428531; this version posted December 7, 2021. The copyright holder for this preprint (which was not certified by peer review) is the author/funder, who has granted bioRxiv a license to display the preprint in perpetuity. It is made available under aCC-BY-NC-ND 4.0 International license.

(a)

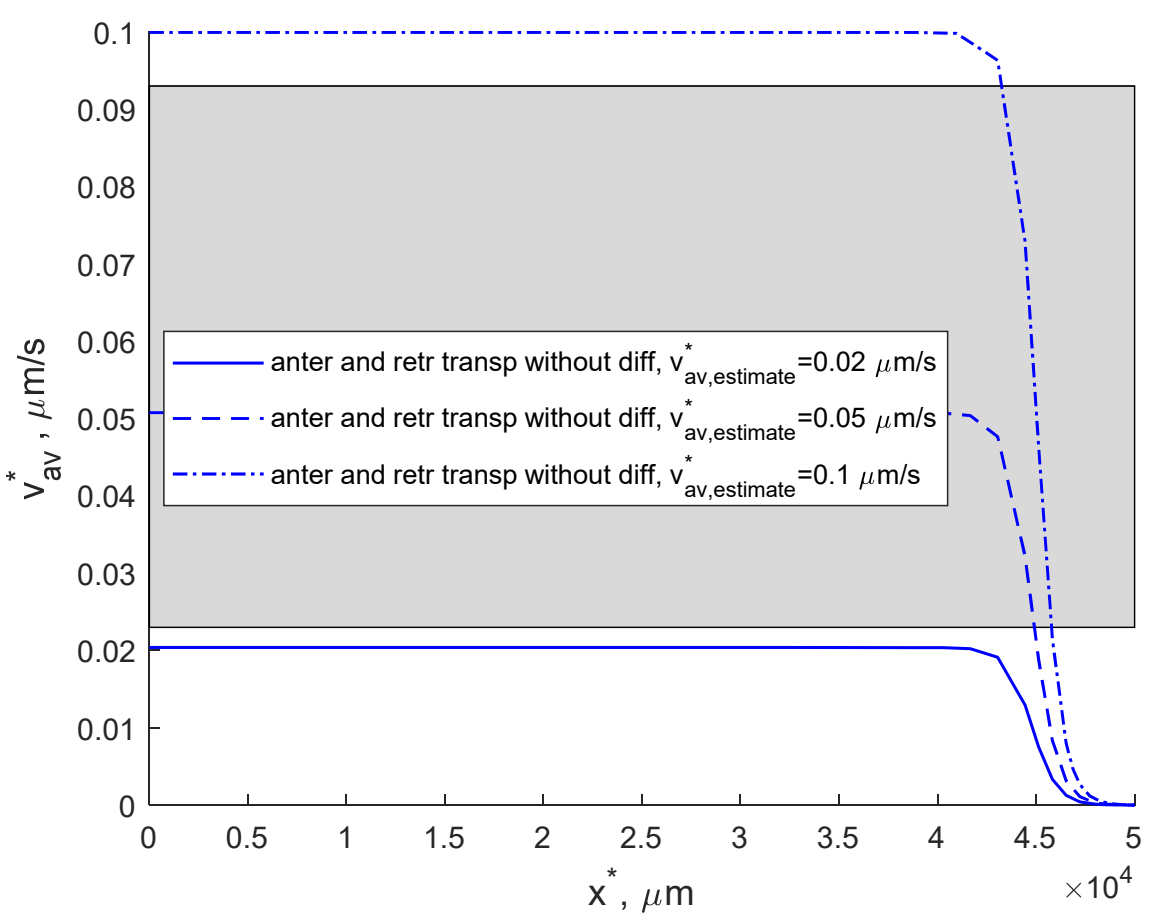

(b)

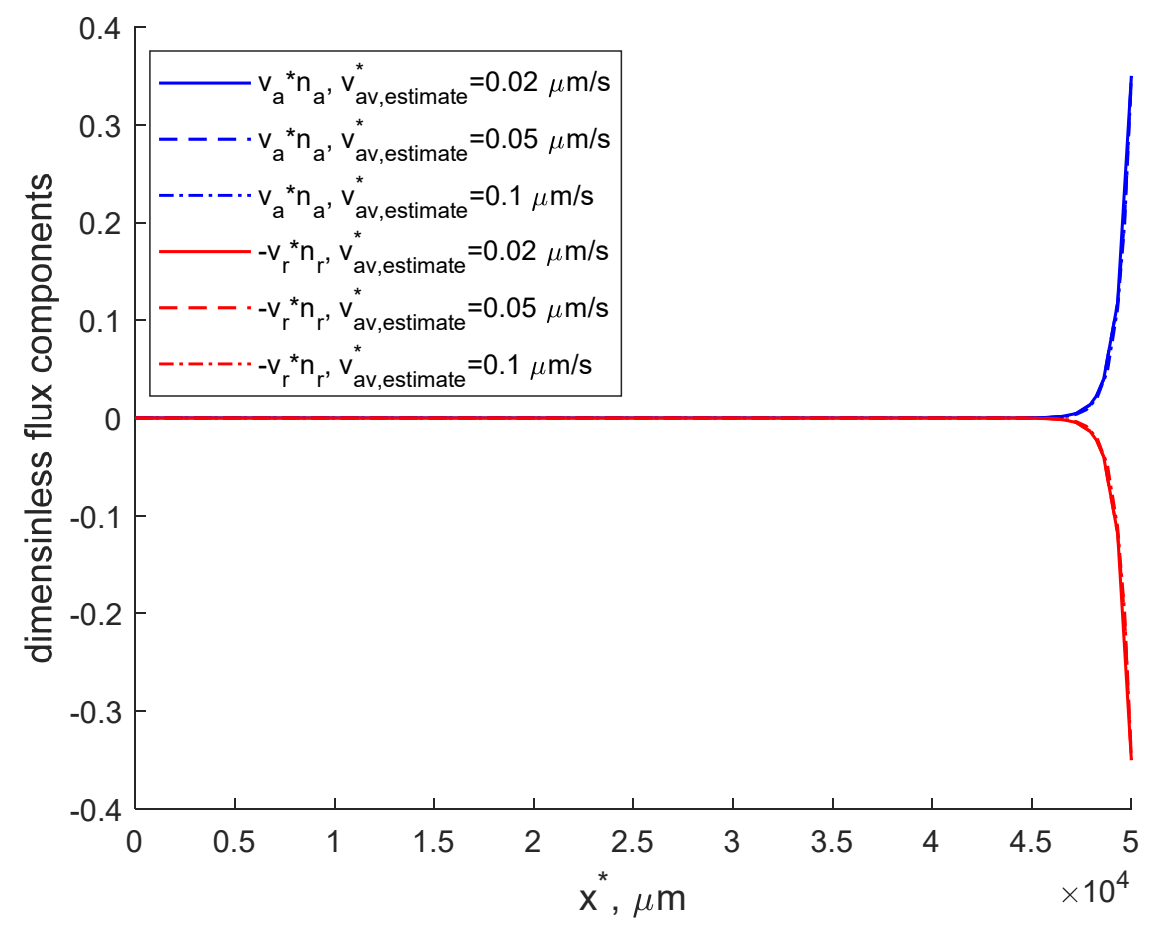


bioRxiv preprint doi: https://doi.org/10.1101/2021.01.27.428531; this version posted December 7, 2021. The copyright holder for this preprint

(which was not certified by peer review) is the author/funder, who has granted bioRxiv a license to display the preprint in perpetuity. It is made available under aCC-BY-NC-ND 4.0 International license.

Fig. S10. Anterograde and retrograde axonal transport model without pausing states and diffusion. (a) Average cargo velocity. (b) Anterograde motor-driven and retrograde motor-driven components of the total $\alpha$-syn flux. 